\title{
I mersão de espaços métricos em espaços multidimensionais para indexação de dados usando detecção de agrupamentos
}



SERVIÇO DE PÓS-GRADUAÇÃO DO ICMC-USP

Data de Depósito:

Assinatura:

\title{
Imersão de espaços métricos em espaços multidimensionais para indexação de dados usando detecção de agrupamentos
}

\author{
Adriano Arantes Paterlini \\ Orientador: Prof. Dr. Caetano Traina Junior \\ Dissertação apresentada ao Instituto de Ciências Matemáticas e \\ de Computação - ICMC-USP, como parte dos requisitos para \\ obtenção do título de Mestre em Ciências - Ciências de \\ Computação e Matemática Computacional. EXEMPLAR DE \\ DEFESA.
}

USP - São Carlos

Fevereiro/2011 
Ficha catalográfica elaborada pela Biblioteca Prof. Achille Bassi e Seção Técnica de Informática, ICMC/USP, com os dados fornecidos pelo(a) autor(a)

\begin{tabular}{|c|c|}
\hline \multirow[t]{3}{*}{ P295i } & $\begin{array}{l}\text { Paterlini, Adriano Arantes } \\
\text { Imersão de espaços métricos em espaços } \\
\text { multidimensionais para indexação de dados usando } \\
\text { deteç̧ão de agrupamentos / Adriano Arantes Paterlini; } \\
\text { orientador Caetano Traina Jr. -- São Carlos, } 2011 . \\
\quad 90 \text { p. }\end{array}$ \\
\hline & $\begin{array}{l}\text { Dissertação (Mestrado - Programa de Pós-Graduação en } \\
\text { Ciências de Computação e Matemática Computacional) -- } \\
\text { Instituto de Ciências Matemáticas e de Computação, } \\
\text { Universidade de São Paulo, 2011. }\end{array}$ \\
\hline & $\begin{array}{l}\text { 1. BANCO DE DADOS . 2. MINERAÇÃO DE DADOS. } 3 . \\
\text { CLUSTERS. I. Traina Jr., Caetano, orient. II. } \\
\text { Título. }\end{array}$ \\
\hline
\end{tabular}


Aos meus pais Zélia e Marcos.

À minha noiva Ana Paula. 



\section{Agradecimentos}

A DEUS, por mais uma vez, ter permitido vencer uma importante etapa da minha vida.

Aos meus pais, Zélia e Marcos, pelo amor, confiança, força, dedicação e preocupação. Sem vocês nada seria possível.

A Ana Paula, em breve esposa, pelo amor, carinho, companhia, dedicação e atenção. Por todos os momentos que passamos juntos, ontem, hoje e sempre. Aos seus pais, Anna e José, aos meus cunhados Ana Beatriz, Antônio José e Solimar, e aos filhos deles, Bruna, Matheus e Pedro, agradeço pelo carinho e apoio.

Aos meus irmãos, William e Matheus, que não mediram esforços para me apoiar nesta etapa da minha vida. E a toda minha família, especialmente meu tio Roberto, esposa e filhos, pelo acolhimento e incentivos.

Aos Professores Dr. Caetano e Dr. Mário, não só pela excelente orientação, mas por terem acreditado na minha capacidade de lutar e vencer. Obrigado pela confiança, oportunidade, paciência, ajuda nas horas de dúvidas e principalmente pela amizade.

Aos colegas e amigos do ICMC agradeço pela atenção, apoio, força nos momentos mais difíceis e companheirismo durante estes anos.

Às instituições de fomento a pesquisa CNPq, Capes, GSEP e FAPESP o meu agradecimento. 



\section{Resumo}

O sucesso dos Sistemas de Gerenciamento de Banco de Dados (SGBDs) em aplicações envolvendo dados tradicionais (números e textos curtos) encorajou o seu uso em novos tipos de aplicações, que exigem a manipulação de dados complexos. Séries temporais, dados científicos, dados multimídia e outros são exemplos de Dados Complexos. Inúmeras áreas de aplicação têm demandado soluções para o gerenciamento de dados complexos, dentre as quais a área de informática médica. Dados complexos podem também ser estudos com técnicas de descoberta de conhecimentos, conhecidas como KDD (Knowledge Discovery in Database), usando alguns algoritmos de detecção de agrupamentos apropriados. Entretanto, estes algoritmos possuem custo computacional elevado, o que dificulta a sua utilização em grandes conjuntos de dados. As técnicas já desenvolvidas na Área de Bases de Dados para indexação de espaços métricos usualmente consideram o conjunto de maneira uniforme sem levar em conta a existência de agrupamentos nos dados, por isso as estruturas buscam maximizar a eficiência das consultas para todo o conjunto simultaneamente. No entanto muitas vezes as consultas por similaridade estão limitadas a uma região específica do conjunto de dados. Neste contexto, esta dissertação propõe a criação de um novo método de acesso, que seja capaz de indexar de forma eficiente dados métricos, principalmente para conjuntos que contenham agrupamentos. Para atingir esse objetivo este trabalho também propõe um novo algoritmo para detecção de agrupamentos em dados métricos tornando mais eficiente a escolha do medoide de determinado conjunto de elementos. Os resultados dos experimentos mostram que os algoritmo propostos FAMES e M-FAMES podem ser utilizados para a detecção de agrupamentos em dados complexos e superam os algoritmos PAM, CLARA e CLARANS em eficácia e eficiência. Além disso, as consultas por similaridade realizadas com o método de acesso métrico 
proposto FAMESMAM mostraram ser especialmente apropriados para conjuntos de dados com agrupamentos.

PATERLINI, A. A. Imersão de espaços métricos em espaços multidimensionais para indexação de dados usando detecção de agrupamentos. São Carlos, 2011. 90 p. Dissertação de Mestrado - Instituto de Ciências Matemáticas e de Computação - ICMC/USP. 


\section{Abstract}

The success of Database Management System (DBMS) for applications with traditional data (numbers and short texts) has encouraged its use in new types of applications that require manipulation of complex data. Time series, scientific data and other multimedia data are examples of complex data. Several application fields, like medical informatics, have demanded solutions for managing complex data. Complex data can also be studied by means of Knowledge Discovery Techniques (KDD) applying appropriate clustering algorithms. However, these algorithms have high computational cost hindering their use in large data sets. The techniques already developed in the Databases research field for indexing metric spaces usually consider the sets have a uniform distribution, without taking into account the existence of clusters in the data, therefore the structures need to generalize the efficiency of queries for the entire set simultaneously. However the similarity searching is often limited to a specific region of the data set. In this context, this dissertation proposes a new access method able to index metric data efficiently, especially for sets containing clusters. It also proposes a new algorithm for clustering metric data so that selection of a medoid from a particular subset of elements becomes more efficient. The experimental results showed that the proposed algorithms FAMES and M-FAMES can be used as a clustering technique for complex data that outperform PAM, CLARA and CLARANS in effectiveness and efficiency. Moreover, the similarity searching performed with the proposed metric access method FAMESMAM proved to be especially appropriate to data sets with clusters. 
1 Introdução 1

1.1 Motivação . . . . . . . . . . . . . . . . . . . . 2

1.2 Objetivos do projeto . . . . . . . . . . . . . . . . 2

1.3 Resultados Obtidos . . . . . . . . . . . . . . . . . . . 3

1.4 Organização do trabalho . . . . . . . . . . . . . . . . . 4

2 Métodos de Acesso e Consultas por Similaridade 5

2.1 Espaços . . . . . . . . . . . . . . . . . . . . . . . . 6

2.1 .1 Espaço Vetorial . . . . . . . . . . . . . . . . . . 6

2.1.2 Espaço Multidimensional . . . . . . . . . . . . . . . 8

2.1 .3 Espaço Métrico . . . . . . . . . . . . . . . . . . . 8

2.2 Funções de Comparação . . . . . . . . . . . . . . . . . . . . . . . . . . . . 9

2.2.1 Função de Distância . . . . . . . . . . . . . . . . . . . . . . . . 9

2.2.2 Função de Similaridade . . . . . . . . . . . . . . . . . . . . 9 9

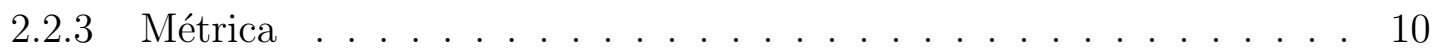

2.2.4 Distâncias para vetores . . . . . . . . . . . . . . . . . . 12

2.2.5 Métricas para dados puramente métricos . . . . . . . . . . . . . . 14

2.3 Consultas por Similaridade . . . . . . . . . . . . . . . . . 15

2.3.1 Consulta por Abrangência . . . . . . . . . . . . . . . 16

2.3.2 Consulta aos $\kappa$-Vizinhos Mais Próximos . . . . . . . . . . . . 16

2.4 Métodos de Imersão ～. . . . . . . . . . . . . . . . . . . . . . . . . . . 18

2.4 .1 Imersões de Lipschitz . . . . . . . . . . . . . . . . . . . . 20

2.5 Algoritmos para Consultas por Similaridade . . . . . . . . . . . . . . 21 
2.5.1 Desigualdade Triangular . . . . . . . . . . . . . . . . . 22

2.5.2 Filtragem e Refinamento . . . . . . . . . . . . . . . . 22

2.6 Métodos de Acesso . . . . . . . . . . . . . . . . . . . . . . . 23

2.6.1 Métodos de Acesso Multidimensionais . . . . . . . . . . . . . . . . 24

2.6.2 Métodos de Acesso Métricos . . . . . . . . . . . . . . . . . . . 26

2.7 Considerações finais . . . . . . . . . . . . . . . . . . . . . . . . . . . 31

3 Detecção de agrupamento 33

3.1 Particionamento . . . . . . . . . . . . . . . . . . . 35

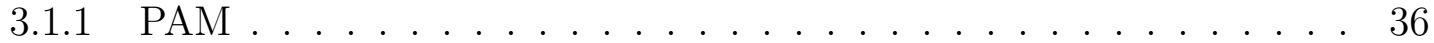

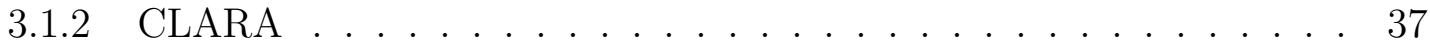

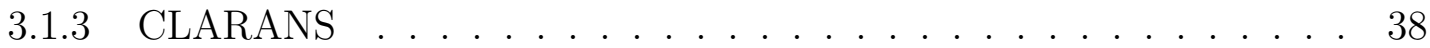

3.2 Hierárquicos . . . . . . . . . . . . . . . . . . . . . . . . . . . . . . . 39

3.3 Densidade . . . . . . . . . . . . . . . . . . . . . . . 40

3.4 Considerações finais . . . . . . . . . . . . . . . . . . . . . . . . 41

4 Trabalho Desenvolvido 43

4.1 FAMES (FAst MEdoid Selection) . . . . . . . . . . . . . . . . . 43

4.1 .1 Adicionando mais eixos ao FAMES . . . . . . . . . . . . . . . . . 48

4.2 Detecção de agrupamentos com FAMES . . . . . . . . . . . . . . . . . . . 51

4.3 Consultas por similaridade com o FAMESMAM . . . . . . . . . . . . . . 52

4.3.1 Motivação . . . . . . . . . . . . . . . . . 52

4.3 .2 Método de construção . . . . . . . . . . . . . . . . . . . 54

4.3.3 Consultas por similaridade . . . . . . . . . . . . . . . 57

4.4 Considerações finais . . . . . . . . . . . . . . . . . . . . . . . . . . 59

5 Experimentos $\quad 61$

5.1 Conjuntos de dados . . . . . . . . . . . . . . . . . . . . . . . . . . . . . . 61

5.2 Detecção de Agrupamentos com o FAMESe com o M-FAMES . . . . . . . . 63

5.2.1 Analisando o efeito da variação do número de agrupamentos $k$. . . 64

5.2.2 Aumento da dimensionalidade e a Variante M-FAMES . . . . . . . . 67

5.2 .3 Escalabilidade . . . . . . . . . . . . . . . . . . . . . . 69

5.2.4 Explorando conjuntos de dados reais . . . . . . . . . . . . . . . 69

5.3 Consultas por similaridade usando o algoritmo FAMESMAM . . . . . . . . 71

5.3.1 Consulta por abrangência . . . . . . . . . . . . . . . . 72

5.3.2 Consulta aos $\kappa$-Vizinhos Mais Próximos . . . . . . . . . . . . 75

5.3.3 Explorando conjuntos de dados reais . . . . . . . . . . . . . 76

5.4 Considerações Finais . . . . . . . . . . . . . . . . . . . . . . . . 77 
$\begin{array}{llr}6 & \text { Conclusão } & 79\end{array}$

6.1 Principais Contribuições . . . . . . . . . . . . . . . . . . 80

6.2 Trabalhos Futuros . . . . . . . . . . . . . . . . . . . . 80

6.3 Publicações . . . . . . . . . . . . . . . . . . . . . . . . 81

6.4 Considerações Finais . . . . . . . . . . . . . . . . . . . . . . . . . . 82 


\section{Lista de Figuras}

2.1 Representação das formas geométricas geradas conforme a distância $L_{p}$. . 13

2.2 Representação de uma consulta por abrangência. . . . . . . . . . . . . . . 16

2.3 Representação de uma consulta aos $\kappa$-vizinhos mais próximos. . . . . . . . 17

2.4 Descarte por desigualdade triangular . . . . . . . . . . . . . . . 23

2.5 Representação da estrutura de indexação OMNI-Sequencial [Santos Filho, 2003]. . . . . . . . . . . . . . 30

3.1 Um exemplo de um conjunto de dados agrupado em três agrupamentos. . . 34

4.1 Intuição do método FAMES. . . . . . . . . . . . . . . . . . . . 45

4.2 Lei dos cossenos. . . . . . . . . . . . . . . . . . . . 46

4.3 Distribuição distintas de densidade no espaço. (a) Normal; (b) Espiculado. 48

4.4 Intuição do método M-FAMES . . . . . . . . . . . . . . . . . 50

4.5 Conjunto de dados com 4 agrupamentos, sendo $s_{q}$ um elemento de consulta e os elementos $s_{1}$ e $s_{2}$ posicionados na borda do conjunto e afastados entre si são utilizados para realizar um poda por desigualdade triangular. . . . . 53

4.6 Comparativo entre o espaço de busca com dois representantes utilizando o método proposto (região cinza) e o método tradicional (região quadriculada) 54

5.1 Amostra de imagens da base dados Aloi com duas iluminações de quatro imagens distintas. . . . . . . . . . . . . . . . . . . . . 62

5.2 Distância média de todos os elementos para o medoide correspondente (mais próximo) para avaliar a qualidade dos agrupamentos encontrados pelos algoritmos FAMES, CLARA, CLARANS e PAM em conjuntos sintéticos de 5 mil elementos, 5 dimensões e com 5, 10 e 20 agrupamentos. 
5.3 Número de cálculos de distâncias para avaliar a eficiência dos algoritmos FAMES, CLARA, CLARANS e PAM para encontrar agrupamentos em conjuntos sintéticos de 5 mil elementos, 5 dimensões e com 5, 10 e 20 agrupamentos. . . . . . . . . . . . . . . . . .

5.4 Distância média de todos os elementos para o medoide correspondente (mais próximo) para avaliar a qualidade dos agrupamentos encontrados pelos algoritmos FAMES, CLARA, CLARANS e PAM em conjuntos sintéticos de 10 mil elementos, 5 dimensões e com 5, 10 e 20 agrupamentos. . . .

5.5 Número de cálculos de distâncias para avaliar a eficiência dos algoritmos FAMES, CLARA, CLARANS e PAM para encontrar agrupamentos em conjuntos sintéticos de $10 \mathrm{mil}$ elementos, 5 dimensões e com 5, 10 e 20 agrupamentos.

5.6 Distância média de todos os elementos para o medoide correspondente (mais próximo) para avaliar a qualidade dos agrupamentos encontrados pelos algoritmos M-FAMES, CLARA, CLARANS e PAM em conjuntos sintéticos de 10 mil elementos, 5, 10 e 20 dimensões e 10 agrupamentos. . . . .

5.7 Número de cálculos de distâncias para avaliar a eficiência dos algoritmos M-FAMES, CLARA, CLARANS e PAM para encontrar agrupamentos em conjuntos sintéticos de 10 mil elementos, 5, 10 e 20 dimensões e 10 agrupamentos.

5.8 Distância média de todos os elementos para o medoide correspondente (mais próximo) para avaliar a qualidade dos agrupamentos encontrados pelos algoritmos FAMES, CLARA, CLARANS e PAM em conjuntos sintéticos de 5 mil, 10 mil e 20 mil elementos, 10 dimensões e 10 agrupamentos. .

5.9 Número de cálculos de distâncias para avaliar a eficiência dos algoritmos FAMES, CLARA, CLARANS e PAM para encontrar agrupamentos em conjuntos sintéticos de 5 mil, 10 mil e 20 mil elementos, 10 dimensões e 10 agrupamentos. . . . . . . . . . . . . . . . . . . 70

5.10 Tempo em segundos para avaliar a eficiência dos algoritmos FAMES, CLARA, CLARANS e PAM para encontrar agrupamentos em conjuntos sintéticos de $5 \mathrm{mil}, 10 \mathrm{mil}$ e $20 \mathrm{mil}$ elementos, 10 dimensões e 10 agrupamentos. . . . . . . . . . . . . . . . . . . .

5.11 Distância média de todos os elementos para o medoide correspondente (mais próximo) para avaliar a qualidade dos agrupamentos encontrados pelos algoritmos FAMES, CLARA, CLARANS e PAM no conjunto Aloi Ilumination com 12mil Histogramas métricos e no conjunto Pendigits . . . 
5.12 Número de cálculos de distâncias para avaliar a eficiência dos algoritmos FAMES, CLARA, CLARANS e PAM para encontrar agrupamentos no conjunto Aloi Ilumination com 12 mil Histogramas métricos e no conjunto Pendigits . . . . . . . . . . . . . . . . . . . . . . 72

5.13 Consultas por abrangência com raio $\xi=0.2$ em 3 conjuntos de dados com 5 mil elementos, 5 agrupamentos e com 5,30 e 100 dimensões. . . . . . . . 73

5.14 Consultas por abrangência com $\xi=0.2$ em 3 conjuntos de dados com 10 agrupamentos, 10 dimensões e com 5 mil,10 mil e 20 mil elementos. . . . . . 74

5.15 Consultas por abrangência com o conjuntos de dados sintético que possui 5 mil elementos, 5 agrupamentos e 30 dimensões, com raio de cobertura da

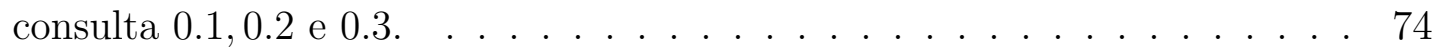

5.16 Consulta aos 10-Vizinhos Mais Próximos com 3 conjuntos de dados com 5 mil elementos e 5 agrupamentos, variando a dimensão do conjunto entre 5,30 e 100 dimensões. . . . . . . . . . . . . . . . . . . . . . . . 75

5.17 Consulta aos 10-Vizinhos Mais Próximos com 3 conjuntos de dados com 10 agrupamentos e 10 dimensões, variando o número de elementos do conjunto entre 5 mil, 10 mil e 20 mil. . . . . . . . . . . . . . . . . . 76

5.18 Consulta aos $\kappa$-Vizinhos Mais Próximos com o conjuntos de dados sintético que possui 5 mil elementos, 5 agrupamentos e dimensionalide 30 , com $\kappa=$

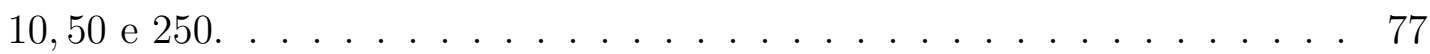

5.19 Consulta aos $\kappa$-Vizinhos Mais Próximos com o conjunto de dados Haralick 78

5.20 Consulta aos $\kappa$-Vizinhos Mais Próximos com o conjunto de dados Zernike . 78 


$\begin{array}{ll}\|\cdot\| & \text { Norma } \\ \alpha, \beta & \text { Escalares } \\ \delta & \text { Função de Distância } \\ \Delta & \text { Função de Similaridade } \\ D & \text { Dimensão Intrínseca } \\ E & \text { Dimensão de Imersão } \\ \Phi & \text { Base de Focos } \\ f & \text { Elemento da Base de Focos } \\ F & \text { Função de Imersão ou Mapeamento } \\ k & \text { Número de agrupamentos } \\ \kappa-N N q & \text { Consulta aos } \kappa \text {-Vizinhos Mais Próximos } \\ \kappa-F N q & \text { Consulta aos } \kappa \text {-Vizinhos Mais Distantes } \\ \Lambda & \text { Corpo de Escalares } \\ L E d i t & \text { Distância de Edição (edit distance) } \\ L_{p} & \text { Distâncias da Família Minkowski } \\ N & \text { Número de Elementos } \\ O I d & \text { Identificador do elemento } \\ P & \text { Matriz de Covariância } \\ P q & \text { Consulta Pontual } \\ Q & \text { Matriz da Distância Quadrática } \\ r & \text { Medoide } \\ \mathbb{R} & \text { Domínio dos Números Reais } \\ R \kappa-N N q & \text { Consulta aos } k \text {-Vizinhos Mais Próximos Reversos } \\ R q & \text { Consulta por Abrangência } \\ R q-1 & \text { Consulta por Abrangência Reversa } \\ \mathbb{S} & \text { Domínio do atributo } i \\ s & \text { Elemento } \\ s_{q} & \text { Elemento de Consulta } \\ S & \text { Conjunto de Elementos } \\ \mathbb{S} & \text { Domínio do Elementos } \\ \xi & \text { Raio } \\ \mathbb{V} & \text { Espaço Vetorial } \\ & \end{array}$


CLARA

CLARANS

DCF

FAPESP

FQ-Tree

FAMES

GBdI

$\mathrm{HF}$

ICMC

JPEG

$\mathrm{KDD}$

$M-F A M E S$

MA

MAE

MAM

MAMD

FAMESMAM

MAP

MBR

MDS

M-Grid

MiCRoM

MPEG

MST

MVP-Tree

PAM

ROT

SGBD

VA-File

VP-Tree
Clustering LARge Applications.

Clustering Large Applications based upon RANdomized Search. Dimensão de Correlação Fractal.

Fundação de Amparo à Pesquisa do Estado de São Paulo.

Fixed-Queries Tree.

FAst MEdoid Selection.

Grupo de Bases de Dados e de Imagens.

Hull Foci.

Instituto de Ciências Matemáticas e de Computação.

Joint Photographic Experts Group.

Descoberta de Conhecimento em Bases de Dados.

Multiple axes - FAst MEdoid Selection.

Métodos de Acesso.

Método de Acesso Espacial.

Método de Acesso Métrico.

Método de Acesso MultiDimensional.

Método de Acesso Métrico FAMES

Método de Acesso Pontual.

Minimum Bound Retangle.

Multidimensional Scaling - Escalonamento Multidimensional.

Metric Pseudo-Grid.

Minimum-Cost Region Matching.

Moving Picture Experts Group.

Minimum Spanning Tree - Árvore de Espalhamento Mínimo.

Multi-Vantage Point Tree.

Partitioning Around Medoids.

Relação de Ordem Total.

Sistema de Gerenciamento de Bases de Dados.

Vector Approximation File - Arquivo de Aproximação Vetorial.

Vantage Point Tree. 


\section{Capítulo \\ 1 \\ Introdução}

o início da computação, as primeiras aplicações desenvolvidas foram voltadas
ao processamento numérico e de textos curtos. Na década de 60 surgiram os primeiros Sistemas de Gerenciamento de Banco de Dados (SGBDs), inicialmente voltados a aplicações de grandes organizações, como corporações, universidades, hospitais e bancos. Gradativamente, outras áreas começaram a fazer uso dos SGBDs para armazenamento de dados, porém ainda tipicamente manipulando números, datas e textos curtos.

O sucesso dos SGBDs nessas aplicações, hoje consideradas tradicionais, encorajou os desenvolvedores de outros tipos de aplicações, que exigem a manipulação de novos tipos de dados. Esses novos tipos de dados são comumente denominados dados complexos, termo utilizado neste texto para denotar toda informação que não é representável por apenas um dado tradicional (números, datas ou textos curtos). Alguns exemplos de uso de dados complexos são: aplicações científicas, que armazenam uma grande quantidade de dados resultantes de experimentos científicos; aplicações multimídia, que provêm funções para que os usuários possam manipular e interagir com imagens, sons e vídeos digitais; aplicações espaciais e de geoprocessamento, que armazenam as localizações espaciais dos dados; e aplicações referentes a séries temporais, que manipulam os dados considerando sua evolução histórica e com validade temporal. 
O processo de descoberta de conhecimento, conhecido como KDD (Knowledge Discovery in Database), é um processo interativo e iterativo com diversas fases, sendo a mais conhecida delas a mineração de dados. A mineração é composta por diversas tarefas, das quais podemos destacar a classificação, regras de associação e a detecção de agrupamentos. Os dados complexos também podem ser analisados com técnicas de descoberta de conhecimento. Entretanto, muitas dessas tarefas têm um custo computacional elevado, o que dificulta a sua utilização em grandes conjuntos de dados.

\subsection{Motivação}

Dados complexos trazem uma demanda inerente por recursos de recuperação de dados que os SGBDs tradicionalmente não provêm. Isto advem principalmente, do fato de que a maioria dos domínios de dados complexos não permitem definir uma Relação de Ordem Total (ROT) entre seus elementos. Assim, os operadores de comparação relacionais ('<', ' $\leq$ ', '>’ e ' $\geq$ ') tipicamente não podem ser usados, pois os dados complexos são usualmente representados em domínios que não atendem à propriedade de ROT. De maneira similar, as consultas por igualdade têm pouca utilidade sobre dados complexos, fazendo com que, nesse contexto, os operadores ' $=$ ' e ' $\neq$ ' se tornem praticamente inúteis [Chávez et al., 2001]. A área de consultas por similaridade tem evoluído consideravelmente nos últimos anos. Vários algoritmos e estruturas de indexação têm sido propostos [Hjaltason and Samet, 2003b, Zezula et al., 2006, Santos Filho, 2003], subsidiando inúmeras áreas de aplicação. Entretanto, a maioria dessas estruturas considera o conjunto de dados de forma homogênea e normalmente é utilizado um único índice independentemente da região que origina a consulta por similaridade, desprezando as peculiaridades de cada região.

\section{$1.2 \quad$ Objetivos do projeto}

As técnicas já desenvolvidas na Área de Bases de Dados para indexação de espaços métricos usualmente tratam o conjunto de maneira uniforme sem considerar a existência de 
agrupamentos nos dados, por isso as estruturas buscam maximizar a eficiência das consultas para todo o conjunto simultaneamente. No entanto, a experiência do GBdI tem mostrado que, muitas vezes, os conjuntos de dados não apresentam um distribuição uniforme, embora as consultas por similaridade sejam limitadas a uma região específica do conjunto.

Neste contexto, esta dissertação de mestrado tem como objetivo a criação de um novo método de acesso, que seja capaz de indexar de forma eficiente dados métricos, em conjuntos que contenham agrupamentos. Para atingir este objetivo, este trabalho também propõem um novo algoritmo para detecção de agrupamentos em dados métricos, baseado em um técnica desenvolvida também durante o programa de mestrado, que torna mais eficiente a escolha do medoide de determinado sub-conjunto de elementos.

\subsection{Resultados Obtidos}

As principais contribuições trazidas por esta dissertação na área de banco de dados e mineração de dados são:

- Desenvolvimento de um método para seleção do medoide de um conjunto de elementos chamado FSM, e aplicação do referido método em um algoritmo de detecção de agrupamentos.

- Desenvolvimento de um método de acesso métrico com elementos representantes escolhidos em cada um dos agrupamentos do conjunto.

Além disso, dois trabalhos adicionais foram desenvolvidos no período de realização do mestrado, que por não serem os objetivos deste trabalho serão apenas citados.

- Utilização de múltiplos descritores para melhorar os resultados obtidos em consultas por similaridades em imagens médicas. A principal contribuição nesse trabalho abrange a conceituação de métricas produtos, até então pouco exploradas em consultas por similaridade. Este trabalho foi publicado no CBMS [Bueno et al., 2009]. 
- A segunda contribuição resultou no trabalho [Appel et al., 2010] publicado no JIDM. Este trabalho teve como objetivo realizar a mineração de dados em grandes redes complexas utilizando as otimizações disponíveis em um SGBD.

\subsection{Organização do trabalho}

O restante do texto está organizado como segue:

- No Capítulo 2 são definidos os espaços vetorial, multidimensional e métrico, onde também se define e exemplifica funções de distâncias, descreve as principais consultas por similaridade e os respectivos algoritmos para consulta por similaridade.

- Os conceitos relacionados à detecção de agrupamentos como técnica de mineração de dados são apresentados no Capítulo 3.

- O Capítulo 4 apresenta os métodos propostos por este trabalho de mestrado: um método para detecção de agrupamentos em dados métricos e um método de acesso métrico, que utiliza o método detecção de agrupamentos proposto.

- O Capítulo 5 mostra os experimentos realizados com os algoritmos propostos e os resultados obtidos.

- Finalmente, no Capítulo 6 são apresentadas as conclusões finais do trabalho e os trabalhos futuros. 


\section{Capítulo \\ 2 \\ Métodos de Acesso e Consultas por Similaridade}

$\mathrm{O}$

s SGBDs oferecem recursos adequados para realizar buscas sobre os dados por meio de relações de igualdade e de ordem total existentes nos dados armazenados (tais como números e textos curtos). Porém, para dados multimídia e outros dados complexos, as buscas por igualdade ou por ordem muitas vezes não se aplicam. Para esses tipos de dados é mais relevante fazer uso de consultas por similaridade, que consistem em procurar por elementos em um conjunto que, segundo algum critério de similaridade, sejam mais "parecidos" ou mais "distintos" com/de um determinado elemento.

O aumento no volume dos dados armazenados, e que devem ser recuperados nas consultas, requerem o uso de estruturas de indexação para acelerar as consultas por similaridade. Para dados de alta dimensionalidade ou adimensionais foram propostos os Métodos de Acesso Métricos (MAMs). Os Métodos de Acesso mais relevantes são apresentados na Seção 2.6 .

Neste Capítulo serão definidos: Os espaços vetorial, multidimensional e métrico, que são compostos por elementos de determinado domínio e propriedades específicas; Funções de comparação que podem ser aplicadas entre pares de elementos; Métodos de 
imersão de espaços métricos em espaços multidimensionais; As principais consultas por similaridade e os respectivos algoritmos para realização dessas consultas; E finalmente, os Métodos de Acesso mais relevantes.

\subsection{Espaços}

Nesta subseção são apresentados os conceitos e as definições do Espaço Vetorial, do Espaço Multidimensional e do Espaço Métrico.

\subsubsection{Espaço Vetorial}

Um espaço vetorial $\mathbb{V}=\mathbb{S}, \Lambda$ é composto por um conjunto de elementos $S$ que pertencem a um domínio $\mathbb{S}$ e escalares que pertencem a um corpo $\Lambda$ [Halmos, 1978]. Os elementos $s_{a} \in S$ do espaço vetorial são representados por $\mathrm{E}$ valores reais, $s_{a}=\left\{s_{a_{1}}, s_{a_{2}}, \ldots, s_{a_{E}}\right\}$. Esse espaço satisfaz as seguintes propriedades para quaisquer $s_{a}, s_{b}, s_{c} \in \mathbb{S}$ e quaisquer $\alpha, \beta \in \Lambda$ :

- Regras da adição $(\mathbb{S}+\mathbb{S} \rightarrow \mathbb{S})$ :

Comutatividade: $s_{a}+s_{b}=s_{b}+s_{a}$;

Associatividade: $s_{a}+\left(s_{b}+s_{c}\right)=\left(s_{a}+s_{b}\right)+s_{c}$;

Elemento neutro: existe um elemento $0 \mathrm{em} \mathbb{S}$, tal que $s_{a}+0=s_{a}$; e

Elemento simétrico: existe um elemento $-s_{a}$ em $\mathbb{S}$, tal que $s_{a}+\left(-s_{a}\right)=0$.

- Regras da multiplicação por um escalar $(\Lambda \times \mathbb{S} \rightarrow \mathbb{S})$ :

Identidade: se 1 é a identidade da multiplicação em $\Lambda$, então $1 \times s_{a}=s_{a}$;

Associatividade: $\alpha\left(\beta s_{a}\right)=(\alpha \beta) s_{a}$;

Distributividade: $\alpha\left(s_{a}+s_{b}\right)=\alpha s_{a}+\alpha s_{b}$; e

Distributividade: $(\alpha+\beta) s_{a}=\alpha s_{a}+\beta s_{a}$.

Existem algumas variações do espaço vetorial que se caracterizam por atenderem a alguma propriedade específica. A seguir são dados alguns exemplos. 


\section{Espaço Normado}

O Espaço Normado é um espaço vetorial com uma norma ||.||, que é equivalente a uma função de distância (Seção 2.2.1) entre o elemento do espaço vetorial e o elemento neutro $(\|s\|=\delta(s, 0))$. Um Espaço Normado é também um Espaço Métrico (Seção 2.1.3), cuja métrica é uma função de distância para vetores (Seção 2.2.4), que possua as seguintes propriedades para quaisquer $s_{a}, s_{b} \in \mathbb{S}$ e qualquer $\alpha \in \Lambda$ :

- Invariante a Translação: $\delta\left(s_{a}, s_{b}\right)=\delta\left(s_{a}+\alpha, s_{b}+\alpha\right)$;

- Homogênea: $\alpha *\left\|s_{a}\right\|=\left\|\alpha * s_{a}\right\|$.

\section{Espaço Vetorial com Produto Interno}

O Espaço Vetorial com Produto Interno é um espaço vetorial que possui um produto interno definido. Um produto interno é uma função $\bullet: \mathbb{S} \times \mathbb{S} \rightarrow \mathbb{R}$ que pode ser calculada como a multiplicação atributo por atributo dos elementos:

$$
s_{a} \bullet s_{b}=\sum_{i=1}^{E} s_{a_{i}} s_{b_{i}}
$$

O espaço vetorial com produto interno possui as seguintes propriedades para quaisquer elementos $s_{a}, s_{b}, s_{c}$ pertencentes ao domínio $\mathbb{S}$ e quaisquer $\alpha, \beta \in \Lambda$ :

- Simetria: $s_{a} \bullet s_{b}=s_{b} \bullet s_{a}$;

- Distributividade: $\left(s_{a}+s_{b}\right) \bullet s_{c}=\left(s_{a} \bullet s_{c}\right)+\left(s_{b} \bullet s_{c}\right)$;

- Não-negatividade: $s_{a} \bullet s_{a} \geq 0, \operatorname{com} s_{a} \bullet s_{a}=0$ se e somente se $s_{a}=0$

Em um espaço vetorial com produto interno, é possível definir os conceitos de ortogonalidade, norma e ângulo entre os elementos:

- Ortogonalidade: Os elementos $s_{a}$ e $s_{b}$ são ortogonais se, e somente se, $s_{a} \bullet s_{b}=0$;

- Norma: $\left\|s_{a}\right\|=\sqrt{s_{a} \bullet s_{a}}$;

- Ângulo: $\arccos \frac{s_{a} \bullet s_{b}}{\left\|s_{a}\right\| \cdot\left\|s_{b}\right\|}$. 


\subsubsection{Espaço Multidimensional}

Um espaço multidimensional é composto por um conjunto $S$ de elementos. Todos os elementos do espaço multidimensional possuem o mesmo número de atributos $E$, correspondendo às dimensões do conjunto, os elementos são representados como $s_{a}=$ $\left\{s_{a_{1}}, s_{a_{2}}, \ldots, s_{a_{E}}\right\}$.

As seguintes propriedades devem ser satisfeitas para qualquer $s_{a}, s_{b} \in S$ :

- O valor $s_{a_{i}}$ do atributo $i$ do elemento $s_{a}$ pertence a um domínio $\mathbb{S}_{i}$, para todos os elementos: $\left\{s_{a_{i}} \in \mathbb{S}_{i}\right\}$

- Nesse espaço deve ser definida a função de diferença entre cada atributo - : $\mathbb{S}_{i} \times$ $\mathbb{S}_{i} \rightarrow \mathbb{R}$ representado como $\left(s_{a_{i}}-s_{b_{i}}\right)$, sendo, o módulo dessa diferença simétrico: $\left|s_{a_{i}}-s_{b_{i}}\right|=\left|s_{b_{i}}-s_{a_{i}}\right|$.

Histogramas de cores formam um exemplo de espaço multidimensional, cujas dimensões representam contadores com domínio $\mathbb{R}^{+}$. A inexistência de valores negativos impede a definição de algumas propriedades do espaço vetorial, como a propriedade do elemento simétrico. Assim, mesmo que os valores de cada dimensão sejam números reais, um conjunto de histograma de cores não pode ser considerado como um espaço vetorial.

Outros exemplos de espaços multidimensionais são aqueles em que as unidades de cada dimensão são distintas, caso tipicamente encontrado em relações de um banco de dados.

\subsubsection{Espaço Métrico}

Um espaço métrico é formalmente definido como um par $<\mathbb{S}, \delta()>$, onde $\mathbb{S}$ é um domínio de dados e $\delta()$ é uma função $\mathbb{S} \times \mathbb{S} \rightarrow \mathbb{R}^{+}$, denominada métrica, que expressa a distância ou dissimilaridade entre elementos de $\mathbb{S}$ e satisfaz as propriedades definidas na Seção 2.2.3. 


\subsection{Funções de Comparação}

Nesta subseção são apresentadas as funções mais relevantes para esse trabalho que podem ser utilizadas para comparar os elementos de determinado conjunto de dados.

\subsubsection{Função de Distância}

Uma função de distância $\delta: \mathbb{S} \times \mathbb{S} \rightarrow \mathbb{R}^{+}$calcula a dissimilaridade entre elementos do domínio $\mathbb{S}$. Esse cálculo é definido de tal maneira que quanto mais similares dois elementos são entre si, menor o valor dessa função.

Em geral, as funções de distância são definidas para aplicações específicas ou para domínios de aplicações. Portanto, nesses casos a função deve ser definida por um especialista da aplicação.

As funções de distância podem ser divididas em dois grupos com relação ao valor da função (contradomínio).

- discreta: o conjunto de valores da função é um conjunto pequeno de valores;

- contínua: o conjunto de valores da função é infinito ou muito grande.

Um exemplo de métrica contínua é a Euclidiana que será apresentada na Seção 2.2.4 e um exemplo de métrica discreta é a métrica de Levenshtein, aplicável a palavras de um dicionário [Levenshtein, 1966].

\subsubsection{Função de Similaridade}

Uma função $\Delta: \mathbb{S} \times \mathbb{S} \rightarrow \mathbb{R}$ é chamada similaridade (ou proximidade) no domínio $\mathbb{S}$ se $\Delta$ é não-negativo, simétrico, e se $\Delta\left(s_{a}, s_{b}\right)<\Delta\left(s_{a}, s_{a}\right)$ para todo $s_{a}, s_{b} \in S$, com igualdade se e somente se $s_{a}=s_{b}$.

Em geral uma função de similaridade pode ser transformada em uma função de distância. As principais transformações utilizadas para obter uma distância (dissimilaridade) $\delta$ a partir de uma similaridade $\Delta$ são: 


$$
\begin{array}{r}
\delta=1-\Delta \\
\delta=\frac{1-\Delta}{\Delta} \\
\delta=\sqrt{1-\Delta} \\
\delta=\sqrt{2\left(1-\Delta^{2}\right)} \\
\delta=-\ln (\Delta) \\
\delta=\arccos (\Delta)
\end{array}
$$

A escolha de qual transformação usar depende da aplicação e da função de similaridade. Essas transformações possibilitam a indexação dos espaços pela dissimilaridade, e se o resultado da transformação for uma métrica, as propriedades de espaço métrico se aplicam.

\subsubsection{Métrica}

Uma métrica é uma função de distância que satisfaz as seguintes propriedades para quaisquer $s_{a}, s_{b}, s_{c} \in \mathbb{S}$ :

- identidade: $\delta\left(s_{a}, s_{a}\right)=0$;

- simetria: $\delta\left(s_{a}, s_{b}\right)=\delta\left(s_{b}, s_{a}\right)$;

- não-negatividade: $0<\delta\left(s_{a}, s_{b}\right)<\infty$ se $s_{a} \neq s_{b}$; e

- desigualdade triangular: $\delta\left(s_{a}, s_{b}\right) \leq \delta\left(s_{a}, s_{c}\right)+\delta\left(s_{c}, s_{b}\right)$.

Algumas funções de distâncias específicas podem não satisfazer algumas das quatro propriedades, esses casos especiais são classificados em [Deza and Deza, 2006] como:

- Pseudo-métrica: permite que dois elementos distintos possuam distância zero, então pode existir $\delta\left(s_{a}, s_{b}\right)=0$;

- Quase-métrica: a função de distância não é simétrica, uma métrica pode ser obtida de uma Quase-métrica da seguinte forma: $\delta\left(s_{a}, s_{b}\right)=\frac{\delta_{q}\left(s_{a}, s_{b}\right)+\delta_{q}\left(s_{b}, s_{a}\right)}{2}$. 


\section{Métrica Produto}

Dados $M$ Espaços Métricos $<\mathbb{S}_{d}, \delta_{d}()>$ com o índice $d$ variando de 1 a $M$, a Métrica Produto é uma métrica sobre o produto cartesiano:

$$
\mathbb{S}=\mathbb{S}_{1} \times \mathbb{S}_{2} \times \ldots \times \mathbb{S}_{M}
$$

A Métrica Produto é definida em função das métricas $\delta_{d}$, o objetivo é juntar em um único resultado as métricas de espaços métricos distintos. Cada métrica $\delta_{d}$ opera apenas sobre os elementos que pertencem ao domínio $\mathbb{S}_{d}$. A métrica resultante avalia a distância entre os elementos correspondentes nos diversos espaços [Deza and Deza, 2006].

As Métricas Produto podem ser definidas de diversas maneiras. Para quaisquer $s_{a}, s_{b} \in \mathbb{S}_{d}$ alguns exemplos comuns são:

$$
\begin{array}{r}
\delta\left(s_{a}, s_{b}\right)=\sum_{d=1}^{M} \delta_{d}\left(s_{a}, s_{b}\right) \\
\delta\left(s_{a}, s_{b}\right)=\sqrt[2]{\sum_{d=1}^{M} \delta_{d}\left(s_{a}, s_{b}\right)^{2}} \\
\delta\left(s_{a}, s_{b}\right)=\max _{d=1}^{M} \delta_{d}\left(s_{a}, s_{b}\right) \\
\delta\left(s_{a}, s_{b}\right)=\sum_{d=1}^{M} \frac{1}{2^{d}} \frac{\delta_{d}\left(s_{a}, s_{b}\right)}{1+\delta_{d}\left(s_{a}, s_{b}\right)} \\
\delta\left(s_{a}, s_{b}\right)=\min _{d=1}^{M}\left\{\delta_{d}\left(s_{a}, s_{b}\right), 1\right\}
\end{array}
$$

Um caso particular considera o mesmo domínio $\mathbb{S}_{d}=\mathbb{S}$ para todos os espaços, mas definindo diferentes espaços métricos da forma $<\mathbb{S}, \delta_{d}>$, caracterizados pelas diferentes métricas.

A métrica produto pode ser utilizada, por exemplo, para calcular a distância entre imagens imersas em espaços métricos distintos, usando distintas características extraídas das imagens, por exemplo histograma e textura. A distância entre as imagens é calculada 
normalmente, considerando apenas um dos espaços métricos de cada vez, e computando a distância final pela métrica produto.

\subsubsection{Distâncias para vetores}

\section{Métricas de Minkowski}

A família de distâncias Minkowski [Wilson and Martinez, 1997], também conhecida como família $L_{p}$, é comumente empregada em espaços multidimensionais e vetoriais.

Como apresentado na Seção 2.1, os elementos pertencentes a um espaço vetorial $\mathbb{V}$ com domínio $\mathbb{S}$ dimensionalidade $E$ cujos atributos assumem valores reais $s_{a}=\left\{s_{a_{1}}, \ldots, s_{a_{E}}\right\}$, para todo $s_{a} \in \mathbb{S}$. Sendo assim, o conjunto de funções de distância $\delta_{L_{p}}$ é definido como:

$$
\delta_{L_{p}}\left(s_{a}, s_{b}\right)=\sqrt[p]{\sum_{i=1}^{E}\left|s_{a_{i}}-s_{b_{i}}\right|^{p}}
$$

A família $L_{p}$ é bem vasta e diversas variantes podem ser obtidas a partir de sua definição. A seguir são apresentados três dos exemplos mais utilizados em consultas por similaridade.

A função de distância $\delta_{L_{1}}$, também denominada City Block ou Manhattan, corresponde ao somatório do módulo das diferenças entre os atributos. Nesse caso, o conjunto de pontos equidistantes a um dado raio de abrangência $\xi$ forma um losango com os diâmetros paralelos aos eixos das coordenadas. A $\delta_{L_{1}}$ é definida como:

$$
\delta_{L_{1}}\left(s_{a}, s_{b}\right)=\sum_{i=1}^{E}\left|s_{a_{i}}-s_{b_{i}}\right|
$$

A função de distância $\delta_{L_{2}}$ denominada Euclidiana, corresponde, à função comumente utilizada para o cálculo de distância entre vetores. O conjunto de pontos de mesma distância segundo a função $\delta_{L_{2}}$ forma uma circunferência. Tal distância é definida como:

$$
\delta_{L_{2}}\left(s_{a}, s_{b}\right)=\sqrt{\sum_{i=1}^{E}\left(s_{a_{i}}-s_{b_{i}}\right)^{2}}
$$


Calculando-se o limite da equação 2.14 quando $p$ tende ao infinito, obtém-se a função de distância $\delta_{L_{\infty}}$, conhecida também como LInfinity ou Chebychev, na qual o conjunto de pontos equidistantes formam um quadrado com os lados paralelos aos eixos das coordenadas. A função $\delta_{L_{\infty}}$ é definida como:

$$
\delta_{L_{\infty}}\left(s_{a}, s_{b}\right)=\max _{i=1}^{E}\left|s_{a_{i}}-s_{b_{i}}\right|
$$

Na Figura 2.1 são ilustradas as formas geométricas das regiões com mesma distância geradas pelas funções $\delta_{L_{1}}$ (Figura $2.1(\mathrm{a})$ ), $\delta_{L_{2}}$ (Figura $\left.2.1(\mathrm{~b})\right)$ e $\delta_{L_{\infty}}$ (Figura 2.1 (c)) em um espaço bidimensional. A sobreposição das representações geométricas das funções na Figura 2.1 (d) distingue os subespaços distintos englobados pelas diferentes funções de distância.

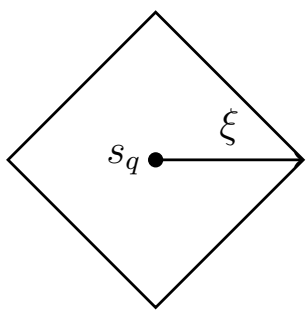

(a)

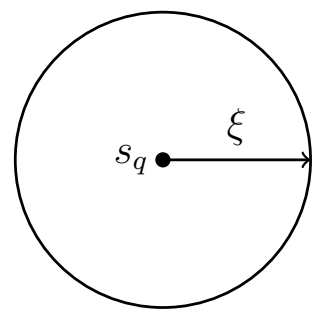

(b)

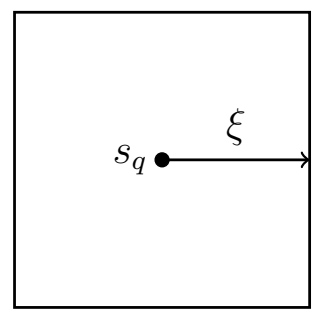

(c)

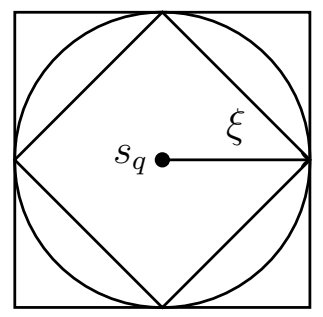

(d)

Figura 2.1: Representação das formas geométricas geradas conforme a distância $L_{p}$ utilizada e em relação aos pontos equidistantes à distância $\xi$ a partir do objeto centro $s_{q}$.

\section{Métrica de Canberra}

A métrica de Canberra [Lance and Williams, 1967] é calculada como a diferença absoluta dos valores dos atributos dividida pela soma absoluta dos mesmos. Essa distância é definida como:

$$
\delta_{C}\left(s_{a}, s_{b}\right)=\sum_{i=1}^{E} \frac{\left|s_{a_{i}}-s_{b_{i}}\right|}{\left|s_{a_{i}}\right|+\left|s_{b_{i}}\right|}
$$

Esta distância não é continua em zero, é dependente da translação, e é bastante sensível a pequenas variações quando os valores se aproximam de zero. 
A métrica de Canberra é aplicada em diferentes áreas, como em sequências de DNA na bioinformática e para detecção de intrusão [Emran and Ye, 2002].

\subsubsection{Métricas para dados puramente métricos}

Algumas vezes os elementos não podem ser representados em um domínio com número fixo de dimensões, ou seja, não pertencem nem a um espaço vetorial e nem a um espaço multidimensional. No entanto, se sobre o domínio puder ser definida um métrica, então esses dados são frequentemente chamados de puramente métricos. Para esses dados somente as estruturas de indexação que utilizam apenas as propriedades de uma métrica podem ser utilizadas.

\section{Distância Histograma Métrico}

O Histograma Métrico foi proposto em [Bueno, 2002] para comparar imagens monocromáticas e considera a correlação dos níveis de cinza adjacentes, permitindo, inclusive, que a comparação seja invariante às transformações de brilho, escala, rotação e translação nas imagens. O número de atributos do histograma métrico é variável, dependendo somente de cada imagem em análise e não de todo o conjunto de imagens.

A comparação entre as imagens é realizada utilizando a Distância Histograma Métrico apresentada em [Traina et al., 2002] e é calculada como o valor da área não sobreposta entre as duas curvas que representam os histogramas métricos.

\section{Imagens Comprimidas}

Imagens comprimidas (JPEG, MPEG) podem ser comparadas diretamente, sem a necessidade de mapeá-las em um espaço multidimensional. Em [Brent Seales et al., 1997] utilizam-se imagens comprimidas para as quais os custos de comparação e de armazenamento são reduzidos por causa da compressão. Segundo os autores, essa técnica não gera grande perda de informação (não haverá erro significativo na quantificação da distância) e o uso das imagens é mais vantajoso por não necessitar intervenção humana (para definir 
os objetos, por exemplo) e por trabalhar diretamente sobre as informações contidas nas imagens e não sobre características extraídas.

\section{MiCRoM}

A métrica MiCRoM (Minimum-Cost Region Matching) proposta por [Stehling et al., 2002] é utilizada para comparar imagens segmentadas. A métrica MiCroM é modelada como um problema de fluxo de custo mínimo em um grafo. Mais especificamente, a comparação das imagens segmentadas em regiões é modelada como um problema de transporte (produtor-consumidor).

As regiões de uma imagem são representadas como os nós produtores com determinado valor de produção. As regiões da outra imagem são os nós consumidores com determinado valor negativo de demanda. A produção do nó é transportada para suprir a demanda do nós consumidores gerando um fluxo entre os nós. O grafo é bipartido, ligando todos os nós produtores a todos os nós consumidores. O sistema é balanceado, portanto a soma da produção e da demanda é zero. Cada aresta possui um custo de transporte entre o produtor e o consumidor. A métrica é o valor mínimo do custo total, calculado pelo somatório do custo de cada aresta multiplicado pelo fluxo transportado.

\subsection{Consultas por Similaridade}

Para que um sistema possa responder a consultas por similaridade e retornar os elementos que mais se assemelham a um dado elemento de consulta, é necessário mensurar o quão similares são os elementos envolvidos. A quantificação do valor dessa similaridade é obtida por meio da aplicação de uma função de distância, que calcula o grau de semelhança entre dois elementos.

Existem dois tipos básicos de consultas de seleção por similaridade: as consultas por abrangência e as consultas aos $\kappa$-vizinhos mais próximos [Chávez et al., 2001, Böhm et al., 2001]. A seguir, essas categorias de consultas são apresentadas. 


\subsubsection{Consulta por Abrangência}

Uma consulta por abrangência (Range query - Rq) tem como objetivo encontrar todos os elementos dissimilares de um elemento de consulta até no máximo um certo limiar. Formalmente, seja $\mathbb{S}$ um domínio de dados, $S \subseteq \mathbb{S}$ um conjunto de elementos, $s_{q} \in \mathbb{S}$ um elemento de consulta, $\delta$ uma métrica definida sobre elementos de $\mathbb{S}$ e $\xi$ um limiar de dissimilaridade. Uma consulta por abrangência é dada por:

$$
R q\left(S, s_{q}, \delta, \xi\right)=\left\{s_{a} \in S \mid \delta\left(s_{q}, s_{a}\right) \leq \xi\right\}
$$

A Figura 2.2 mostra uma representação visual desta consulta. Os elementos de $S$ localizados na bola centrada em $s_{q}$ com raio $\xi$ compõem a resposta para a consulta.

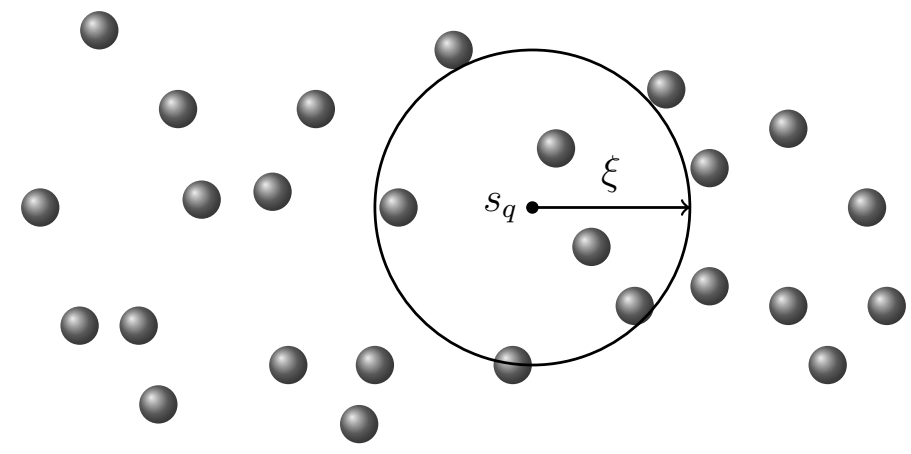

Figura 2.2: Representação de uma consulta por abrangência com elemento de consulta $s_{q}$ e raio $\xi$.

Existem duas variações comuns para a consulta por abrangência: a consulta pontual e a consulta por abrangência reversa. A consulta pontual (Point query - Pq) é uma consulta por abrangência com $\xi=0$, cujo objetivo é identificar se o elemento de consulta está armazenado na base de dados. A consulta por abrangência reversa (Reversed Range query $-\mathrm{Rq}^{-1}$ ), é uma busca por abrangência que procura pelos elementos fora da área de abrangência, isto é, a resposta é formada pelos elementos $s_{a} \in S$ tal que $\delta\left(s_{q}, s_{a}\right)>\xi$.

\subsubsection{Consulta aos $\kappa$-Vizinhos Mais Próximos}

Uma consulta aos $\kappa$-vizinhos mais próximos $(\kappa$-Nearest Neighbors query $-\kappa$-NNq) retorna os $\kappa$ elementos mais similares ao elemento de consulta. Formalmente, seja um domínio $\mathbb{S}$, 
um conjunto de elementos $S \subseteq \mathbb{S}$, um elemento de consulta $s_{q} \in \mathbb{S}$, uma métrica $\delta$ definida sobre $\mathbb{S}$ e um inteiro $\kappa \geq 1$. o resultado de uma $\kappa$-NNq é dado por:

$$
\kappa-N N q\left(S, s_{q}, \delta, \kappa\right)=S_{\kappa}=\left\{s_{i} \in S\left|\forall s_{j} \in S \backslash S_{\kappa},\right| S_{\kappa} \mid=\kappa, \delta\left(s_{q}, s_{i}\right) \leq \delta\left(s_{q}, s_{j}\right)\right\}
$$

onde $\left|S_{\kappa}\right|$ é a cardinalidade do conjunto $S_{\kappa}$, e $\kappa-N N q\left(S, s_{q}, \delta, \kappa\right)=\bigcup_{1 \leq i \leq \kappa}\left\{s_{i}\right\}$, tal que cada $\left\{s_{i}\right\}$ é dado por:

$$
\begin{aligned}
& \left\{s_{1}\right\}=\left\{s \in S \mid \forall s_{j} \in S \backslash\{s\}, \delta\left(s_{q}, s\right) \leq \delta\left(s_{q}, s_{j}\right)\right\} \\
& \left\{s_{2}\right\}=\left\{s \in S \backslash\left\{s_{1}\right\} \mid \forall s_{j} \in S \backslash\left\{s_{1}, s\right\}, \delta\left(s_{q}, s\right) \leq \delta\left(s_{q}, s_{j}\right)\right\} \\
& \quad \vdots \\
& \left\{s_{\kappa}\right\}=\left\{s \in S \backslash\left\{s_{1}, \ldots, s_{\kappa-1}\right\} \mid \forall s_{j} \in S \backslash\left\{s_{1}, \ldots, s_{\kappa-1}, t\right\}, \delta\left(s_{q}, s\right) \leq \delta\left(s_{q}, s_{j}\right)\right\} .
\end{aligned}
$$

A Figura 2.3 ilustra uma $5-N N q$, tendo $s_{q}$ como elemento de consulta e, neste exemplo, $s_{q} \notin S$.

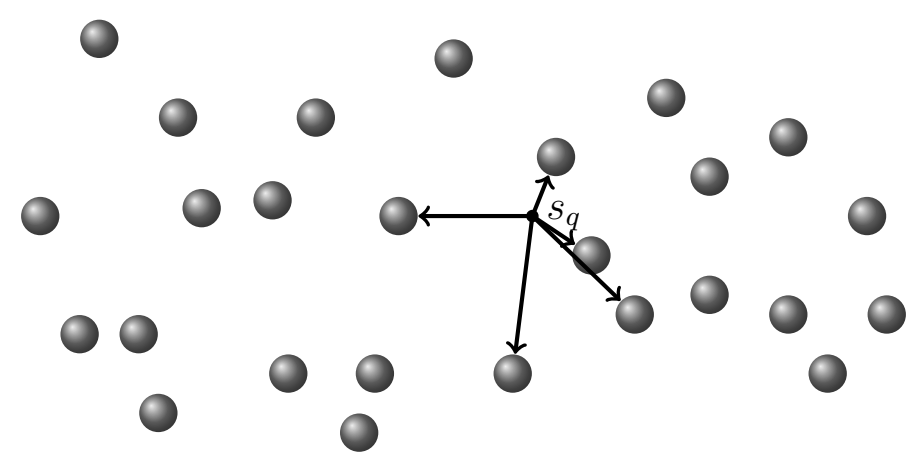

Figura 2.3: Representação de uma consulta aos $\kappa$-vizinhos mais próximos, tendo $s_{q}$ como elemento de consulta e $\kappa=5$.

É importante notar que podem ocorrer empates no $\kappa$-ésimo elemento. Isto é, pode haver mais de um elemento encontrado à distância máxima. Há basicamente duas formas de tratar empates em uma $\kappa-N N q$ :

- escolhe-se aleatoriamente alguns dos elementos à distância máxima e desprezam-se os demais, de tal forma que retorna-se exatamente $\kappa$ elementos $(\kappa$-NNq sem lista de empate); ou 
- incluem-se todos os elementos à distância máxima, retornando-se mais do que $\kappa$ elementos $(\kappa-N N q$ com lista de empate).

Na literatura, há referências também à consulta ao vizinho mais próximo (Nearest Neighbor query - NNq), que nada mais é que uma $\kappa$ - $N N q \operatorname{com} \kappa=1$.

Uma variação de busca por vizinhança é a consulta aos $\kappa$-vizinhos mais distantes $(\kappa$-Farthest Neighbors query $-\kappa-F N q)$, que procura pelos $\kappa$ elementos mais dissimilares ao elemento de consulta. A consulta aos $\kappa$-vizinhos mais distantes é complementar à consulta aos $\kappa$-vizinhos mais próximos, sendo $k$-NNq $\left(S, s_{q}, \delta, \kappa\right) \cup \kappa$-FNq $\left(S, s_{q}, \delta,|S|-\kappa\right)=S$, onde $|S|$ é a quantidade de elementos de $S$.

Outra variação é a consulta por similaridade aos $\kappa$-Vizinhos mais Próximos Reversos, inicialmente descrita por [Korn and Muthukrishnan, 2000]. O $R \kappa-N N q$ recebe como parâmetros o elemento de consulta $s_{q}$ e uma quantidade $\kappa$, e recupera os elementos do conjunto que têm o elemento de consulta como um de seus $\kappa$ vizinhos mais próximos [Lee et al., 2008b, Achtert et al., 2009, Tran et al., 2009].

\subsection{Métodos de Imersão}

Os métodos de imersão são elaborados para facilitar as consultas por similaridade em espaços métricos. Métodos de imersão são especialmente indicados quando o custo do cálculo da distância no espaço original é caro. Nesses casos pode-se substituir a função de distância por outra mais barata. Para atingir esse objetivo realiza-se o mapeamento ou a imersão do conjunto $S$ para elementos de um espaço multidimensional de baixa dimensionalidade [Zezula et al., 2006, Samet, 2006].

Formalmente a imersão do espaço métrico original $<\mathbb{S}, \delta>$ em um espaço multidimensional $<\mathbb{S}^{E}, \delta_{m}>$ é feito através do mapeamento $F: \mathbb{S} \rightarrow \mathbb{S}^{E}$ onde $\mathbb{S}^{E}$ é o domínio do espaço de imersão formado pelas distâncias dos elementos para os elementos representantes, comumente denominados focos ou pivôs, e $\delta_{m}$ é a função de distância aplicada no espaço mapeado. 
A propriedade de contratividade do mapeamento é essencial para que não ocorram falsos descartes nas consultas.

Definição 2.4.1 (Contratividade do Mapeamento). : As distâncias entre todos os pares de elementos no espaço mapeado devem ser menores ou iguais às distâncias correspondentes dos pares de elementos no espaço original, conforme a equação:

$$
\delta_{m}\left(F\left(s_{a}\right), F\left(s_{b}\right)\right) \leq \delta\left(s_{a}, s_{b}\right)
$$

O conceito de distorção [Hjaltason and Samet, 2003a, Linial et al., 1995] é frequentemente utilizado para medir a qualidade do método de imersão.

Definição 2.4.2 (Qualidade do método de imersão). : A qualidade é definida como os menores valores de $c_{1}, c_{2}$ que considerando os elementos $s_{a}$ e $s_{b}$, os elementos imersos $F\left(s_{a}\right)$ e $F\left(s_{b}\right)$ e a distância em cada espaço, garantam que:

$$
\frac{1}{c_{1}} \cdot \delta\left(s_{a}, s_{b}\right) \leq \delta_{m}\left(F\left(s_{a}\right), F\left(s_{b}\right)\right) \leq c_{2} \cdot \delta\left(s_{a}, s_{b}\right)
$$

O stress é outra medida usada para a determinar qualidade do mapeamento $F$ sobre um conjunto de dados $S$.

Definição 2.4.3 (Stress do espaço mapeado). :

O stress mede a diferença total entre as distâncias originais e as distâncias mapeadas e é tipicamente definido como:

$$
\frac{\sum_{s_{a}, s_{b}}\left(\delta_{m}\left(F\left(s_{a}\right), F\left(s_{b}\right)\right)-\delta\left(s_{a}, s_{b}\right)\right)^{2}}{\sum_{s_{a}, s_{b}} \delta\left(s_{a}, s_{b}\right)^{2}}
$$

O Multidimensional Scaling (MDS) [Cox and Cox, 2001] é um método de mapeamento baseado na minimização do stress. Dependendo do método de minimização aplicado, o MDS pode ser um mapeamento contrativo. Entretanto, na prática o MDS não deve ser aplicado para consultas por similaridade devido ao elevado custo. O custo de uma consulta não será reduzido, pois para que o elemento de consulta $s_{q}$ seja mapeado, 
é necessário calcular as distâncias para todos os elementos da base, e portanto a consulta já estaria resolvida.

\subsubsection{Imersões de Lipschitz}

As imersões de Lipschitz, que foram utilizadas por métodos propostos em [Linial et al., 1995, Bourgain, 1985], compreendem uma classe de métodos de imersão. Essas imersões são baseadas na definição de um espaço multidimensional onde cada dimensão corresponde a um conjunto de referência que é um subconjunto de elementos do conjunto de dados.

A imersão de Lipschitz é definida formalmente em termos de um conjunto $T$ de $m$ subconjuntos de $S, T=\left\{S_{1}, S_{2}, \ldots, S_{m}\right\}$. Os subconjuntos $S_{i}$ são denominados os conjuntos referência do mapeamento. Seja $\delta\left(s_{a}, S_{i}\right)$ uma extensão da função de distância $\delta$ de um elemento $s_{a} \in S$ para um subconjunto $S_{i} \subset \mathbb{S}$, tal que $\delta\left(s_{a}, S_{i}\right)=$ $\min _{s_{s} \in S_{i}}\left(\delta\left(s_{a}, s_{s}\right)\right)$. Uma imersão em relação a $S$ é definida como um mapeamento $F$ tal que $F_{a}=\left(\delta\left(s_{a}, S_{1}\right), \delta\left(s_{a}, S_{2}\right), \ldots, \delta\left(s_{a}, S_{m}\right)\right)$. Ou seja, a imersão é realizada definindo um espaço multidimensional de $m$ dimensões, onde cada dimensão corresponde a um subconjunto $S_{i} \subset \mathbb{S}$ de elementos. O valor do $i$-ésimo atributo mapeado a partir do elemento $s_{a}$ é a distância do elemento $s_{a}$ para o elemento mais próximo de $S_{i}$.

A maior desvantagem dessa técnica de mapeamento é o elevado custo computacional, pois dado um elemento de consulta, calcula-se a distância para todos os elementos que pertencem a algum dos subconjuntos $S_{i}$, e tal quantidade de elementos pode se aproximar do número de elementos total no conjunto $S$. Além disso, o número de dimensões $m$ do espaço multidimensional pode ser tão alto que o custo do cálculo de distância na imersão se aproxima do custo do cálculo de distância no espaço original.

Um caso específico de imersão de Lipschitz ocorre quando os subconjuntos de $S$ são formados por um único elemento cada. Nesse caso o custo é reduzido, pois para cada dimensão do mapeamento calcula-se apenas uma distância. 


\subsection{Algoritmos para Consultas por Similaridade}

Se nenhuma estrutura de indexação for utilizada, uma consulta por similaridade deve ser executada utilizando-se uma busca sequencial sobre todos os elementos da relação de entrada. Nesse caso, uma $R q\left(S, s_{q}, \delta, \xi\right)$ pode ser resolvida calculando-se a distância entre $s_{q}$ e todos os elementos $s_{i} \in S$ e selecionando apenas aqueles cuja dissimilaridade seja menor ou igual a $\xi$. A complexidade dessa busca é $O(n)$, onde $n=|S|$, em termos de números de cálculos de distância e de número de comparações (do resultado da função de distância com o valor $\xi)$.

Da mesma forma, uma $\kappa-N N q\left(S, s_{q}, \delta, \kappa\right)$ pode ser resolvida percorrendo todos os elementos $s_{i} \in S$, ordenando-os de acordo com o valor $\delta\left(s_{q}, s_{i}\right)$ e retornando os $\kappa$ primeiros elementos. Esse algoritmo também possui complexidade $O(n)$, em termos de números de cálculos de distância, porém, a complexidade em termos de número de comparações (entre os valores $\left.\delta\left(s_{q}, s_{i}\right)\right)$ é $O(n \cdot \log n)$, devido ao custo da ordenação. Entretanto, não é preciso ordenar todos os elementos do conjunto de entrada para identificar os $\kappa$-vizinhos mais próximos ao elemento de consulta. Com base nesta observação, um algoritmo mais eficiente para a $\kappa$-NNq percorre os elementos do conjunto de entrada e identifica os $\kappa$ elementos com menor valor de $\delta$ utilizando uma estrutura de dados com custo logarítmico de manipulação. A complexidade deste algoritmo em termos do número de comparações é $O(n \cdot \log \kappa)$, embora a complexidade em termos de cálculos de distância ainda seja $O(n)$.

Para reduzir o custo das consultas por similaridade pode ser utilizada uma estrutura de indexação adequada. Essas estruturas de indexação são os Métodos de Acesso (MAs). Os exemplos mais relevantes são apresentados no Capítulo 2.6.

Algoritmos de consulta por abrangência e aos $\kappa$-vizinhos mais próximos são executados sobre as estruturas de indexação. Uma abordagem bastante utilizada, quando a estrutura de indexação é uma árvore, é a branch-and-bound, na qual a busca começa pela raiz da árvore, e em cada passo utilizam-se propriedades do domínio de dados em questão para determinar quais nós devem ser examinados e quais podem ser descartados. Para dados métricos, destacam-se dois métodos: o descarte por desigualdade triangular apre- 
sentada na Seção 2.5.1 e os métodos baseados em Filtragem e Refinamento apresentado na Seção 2.5.2.

\subsubsection{Desigualdade Triangular}

O descarte pela desigualdade triangular é realizado como segue. Dados um espaço métrico $\langle\mathbb{S}, \delta\rangle$, um conjunto de elementos $S \subseteq \mathbb{S}$, um elemento de consulta $S_{q} \in \mathbb{S}$, um elemento representante $s_{\text {rep }}$ e um raio de cobertura $\xi$, então um elemento $s_{i} \in S$ pode ser descartado se, e somente se, uma das duas condições a seguir for satisfeita [Burkhard and Keller, 1973]:

$$
\begin{aligned}
& \delta\left(s_{\text {rep }}, s_{i}\right)<\delta\left(s_{\text {rep }}, s_{q}\right)-\xi \\
& \delta\left(s_{\text {rep }}, s_{i}\right)>\delta\left(s_{\text {rep }}, s_{q}\right)+\xi
\end{aligned}
$$

A Figura 2.4 ilustra essa noção. A região 1 satisfaz a Condição 2.22 e a região 3 satisfaz a Condição 2.23. Portanto, os elementos em cada região podem ser descartados sem a necessidade de calcular suas distâncias ao elemento de consulta $s_{q}$. Por outro lado, nenhum elemento localizado na região 2 pode ser descartado pela propriedade de desigualdade triangular, embora apenas uma pequena parte dessa região corresponda à resposta da consulta. É necessário calcular a distância entre cada um desses elementos $\left(s_{2}\right.$ e $s_{4}$, no exemplo) e o elemento de consulta para produzir a resposta correta à consulta $\left(\right.$ apenas $\left.s_{4}\right)$.

\subsubsection{Filtragem e Refinamento}

Os algoritmos para consultas por similaridade baseados em filtragem e refinamento, são avaliados em duas etapas. A etapa de filtragem seleciona uma lista de elementos candidatos que satisfazem a condição de consulta. A função de distância utilizada nessa etapa é uma aproximação, normalmente menos custosa do que a função de distância exata. Os candidatos são verificados na etapa de refinamento, recuperando os elementos originais e calculando a distância exata para o elemento de consulta. 


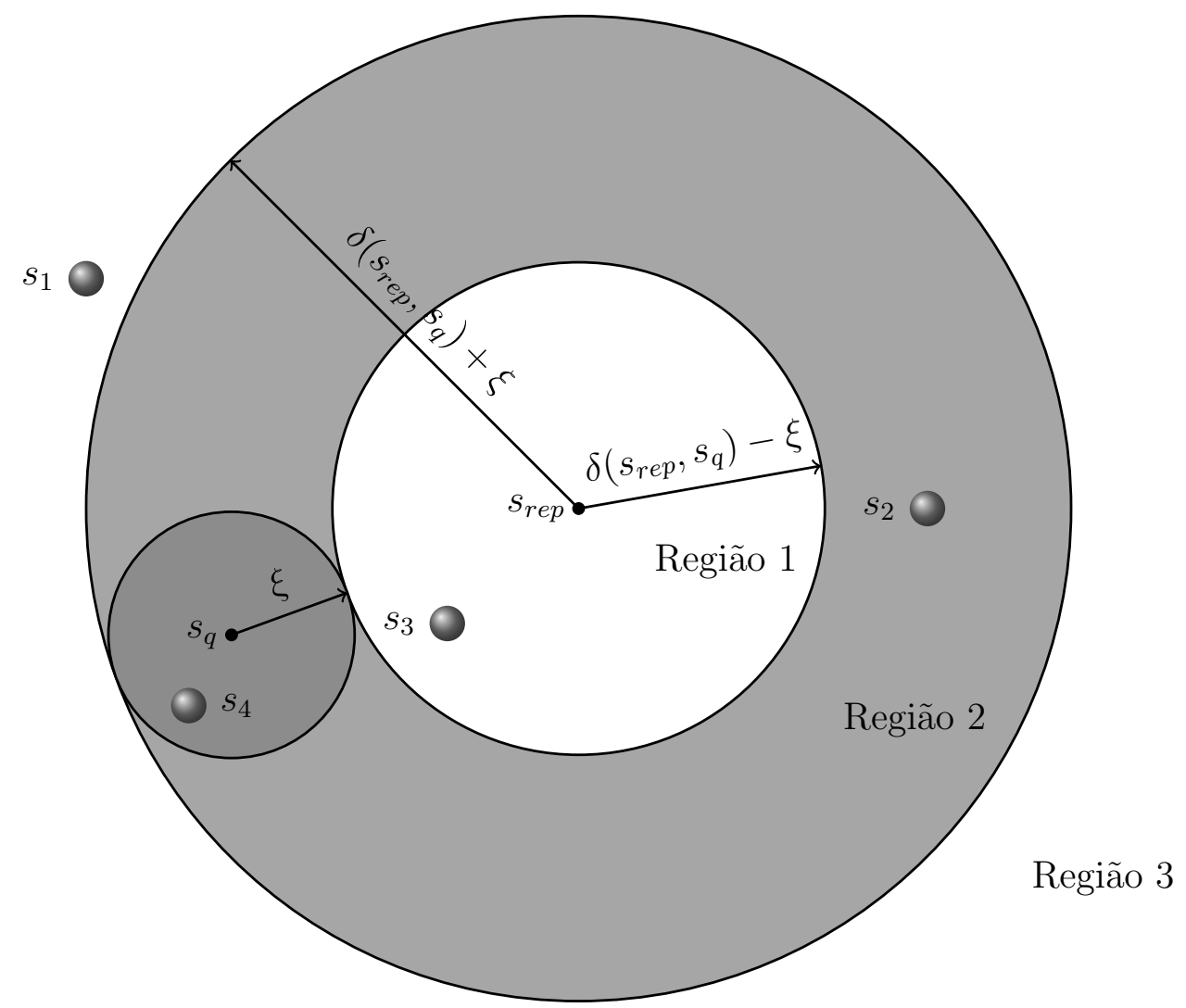

Figura 2.4: Descarte por desigualdade triangular - Os elementos localizados nas regiões 1 ou 3 podem ser descartados sem a necessidade de calcular sua distância ao elemento de consulta $s_{q}$.

Esse algoritmo é bastante utilizado quando o espaço original é imerso em um espaço multidimensional, sendo a filtragem realizada no espaço imerso e o refinamento no espaço original [Korn et al., 1996].

Os métodos de acesso VA-File, M-Grid e os da Família OMNI (Seção 2.6.2) realizam as consultas utilizando a abordagem de filtragem e refinamento.

Para que a resposta dessa consulta seja correta, os elementos da resposta devem estar entre os elementos canditatos. Essa condição é garantida quando o mapeamento atende à propriedade de contratividade (Equação 2.19).

\subsection{Métodos de Acesso}

A maioria dos SGBDs fornecem estruturas de indexação para dados tradicionais, tais como variantes da B-Tree e estruturas de hashing. Contudo, essas estruturas não são adequadas para os sistemas de recuperação que lidam com dados que não atendem a 
propriedade de relação de ordem total entre os elementos. Frente à limitação dos métodos tradicionais, foram propostos novos Métodos de Acesso (MA) para dar suporte aos novos tipos de dados.

\subsubsection{Métodos de Acesso Multidimensionais}

Os Métodos de Acesso MultiDimensionais (MAMDs) são utilizados para indexar dados em espaços multidimensionais. Os MAMDs podem ser classificados como Métodos de Acesso Pontuais (MAPs) e Métodos de Acesso Espaciais (MAEs). Os métodos de acesso pontuais, como a K-D-tree, a Quad-Tree e o VA-File, foram desenvolvidos para manipular pontos. Os métodos de acesso espaciais, como a R-Tree, suportam dados que possuem extensão espacial (linhas, polígonos e poliedros) [Gaede and Günther, 1998].

As consultas por similaridade são otimizadas aplicando propriedades geométricas na construção dos MAMD, evitando buscas sequenciais ao definir regiões delimitadas para as buscas.

Quando os elementos possuem alta dimensionalidade, os MAMDs tendem a degradar rapidamente, por isso são inviáveis para dimensionalidades maiores que poucas dezenas.

\section{K-D-tree}

A $K$-D-tree [Bentley, 1975] é considerada uma das primeiras estruturas para dados $E$ dimensionais. Esta estrutura é representada como uma árvore de busca binária que subdivide recursivamente o espaço multidimensional em subespaços por meio de hiperplanos $(E-1)$-dimensionais. Cada hiperplano divide o espaço em dois subespaços. Estes subespaços são então novamente divididos, e este processo continua recursivamente até que os subespaços gerados não possuam nenhum elemento.

Uma variação deste método de acesso, chamada Adaptive $K$ - $D$-tree [Bentley and Friedman, 1979], não traça os hiperplanos interceptando elementos, mas sim em pontos que melhor dividem o número de elementos do conjunto. Desta forma, são criadas árvores mais balanceadas e todos os elementos passam a ser ar- 
mazenados em nós folhas, pois os nós internos guardam dados do ponto de divisão escolhido.

Já a Bintree [Tamminen, 1984] é uma variação da $K$-D-tree que particiona os subespaços em tamanhos iguais. Apesar de tornar a estrutura menos adaptativa, esta abordagem tem diversas vantagens, como o conhecimento implícito do particionamento dos hiperplanos. Desta forma, este método requer menos processamento durante o processo de particionamento dos subespaços.

\section{Quadtree}

A Quadtree [Finkel and Bentley, 1974], assim como a $K$-D-Tree, divide o espaço por meio de hiperplanos. Contudo, uma diferença importante encontra-se no fato da Quadtree não ser uma árvore binária. Em um espaço E-dimensional, cada nó da estrutura de dados da Quadtree possui $2^{E}$ filhos. Por exemplo, em um espaço tridimensional, cada particionamento forma $2^{3}=8$ subespaços. Os particionamentos continuam a ser recursivamente formados até que o número de nós do subespaço atual seja menor que um certo limiar.

Existem duas variantes bem conhecidas para escolher o local de divisão dos subespaços [Samet, 1984]. A primeira variante, chamada Point quadtree escolhe um ponto e o utiliza como centro das subdivisões geradas, em uma abordagem semelhante à da $K$ - $D$ tree. Já a segunda variante, chamada Region quadtree, assim como a Bintree, particiona os subespaços em regiões iguais.

\section{R-tree}

A $R$-tree [Guttman, 1984] foi proposta para dados espaciais, e é utilizada em espaços multidimensionais considerando cada elemento como um ponto. Cada nó folha da $R$-tree representa o MBR que armazena seus elementos. No processo de inserção, quando um nó atinge a capacidade máxima, uma política de particionamento é executada e o MBR representado por esse nó é dividido em duas novas regiões. As políticas de particionamento propostas por [Guttman, 1984] são: 
- Método exaustivo: testa todas as possibilidades de novos nós que satisfazem os requerimentos de número mínimo e máximo de elementos por nó e escolhe aquele que minimiza a área dos MBR gerados;

- Método quadrático: examina todos os filhos do nó em questão e particiona o par de elementos que gastaria a maior área se fossem inseridos em um mesmo MBR. Os elementos restantes são distribuídos minimizando a sobreposição dos MBR resultantes; e

- Método linear: particiona na dimensão com a maior separação normalizada entre dois MBR. Os elementos restantes são distribuídos minimizando as áreas dos MBR gerados.

A $R$ +-tree [Sellis et al., 1987] é uma variação da $R$-tree que propõe uma maneira de resolver os problemas de sobreposições entre MBRs, armazenando-as como diferentes nós. Apesar de resolver o problema da sobreposição, a $R$--tree torna o algoritmo de divisão de nós mais custoso e aumenta o número de acessos à memória secundária, devido à fragmentação gerada.

A $R^{*}$-tree [Beckmann et al., 1990], uma outra variante da $R$-tree, mostra que as técnicas anteriores são altamente dependentes da ordem de inserção dos elementos e propõe uma abordagem que minimiza esta característica. Além disso, a $R^{*}$-tree também propõe uma nova política de quebra de nós baseada no método quadrático de [Guttman, 1984], minimizando o perímetro dos MBR gerados e maximizando a ocupação dos novos nós.

\subsubsection{Métodos de Acesso Métricos}

Os Métodos de Acesso Métricos (MAMs) são utilizados para indexar dados complexos com base apenas na distância entre pares de elementos. A função de distância deve ser uma métrica, ou seja, deve seguir as propriedades definidas na Seção 2.2.3.

Diversos trabalhos da literatura apresentam propostas de MAM que são diferenciados principalmente pelas seguintes características: método de escolha dos elementos 
representantes; disposição dos elementos em relação aos elementos representantes; e se podem sofrer inserções e remoções de elementos (dinâmicos ou estáticos).

O primeiro trabalho encontrado na literatura descreve as chamadas BK-trees [Burkhard and Keller, 1973]. Nele são propostas três técnicas para particionar o espaço métrico de dados de forma recursiva, materializando o processo recursivo através das árvores. Outros métodos surgiram, por exemplo, os métodos hierárquicos estáticos VP-tree (Vantage Point tree) [Yianilos, 1993], MVP-tree (Multi-Vantage Point tree) [Bozkaya and Özsoyoglu, 1997] e FQ-tree (Fixed-Queries tree) [Baeza-Yates et al., 1994].

\section{O método de Acesso Métrico Slim-Tree}

A M-tree [Ciaccia et al., 1997] foi o primeiro MAM dinâmico desenvolvido para memória secundária a surgir na literatura. Como na B+ tree, a M-tree é um método que produz árvores balanceadas em altura, onde os nós folhas da armazenam todos os elementos do espaço métrico em questão. Os nós internos guardam os elementos representantes, escolhidos a partir dos algoritmos de promoção e cada nó possui um raio de cobertura.

A Slim-tree [Traina Jr. et al., 2000] é uma evolução da M-tree, que traz como melhorias a avaliação e minimização do grau de sobreposição entre seus nós e um novo algoritmo de split, baseado na árvore de espalhamento mínimo (Minimum Spanning Tree - MST).

Em uma Slim-tree, os elementos são agrupados em disco em páginas de tamanho fixo, cada página correspondendo a um nó da árvore. Os elementos são armazenados nas folhas, organizados em uma estrutura hierárquica que utiliza um elemento representante como centro de uma região de cobertura dos elementos de uma subárvore, delimitada por um raio máximo de cobertura. Para reduzir os cálculos de distância durante as buscas, as distâncias entre cada elemento de um nó e o seu respectivo representante são calculadas no momento da inserção e armazenadas na árvore.

A ideia geral desse método consiste em selecionar um elemento e colocá-lo como representante de um subconjunto dos dados. Quando um elemento $s_{i} \in \mathbb{S}$ é inserido, as distâncias entre ele e cada um dos representantes são calculadas e armazenadas juntamente 
com seus dados. Como as distâncias entre todos os elementos armazenados e os seus respectivos representantes são conhecidas, a propriedade de desigualdade triangular (Seção 2.5.1) pode ser usada tanto durante a construção do índice quanto em consultas por similaridade, para descartar elementos que, com certeza, não farão parte do conjunto resposta, sem a necessidade de calcular as suas distâncias para o elemento de consulta.

\section{Família OMNI de Métodos de Acesso Métricos}

Os métodos de acesso da Família OMNI [Santos Filho et al., 2001, Traina et al., 2007] foram propostos visando utilizar estruturas de acesso que já podem, potencialmente, estar disponíveis em um SGBD, para indexar dados em espaços métricos.

Tal como os demais métodos de acesso métricos, a principal ideia por trás dessa técnica é reduzir o custo da busca por similaridade podando alguns dos elementos que não fazem parte do conjunto resposta. O método de acesso OMNI utiliza um conjunto de $h$ focos, $\Phi=\left\{f_{1}, \ldots f_{h}\right\}$ escolhidos dentre os elementos $s_{i} \in S$, onde $S$ é o conjunto a ser indexado. As distâncias entre cada foco e cada elementos de $S$ são pré-calculadas, gerando o conjunto de distâncias $C\left(s_{i}\right)\left\{\delta\left(f_{1}, s_{i}\right), \ldots d\left(f_{h}, s_{i}\right)\right\}$ para cada elemento $s_{i}$ do conjunto $S$. O conjunto de distâncias $C\left(s_{i}\right)$ entre cada elemento $s_{i}$ e o conjunto de focos é chamado de Coordenadas OMNI do elemento $s_{i}$.

O conceito OMNI é baseado na imersão parcial do espaço métrico em um espaço multidimensional de $h$ dimensões. Teoricamente, um conjunto de dados com $N$ elementos num espaço métrico, chamado espaço original, pode ser imerso num espaço de $N-1$ dimensões, chamado espaço de imersão, preservando precisamente as distâncias entre todos os pares de elementos do conjunto. Se o espaço de imersão tiver $h<N-1$ dimensões, podem ocorrer distorções nas distâncias, as quais serão tanto mais intensas quanto maior for a diferença entre $h$ e $N-1$. No entanto, garante-se que as distorções podem provocar a ocorrência de falsos-positivos nas respostas (elementos que não deveriam fazer parte da resposta, que não são eliminados pelos processos de poda das estruturas de indexação utilizadas), mas não de falsos negativos (elementos que deveriam ser incluídos nas respostas mas foram erroneamente podados). 
Para evitar a ocorrência de falsos positivos, as consultas por abrangência $R q\left(s_{q}, \xi_{q}\right)$ são executadas sobre uma estrutura OMNI utilizando a abordagem da filtragem e refinamento. O primeiro passo de filtragem é calcular as coordenas OMNI $C\left(s_{q}\right)$ do elemento central da busca. Em seguida, uma consulta por abrangência $R q\left(C\left(s_{q}\right), \xi_{q}\right)$ é feita sobre as coordenadas OMNI, resultando no conjunto de candidatos $S_{c}$. A etapa de refinamento serve para descartar os falsos positivos existentes em $S_{c}$. Durante a etapa de refinamento, os elementos originais presentes em $T_{c}$ são recuperados e comparados com o elemento central da busca utilizando a métrica original. Dessa forma os falsos positivos são eliminados e é obtido o conjunto resposta correto [Santos Filho, 2003].

O conceito OMNI é baseado em quatro técnicas principais: definir o número $h$ de focos; definir quais serão os elementos escolhidos como focos; definir como medir se a base de focos está adequada depois de escolhida, frente a atualizações que o conjunto de elementos indexados pode sofrer depois da escolha da base de focos; e definir como corrigir o conjunto de focos quando este for considerado desatualizado.

O conceito OMNI estabelece que o número de focos é definido como uma unidade a mais do que a Dimensão de Correlação Fractal (DCF) do conjunto de dados, pois a DCF indica a dimensão intrínseca $D$ do conjunto de dados.

Os focos são escolhidos entre os que estão na borda do conjunto, ou próximos dela, e que se aproximem o mais possível de um hiper-tetraedro de dimensão $h$. O algoritmo Hull Foci (HF) encontra, com complexidade linear em cálculos de distância $O(N)$, focos que estejam afastados entre si, e portanto, próximos da borda do conjunto.

Sempre que novos elementos forem inseridos fora do hiper-tetraedro, é contabilizado um valor positivo baseado em quão afastado do hiper-tetraedro esse ponto está, e sempre que o valor acumulado desses valores ultrapassar um determinado limite, considera-se que a base de focos deixou de estar adequada. Quando isso ocorre, uma nova base de focos é escolhida dentre os elementos que já faziam parte dessa base, unida com os elementos que estão fora do antigo hiper-tetraedro. 


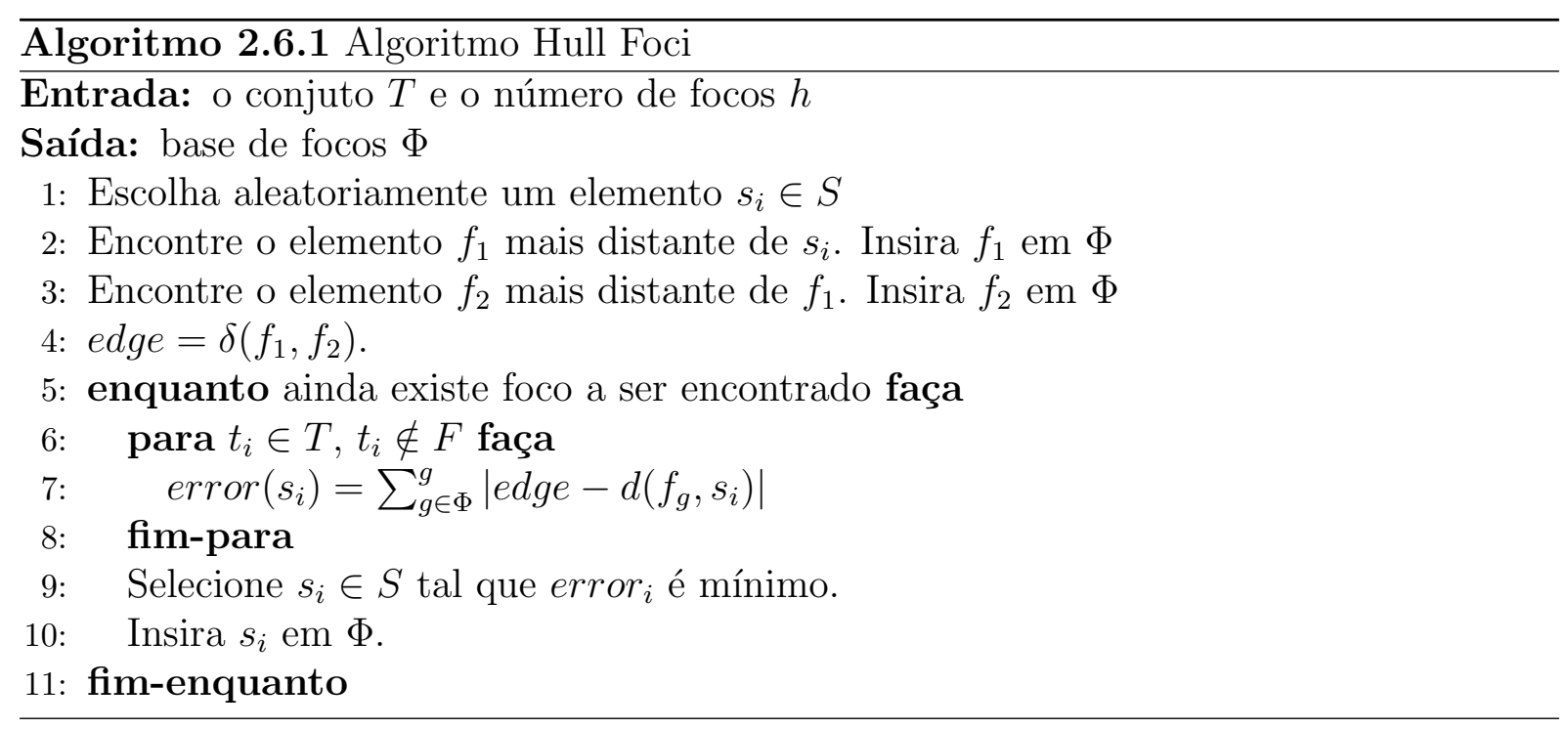

Em [Traina et al., 2007] foram apresentados quatro membros da família OMNI e em [Digout et al., 2004] foram propostas duas variações: OMNI-Seq+ e OMNI-Seq* Na próxima seção descreve-se um dos membros da família OMNI a OMNI-Sequential.

OMNI-Sequential

O método chamado OMNI-Sequential, representado na Figura 2.5, armazena as coordenadas Omni em um arquivo sequencial, onde cada entrada é composta pelo vetor de coordenadas e pelo identificador referente ao elemento original. A busca é realizada percorrendo seqüencialmente o conjunto de coordenadas OMNI, e os elementos que não puderem ser filtrados são recuperados para a etapa de refinamento.

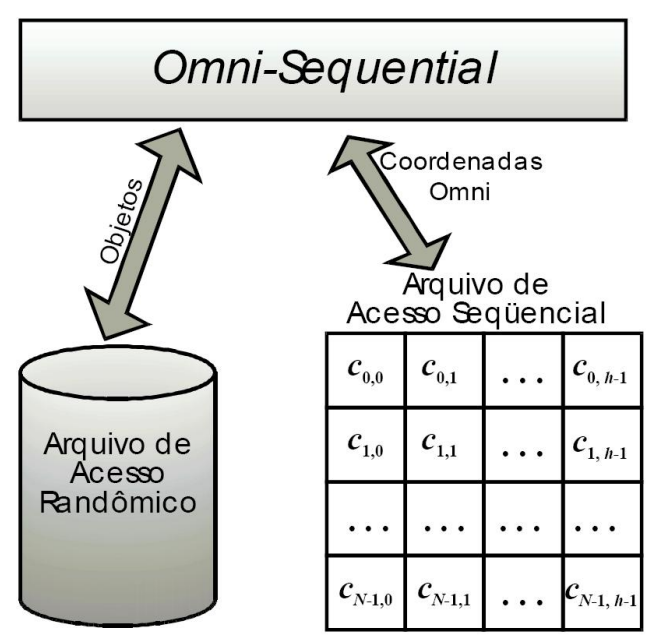

Figura 2.5: Representação da estrutura de indexação OMNI-Sequencial [Santos Filho, 2003]. 


\subsection{Considerações finais}

Neste capítulo foram apresentados os conceitos sobre espaços e funções de comparação. Foram definidas as consultas por similaridade que foram aplicadas neste trabalho e os tipos de algoritmos para realizar essas consultas eficientemente. Apresentou-se os métodos de imersão, cujos conceitos foram utilizados na proposta do método de acesso deste trabalho e finalmente os conceitos e os trabalhos correlatos dos métodos de acesso. 


\section{Capítulo}

3

\section{Detecção de agrupamento}

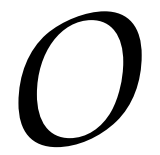

processo de descoberta de conhecimento (KDD - Knowledge Discovery in Database), é um processo interativo, iterativo e exploratório, sendo desejável que este processo produza respostas rápidas. A detecção de agrupamentos de dados é uma das principais técnicas empregadas no processo de KDD, podendo ser aplicada ou como ferramenta isolada, tendo como objetivo explorar a distribuição do conjunto de dados, ou como uma tarefa de pré-processamento para outras técnicas.

De maneira simples, a detecção de agrupamentos pode ser definida como o processo de dividir os dados em agrupamentos de elementos similares de acordo com uma medida de similaridade. Assim, cada agrupamento, ou cluster, é composto de elementos que são similares entre si e dissimilares com os elementos de outros agrupamentos [Han and Kamber, 2000a]. Um exemplo é apresentado na Figura 3.1, na qual pode-se ver que os dados agrupados em três agrupamentos considerando a característica de proximidade espacial.

Usualmente, os algoritmos de agrupamentos de dados sofrem dos problemas de tempo de processamento e complexidade computacional, quando o volume dos dados aumenta em tamanho e dimensão. Com o aumento explosivo do volume de dados acumulados nas últimas décadas, a necessidade de que estes sejam analisados e o surgimento de con- 


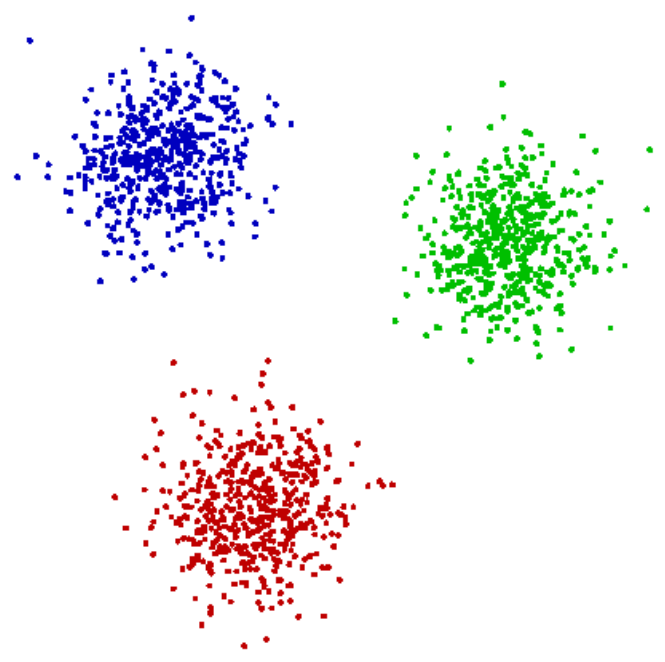

Figura 3.1: Um exemplo de um conjunto de dados agrupado em três agrupamentos.

juntos de dados de diversos tipos e distribuições, vários pesquisadores concentraram seus esforços na tentativa de tornar o processo de detecção de agrupamentos possível também para grandes bases de dados [Han and Kamber, 2000b, Berkhin, 2002, Lee et al., 2008a, Carpineto et al., 2009, Kriegel et al., 2009]. Assim, diversos algoritmos de detecção de agrupamentos foram propostos, para uma grande variedade de aplicações.

Os algoritmos de detecção de agrupamentos podem ser divididos em três grandes classes: Particionamento, Hierárquico e Densidade. Cada uma dessas classes se preocupa em resolver problemas diferentes. Algoritmos hierárquicos produzem agrupamentos hierárquicos consistindo de vários níveis de partições aninhadas. Exemplos de algoritmos hierárquicos são Single-Link [Sibson, 1973], CURE [Guha et al., 1998] e BIRCH [Zhang et al., 1996]. Algoritmos de particionamento tem como objetivo encontrar as melhores $k$ partições em um único nível. Exemplos desses algoritmos incluem $k$-médias [Hartigan and Wong, 1979] e $k$-medoids [Kaufman and Rousseeuw, 2005]. Os algoritmos de densidade encontram agrupamentos baseado na densidade de elementos de uma região no espaço e eles têm por objetivo encontrar agrupamentos em dados que possuam ruídos ou não tenham distribuição normal. Um exemplo desse algoritmo é o DBSCan [Ester et al., 1996]. Nas seções seguintes cada uma dessas classes será apresenta em detalhes. 


\subsection{Particionamento}

Dado um conjunto de $N$ elementos, os métodos de particionamento constroem $k$ partições de dados, na qual cada partição representa um agrupamento, sendo $k \leq N$. Em suma, o método divide os dados em $k$ agrupamentos que satisfazem as seguintes condições:

1. cada agrupamento deve conter ao menos um elemento;

2. cada elemento deve pertencer a exatamente um agrupamento.

Na maioria dos algoritmos de detecção de agrupamento baseados em particionamento, o número de partições $k$ é requerido pelo usuário. O algoritmo inicia criando uma partição inicial e depois melhorando-a, pela movimentação dos elementos de uma partição para outra. Há vários critérios para avaliar a qualidade de uma partição, sendo a mais comum a proximidade entre os elementos. Os métodos de detecção de agrupamentos baseados em particionamento mais conhecidos são o $k$-medoide [Ng and Han, 1994] e o $k$-médias [MacQueen, 1967].

No algoritmo $k$-médias, cada agrupamento é representado por um centro, calculado pela média (ou média ponderada) dos elementos que o compõe (pelos centroides). No algoritmo $k$-medoide, o representante de cada agrupamento é o elemento que esta o mais próximo possível do centro do agrupamento. Em mais detalhes, o objetivo de um algoritmo baseado em $k$-medoide (também referenciado como KMA) é encontrar um conjunto de agrupamentos disjuntos, tal que cada agrupamento é representado por um medoide, que é o elemento mais central localizado no agrupamento. O elemento mais central do conjunto de dados é o elemento que minimiza a soma das distancia para todos os outros elementos. Assim, dado o conjunto $S$ de $N$ elementos, um inteiro $k<N$ como o número desejado de agrupamentos e a função distância $\delta$, então o conjunto de medoides $R \subset S,|R|=k$ é o conjunto de elementos que minimiza a função:

$$
f(R)=\sum_{i=1}^{k} \sum_{j=1}^{n_{k}} \delta\left(r_{i}, s_{i j}\right)^{2}
$$


onde $r_{i} \in R$ é um medoide, $s_{i j} \in S_{i}$ é um elemento de $S$ cujo medoide próximo é $r_{i}$, $S_{i} \cap S_{i^{\prime}}=\emptyset, \forall i \neq i^{\prime}$ e $\bigcup_{i=1}^{k} S_{i}=S$. A Equação 3.1 é chamada de função objetivo do processo de detecção de agrupamentos.

O k-médias é o algoritmo de detecção de agrupamento mais popular, devido a sua simplicidade e eficiência. Contudo, quando a distancia pode ser avaliada entre qualquer par de elementos do conjunto de dados, a variante $k$-medoide pode ser empregada. Algoritmos baseados na variante $k$-medoides têm se mostrado serem mais robustos, já que ele são menos sensíveis a outliers, não apresentam limitações quanto ao tipo de atributos ( $k$-médias são restritos a conjunto de dados multidimensionais com atributos de valores contínuos), e os agrupamentos encontrados não dependem da ordem de entrada do conjunto de dados. Além disso, eles são invariantes a translações e transformações ortogonais dos elementos [Kaufman and Rousseeuw, 2005].

O principal problema dos algoritmos baseados em $k$-medoide é que eles são caros computacionalmente e não podem ser aplicados a grandes volumes de dados. De fato, encontrar o agrupamento $k$-medoide ótimo é um problema NP-difícil [Mouratidis et al., 2005]. Existem algoritmos que têm o objetivo de encontrar respostas aproximas, isto é, eles encontram os medoides que encontram uma boa, mas não necessariamente a resposta ótima. Em consequência disso, várias propostas têm sido desenvolvidas para reduzir o esforço computacional necessário para executar esses algoritmos [Ester et al., 1995, Chu et al., 2002, Zhang et al., 2005].

Os três algoritmos baseados em $k$-medoide mais conhecidos são: PAM (Partitioning Around Medoids), CLARA (Clustering LARge Applications) e CLARANS (Clustering Large Applications based upon RANdomized Search) [Kaufman and Rousseeuw, 2005].

\subsubsection{PAM}

O algoritmo PAM foi um dos primeiros algoritmos desenvolvidos tendo como base o algoritmo $k$-medoide, que baseia-se em um processo de otimização iterativo, que avalia o 
efeito da troca de um elemento medoide por um elemento não-medoide na qualidade do agrupamento resultante.

Ele é executado em três passos, apresentados a seguir:

Fase de Construção: Seleciona randomicamente um conjunto inicial $R \subset$ de $k$ elementos representativos e avalia a função objetivo $f(R)$.

Fase de Troca: Atribui a cada elemento $s_{j} \in S, s_{j} \notin R$ para $S_{i}$, tal que $r_{i}$ é o medoide próximo de $s_{j}$.

Fase de Seleção: Seleciona um novo medoide para cada conjunto $S_{i}$, trocando $R$ para os novos medoides. Avalia a função objetivo $f(R)$ novamente, e se o valor obtido for menor do que na avaliação anterior, repete-se o Passo 2. Caso contrário, o subconjunto corrente $S_{i}$ e $R$ são respectivamente o agrupamento e os seus medoides correspondentes, e o algoritmo termina.

A complexidade computacional do Passo 1 é $O(1)$, e do Passo 2 é $O(k \cdot(n-k))$. Contudo, a parte mais cara do algoritmo PAM é o Passo 3. Este passo requer a avaliação da distância entre todo par de elementos de cada subconjunto $S_{i}$. Deste modo, assumindo no melhor caso que cada agrupamento tem aproximadamente a mesma quantidade de elementos, seu custo computacional é $O\left(k \cdot(n / k)^{2}\right)=O\left(\frac{n^{2}}{k}\right)$ em cada iteração. O algoritmo PAM resulta em agrupamentos de alta qualidade, já que ele avalia cada possibilidade de combinação, funcionando bem para conjuntos de dados pequenos. Contudo, devido à sua complexidade computacional, ele não é aplicável a grandes conjuntos de dados.

\subsubsection{CLARA}

A complexidade computacional elevada do algoritmo PAM motivou o desenvolvimento do algoritmo CLARA, um algoritmo de agrupamento mais rápido baseado em amostragem (sampling) [Kaufman and Rousseeuw, 2005]. A ideia fundamental desse algoritmo consiste em selecionar os $k$ medoides a partir da análise de apenas uma pequena amostragem desses dados. CLARA seleciona várias amostras de um conjunto de dados, aplica o PAM em cada amostra e retorna como saída o melhor conjunto de medoides obtido a 
partir dessas amostras. Nesse algoritmo, a qualidade do agrupamento obtido está relacionada ao tamanho das amostras, que são fixadas de antemão. Experimentos descritos em [Kaufman and Rousseeuw, 2005] indicam que 5 amostras de tamanho $40+2 k$ produzem um resultado satisfatório. A complexidade computacional de cada iteração do CLARA para processar cada amostra é $O\left(p^{2} / k+k(p-k)\right)$, onde $p>k$ é o tamanho da amostra, assim, ele é muito mais rápido que o PAM. Contudo, como os medoides são escolhidos de uma amostra, eles podem resultar em agrupamentos de baixa qualidade.

\subsubsection{CLARANS}

O algoritmo CLARANS foi desenvolvido para a mineração de dados espaciais [Ng and Han, 1994]. Ele utiliza uma estratégia baseada em busca aleatória com o objetivo de superar ambos PAM e CLARA em relação à eficiência computacional (complexidade computacional ou tempo de processamento) e à qualidade do agrupamento resultante (distorção média ou distância entre os elementos e seus medoides), respectivamente. O primeiro elemento selecionado é o que tem a menor soma de dissimilaridades (distancias) para todos os outros elementos (a função objetivo). Assim, o primeiro elemento selecionado é o medoide do conjunto de dados. O outros $(k-1)$ medoides são selecionados subsequentementes, um por vez, considerando os elementos que mais decrescem a função objetivo. Quando busca por novos bons medoides, o CLARANS escolhe randomicamente elementos do restante dos elementos $(n-k)$, buscando por novos medoides de cada agrupamento como seus centros de agrupamento. O número de elementos experimentados em cada passo é restrito por um parâmetro fornecido pelo usuário (maxNeighbor).

Se depois de maxNeighbor tentativas nenhuma solução melhor é encontrada, é assumido que um ótimo local foi encontrado. O procedimento continua até que numLocal locais ótimos terem sido encontrados. É recomendado que os parâmetros numLocal e $\max N e i g h b o r$ tenham parâmetros de 2 e $\max (250,1.25 \% * k *(n-k))$, respectivamente [Ng and Han, 1994]. Contudo, a complexidade computacional do CLARANS ainda é $O\left(n^{2}\right)$. 


\subsection{Hierárquicos}

A base dos algoritmos de detecção de agrupamento hierárquicos é a criação de uma hierarquia de agrupamentos, formada por vários níveis de partições aninhadas de um conjunto de dados. De acordo com o modo como a hierarquia de agrupamentos é construída, os métodos empregados por esse tipo de algoritmos podem ser divididos em: aglomerativos (bottom-up) ou divisivos (top-down).

Os métodos aglomerativos começam com cada elemento sendo um agrupamento. Nos passos seguintes do algoritmo é feita a junção desses agrupamentos em agrupamentos maiores. Os métodos divisivos começam com o conjunto todo sendo um único agrupamento que é dividido em agrupamentos menores sucessivamente pelo algoritmo, até chegar ao número de agrupamentos desejados. Os métodos divisivos são raramente aplicados. Como exemplo dos algoritmos aglomerativos tem-se o BIRCH [Zhang et al., 1996] e o CURE [Guha et al., 1998].

O algoritmo BIRCH (Balanced Iterative Reducing and Clustering using Hierarchies) utiliza uma estrutura em árvore especializada para realizar o agrupamento de grandes conjuntos de dados multidimensionais. Para tanto, ele calcula incrementalmente descrições compactas de subagrupamentos dos dados, chamadas de características do agrupamento (Clustering Feature - $C F$ ). As CFs são organizadas em uma árvore balanceada que é construída por meio da realização de uma busca sequencial sobre todos os dados do conjunto, de maneira similar à construção da $B+$ tree. Os valores das $C F s$ são suficientes para obter informações sobre todo o conjunto de dados, como centroides, raio e diâmetro. O algoritmo BIRCH é reconhecido como sendo o primeiro algoritmo a manusear dados que possuem ruído. Entretanto, o algoritmo mantém a característica dos algoritmos de particionamento ao encontrar agrupamentos somente de formato "esféricos".

O algoritmo CURE é um algoritmo hierárquico aglomerativo que utiliza uma política mista para o cálculo da distância entre dois agrupamentos, a cada iteração. Esta política é uma espécie de mistura entre a política dos centroides (onde a distância entre dois agrupamentos é a distância entre seus centros de gravidade) e a chamada política 
MST (Minimum Spanning Tree) (onde a distância entre dois agrupamentos é igual à distância mínima entre dois elementos, um em cada agrupamento).

Entretanto, a sua complexidade também é $O\left(N^{2}\right)$, fazendo uso de uma amostragem uniforme para poder ajustá-lo a grandes conjuntos de dados. Além disso, o CURE, assim como os outros, não consegue manusear agrupamentos com densidades diferentes

\subsection{Densidade}

Algoritmos de detecção de agrupamentos baseado em densidade, são utilizados para a descoberta de agrupamentos de forma arbitrária, especialmente em conjuntos ruidosos. Neste tipo de método, um agrupamento é considerado uma região em que a densidade de elementos excede um certo limiar, isto é, para cada elemento de um dado agrupamento a vizinhança em um certo raio tem que conter uma quantidade mínima de elementos. O algoritmo DBScan (Density Based Spatial Clustering of Applications with Noise) [Ester et al., 1996] é o principal representante desta categoria.

O algoritmo DBSCAN visita cada ponto do conjunto de dados, possivelmente varias vezes, já que cada ponto pode ser candidato de diferentes agrupamentos. Por considerações práticas, contudo, a complexidade é governada pelo número de consultas aos vizinhos mais próximo. O DBSCAN executa exatamente uma consulta de vizinho mais próximo para cada ponto. Se é usada uma estrutura de indexação, a consulta a vizinhança tem complexidade $\mathrm{O}(\log n)$, lavando a complexidade total de $\mathrm{O}(n \cdot \log n)$. Sem uma estrutura de indexação para acelerar a consulta o tempo de execução é $\mathrm{O}\left(n^{2}\right)$. Frequentemente uma matriz triangular de distância de tamanho $\left(n^{2}-n\right) / 2$ é materializada para evitar re-computações. Contudo isso faz com que o algoritmo precise de $\mathrm{O}\left(n^{2}\right)$ de memória.

O resultado do algoritmo DBSCAN depende da escolha adequada da função de distância para o conjunto de dados. Além disso, se os agrupamentos não são conhecidos a priori, os algoritmos de detecção de agrupamentos baseados em densidades não podem ter sua qualidade mensurada numericamente. Esse fator dificulta a análise comparativa entre diferentes algoritmos, pois não existe uma função objetivo clara. 


\subsection{Considerações finais}

Neste capítulo foram apresentados as técnicas e os conceitos dos algoritmos de mineração de dados para detecção de agrupamentos. O algoritmo de detecção de agrupamentos proposto neste trabalho e apresentado na Seção 4.1 é baseado em $k$-medoides. 


\section{Capítulo \\ 4 \\ Trabalho Desenvolvido}

$\mathcal{E}$

ste trabalho propõem um novo Método de Acesso Métrico (MAM) baseado no

mapeamento de elementos para um espaço multidimensional utilizando distância para focos adequadamente escolhidos em cada um dos agrupamentos que possam existir no conjunto de dados. Como o método requer um método de detecção de agrupamentos, então esse trabalho também propõem um novo método de detecção de agrupamentos mais adequado baseado em $k$-medoides. Inicialmente, o método para determinar o medoide de subconjuntos FAMES e seu variante M-FAMES são apresendados na Seção 4.1, em seguida o método para detecção de agrupamentos é apresentado na Seção 4.2 e o Método de Acesso FAMESMAM é apresentado na Seção 4.3.

\subsection{Fames (FAst MEdoid Selection)}

Os algoritmos típicos para detecção de agrupamento por $k$-medoides sempre utilizam o medoide ótimo. Entretanto, encontrar o medoide ótimo custa $O\left(n^{2}\right)$ cálculos de distância, um custo bastante elevado se levarmos em conta o crescimento dos conjuntos de dados. Os algoritmos existentes reduzem o custo computacional procurando o medoide em uma pequena amostra do conjunto de dados com elementos selecionados randomicamente. Essa 
abordagem de fato consegue reduzir o custo dos algoritmo, mas ao mesmo tempo diminui significativamente a qualidade dos resultados.

Nesse contexto o algoritmo FAMES (FAst MEdoid Selection) foi desenvolvido como parte do projeto de mestrado com o objetivo de encontrar um elemento, cuja distância para todos os demais elementos do subconjunto se aproxime da mínima distância possível. Esse elemento é chamado de $r$ e é encontrado com menos do que $O(n \cdot \log (n))$ operações. O Algoritmo 4.1.1 descreve os passos necessários para encontrar o elemento $r \in S$ de determinado conjunto ou subconjunto de elementos.

Um bom medoide pode ser encontrado, utilizando todo o conjunto de dados, baseando-se em propriedades geométricas que permitam estimar a região do conjunto que deve conter o medoide. A solução proposta não é exata, pois a região estimada pode ser incorreta, mas o erro é usualmente muito menor do que as demais soluções hoje disponíveis. Além disso a complexidade de tempo é log-linear ao invés de quadrática em número de elementos no conjunto. Na verdade, a técnica proposta é linear em número de elementos do conjunto considerando cálculos de distância, e no pior caso é log-linear em número de comparações, pois requer a ordenação de um vetor de valores reais de tamanho no máximo $n$. Com isso, denominamos nossa técnica como FAst MEdoid Selection: FAMES. Nota-se que FAMES não é um novo algoritmo de detecção de agrupamentos, mas uma nova maneira de encontrar o medoide de um grupo de elementos, a qual pode substituir seu equivalente tradicional em qualquer algoritmo que precise encontrar medoides.

A intuição do método proposto é representada na Figura 4.1. Ela assume que o medoide de determinado conjunto de dados deve estar próximo à linha imaginária que conecta os dois elementos mais afastados entre si $s_{1}^{\prime}, s_{1}^{\prime \prime}$. Mais do que isso, o medoide está próximo ao ponto em que a linha intersecta o hiperplano que divide o conjunto de dados na metade, tal que metade do elementos estejam em cada lado do hiperplano. Então, ao invés de procurar o medoide entre todos os elementos do conjunto, o FAMES considera como medoide o elemento mais próximo desse ponto imaginário.

O Algoritmo 4.1.1 descreve os passos do FAMES utilizados para selecionar um medoide seguindo essa intuição. Primeiramente, dois elementos $s_{1}^{\prime}, s_{1}^{\prime \prime}$ afastados entre si 


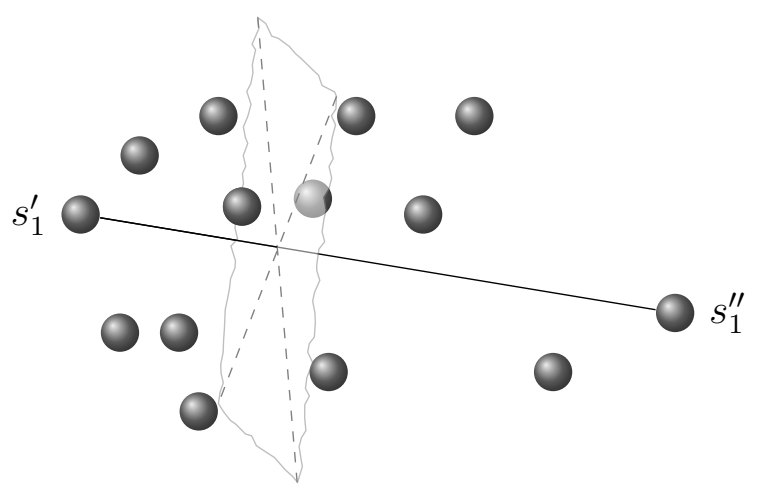

Figura 4.1: O método FAMES intuitivamente propõem que o medoide deve estar próximo da intersecção entre a linha que conecta os elementos $s_{1}^{\prime}, s_{1}^{\prime \prime}$ e o hiperplano que divide o conjunto de dados na metade.

são selecionados na borda do conjunto. Esses elementos são obtidos selecionando um elemento aleatório $s_{i} \in S$ (passo 1 ) e procurando o elemento $s_{1}^{\prime}$ mais distante de $s_{i}$ (passo 2). Então, $s_{1}^{\prime \prime}$ é selecionado como o mais distante de $s_{1}^{\prime}$ (passo 3). Conceitualmente, para conjuntos de dados de alta dimensionalidade ou métrico, o passo 3 pode ser repetido algumas vezes atribuindo $s_{1}^{\prime}$ como sendo o $s_{1}^{\prime \prime}$ já encontrado. Com isso os elementos realmente mais afastados entre si no conjunto de dados são obtidos. Entretanto, os experimentos realizados com diversos conjunto de dados mostraram que não ocorre melhora significativa na qualidade dos resultados quando passos adicionais são realizados. Os elementos $s_{1}^{\prime} \mathrm{e}$ $s_{1}^{\prime \prime}$ são chamados de pivôs.

Em seguida, o conjunto é dividido na metade, considerando a distância para os pivôs. Para tal, os elementos $s_{i} \in S$ são projetos sobre a linha $\overline{s_{1}^{\prime} s_{1}^{\prime \prime}}$, usando a lei dos cossenos, que utiliza apenas distâncias entre elementos conhecidos. Ela é expressa como:

$$
x_{i}=\frac{\delta\left(s_{1}^{\prime}, s_{i}\right)^{2}+\delta\left(s_{1}, s_{2}\right)^{2}-\delta\left(s_{1}^{\prime \prime}, s_{i}\right)^{2}}{2 * \delta\left(s_{1}, s_{2}\right)}
$$

onde cada $x_{i}$ é a distância da projeção do elemento $s_{i}$ sobre a linha para o elemento $s_{1}^{\prime}$, conforme representado na Figura 4.2.

No passo 4 do algoritmo, o vetor $X$ de projeções $x_{i}$ para todos os elementos $s_{i} \in S$ é ordenado para obter o elemento mediano $s_{m d} \in X$.

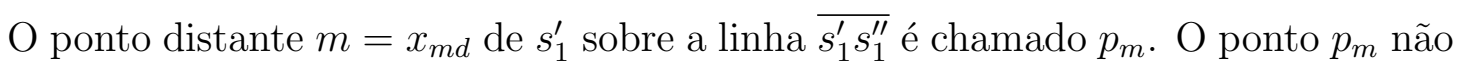
precisa corresponder a um elemento em $S$, então em um espaço métrico normalmente não 


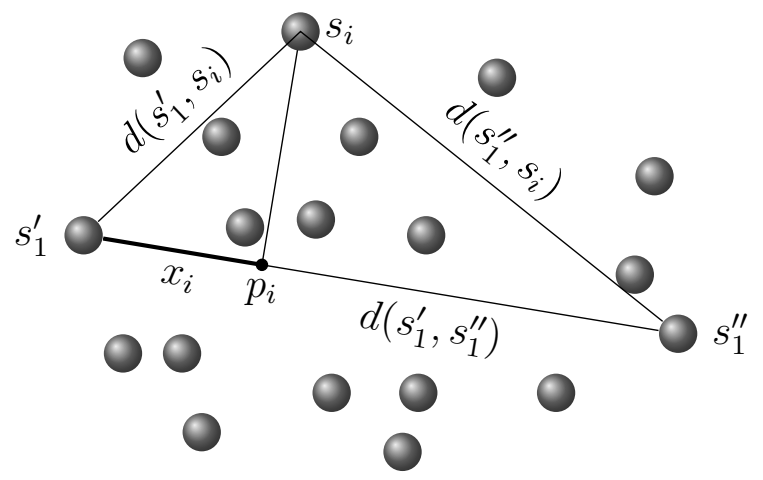

Figura 4.2: Uso da lei dos cossenos para calcular a projeção do elemento $s_{i}$ sobre a linha $\overline{s_{1}^{\prime} s_{1}^{\prime \prime}}$.

é possível calcular a sua distância para qualquer elemento de $S$ que não seja $s_{1}^{\prime}$ e $s_{1}^{\prime \prime}$. Esse ponto é calculado no passo 5 do Algoritmo 4.1.1. Nota-se que as distâncias $x_{i}$ são exatas somente se o espaço métrico puder ser imerso em um espaço euclidiano - sabe-se que para espaços métricos que não podem ser imersos isométricamente em espaços euclidianos, a Equação 4.1 pode ser apenas um aproximação, limitada pela distorção do processo de imersão. Embora a maioria dos conjuntos utilizados em aplicações reais possam ser isométricamente imersos em um espaço euclidiano, os que não possam apresentam um pequeno erro. Por isso, os resultados em $X$ devem ser tratados com uma aproximação. Entretanto, como nosso objetivo até aqui é selecionar um subconjunto de elementos que contenha um bom centro, na grande maioria dos casos o erro de aproximação não elimina o elemento correto desse subconjunto.

Finalmente, o medoide é selecionado como o elemento $r \in S$ que está mais próximo de $p_{m}$. Como não é possível calcular a distância para o ponto imaginário $p_{m}$ para cada elemento $s_{i}$, o medoide é escolhido como o elemento que minimiza a soma das diferenças entre $s_{i}$ e $p_{m}$ para cada pivô, calculado como:

$$
\operatorname{Min}_{i=1}^{n}\left(\left|d\left(s_{1}^{\prime}, s_{i}\right)-m\right|+\left|d\left(s_{1}^{\prime \prime}, s_{i}\right)-\left(d\left(s_{1}, s_{2}\right)-m\right)\right|\right)
$$

Essa equação é aplicada no Passo 6 do Algoritimo 4.1.1.

Considerando a complexidade computacional do Algoritmo 4.1.1, os passos 1-3 percorrerem duas vezes o conjunto completo, comparando cada elemento com um pivô, portanto cada passo tem complexidade de $O(n)$. O passo 4 realiza apenas um varredura no 


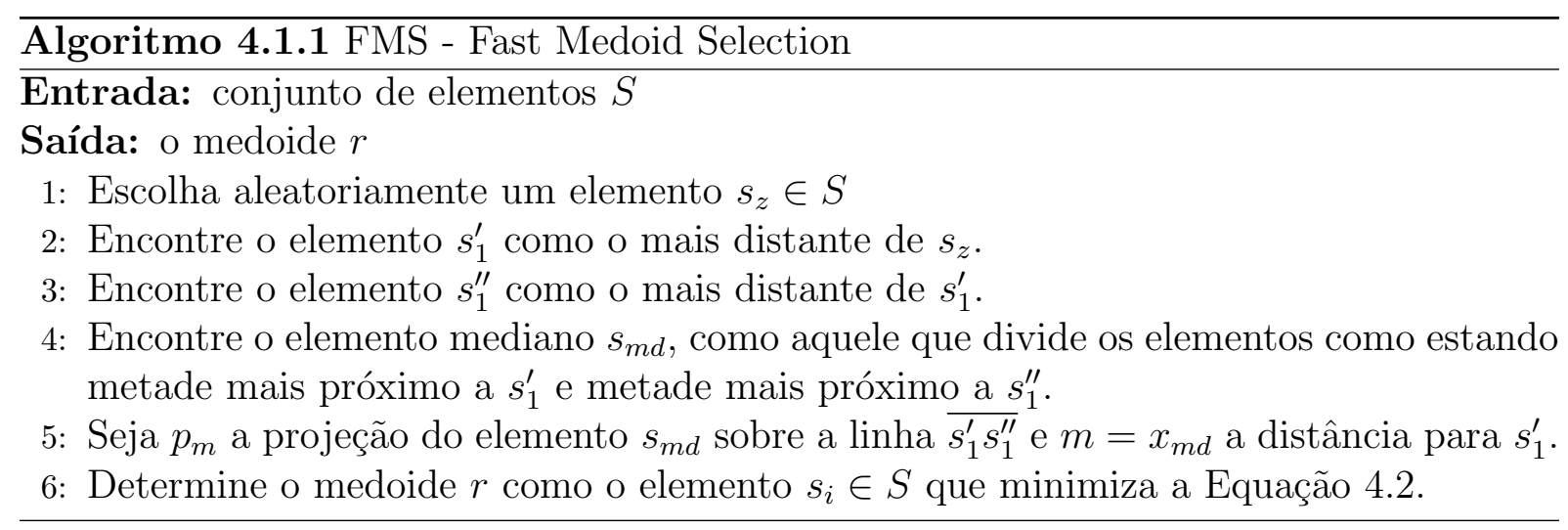

conjunto para determinar $X$, mas como esse passo requer a realização de uma ordenação de tamanho no máximo $n$, a complexidade é $O(n \cdot \log (n))$. O passo 5 independe do tamanho do conjunto de dados e o passo 6 também percorre uma vez o conjunto de dados. Então, nota-se que a maior complexidade aparece no passo 4, devido a necessidade de ordenar o vetor de distância das projeções de cada elemento de $s_{1}^{\prime}$. Entretanto, esse passo possui um constante baixa, pois a ordenação é realizada sobre valores reais pré-calculados. Além disso, não é necessário ordenar o vetor $X$ inteiro, apenas o suficiente para identificar o valor da mediana. Essa tarefa, que teoricamente tem complexidade $O(n \cdot \log (n))$, pode ser na prática realizada com uma complexidade bem próxima de linear, pois a base do logaritmo pode ser muito grande.

Um importante fator dos algoritmos de consultas por similaridade é o número de cálculos de distância requiridos. Na primeira análise, cada passo exceto o quinto querer cálculos de distância. Entretanto, os passos 2, 3, 4 e 6 apenas requerem cálculos de distâncias dos elementos em $S$ para $s_{1}^{\prime}$ e $s_{1}^{\prime \prime}$, as quais são calculadas respectivamente nos passos 2 e 3. Então, se essas distâncias forem armazenadas nos passos 2 e 3, os demais passos não requerem novos cálculos de distância. Nesse sentido, FAMES requerer memória apenas para armazenas três valores reais por elemento: distâncias para $s_{1}^{\prime}$, distância para $s_{1}^{\prime \prime}$ e $x_{i}$, ou seja, complexidade de memória é linear em relação ao número de elementos no conjunto. 


\subsubsection{Adicionando mais eixos ao FAMES}

O Algoritmo FAMES é suficiente para encontrar medoides em conjuntos de dados cuja distribuição siga uma distribuição estatística, como a distribuição gaussiana ou a distribuição uniforme. Esses conjuntos usualmente são densos perto do centro, e a distância do centro para a borda é similar independente da direção, como mostrado da Figura 4.3(a). Entretanto, existem conjuntos reais que não seguem essa distribuição. Por exemplo, isso ocorre em conjuntos de alta dimensionalidade onde para cada elemento distinto diferentes dimensões assumem valores extremos, como mostrado na Figura 4.3(b).

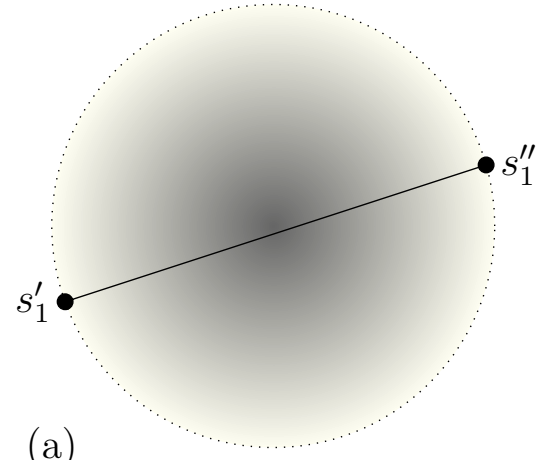

(a)

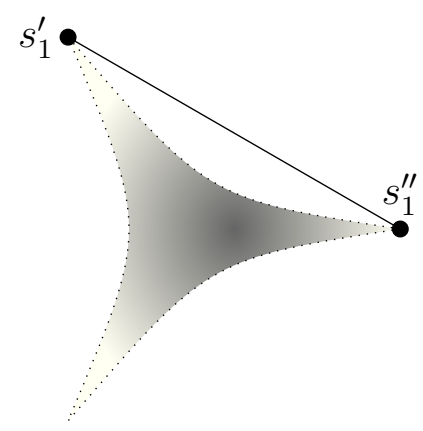

(b)

Figura 4.3: Distribuição distintas de densidade no espaço. (a) Normal; (b) Espiculado.

Assim, percebe-se que para alguns conjuntos de dados complexos, apenas um eixo pode não ser suficiente para determinar corretamente a região apropriada para procurar o medoide. Por isso, uma extensão do algoritmo FAMES é proposta utilizando múltiplos eixos. O novo algoritmo, denominado M-FAMES (Multiple axes - FAst MEdoid Selection), melhora a escolha do medoide, porém aumenta a quantidade de cálculos de distância. Na Figura 4.4 é apresentada a intuição para acrescentar um segundo eixo $\overline{s_{2}^{\prime} s_{2}^{\prime \prime}}$ de maneira a generalizar a quantidade de eixos que podem ser considerados. A ideia é primeiro encontrar um par de elementos $s_{1}^{\prime}$ e $s_{1}^{\prime \prime}$ afastados entre si, conforme os passos 1-3 do Algoritmo 4.1.1, e em seguida encontrar outro par $s_{2}^{\prime}$ e $s_{2}^{\prime \prime}$, de tal forma que ambos $s_{2}^{\prime}$ e $s_{2}^{\prime \prime}$ estão afastados entre si e afastados dos elementos escolhidos pelos eixos anteriores, no caso o eixo $\overline{s_{1}^{\prime} s_{1}^{\prime \prime}}$. Note que o segundo eixo reposiciona a região alvo para a busca do meidod, puxando a linha $\overline{s_{1}^{\prime} s_{1}^{\prime \prime}}$ na direção onde existe uma quantidade maior de elementos. Mais eixos podem ser adicionados, sempre descontando todos os eixos anteriores. Para 
determinar o desconto utilizado, a distância entre $s_{1}^{\prime}$ e $s_{1}^{\prime \prime}$ é considerada como uma aproximação da maior distância no conjunto de dados. A distância entre cada par de pivôs é denominada corda e não diâmetro, uma vez que apenas a corda do primeiro par de pivôs possui provavelmente um valor próximo ao do diâmetro do conjunto de dados. Os pares subsequentes de pivôs para os próximos eixos estão localizados o mais distante possível do pivôs anteriores, usando a diferença entre a primeira corda e a distância entre cada um dos pivôs conforme formulado pelas equações 4.3 e 4.4. Então, considerando $h$ como o par de pivôs sendo calculado, o primeiro pivô desse eixo é o elemento de $S$ que minimiza:

$$
\operatorname{Min}_{i=1}^{n} \sum_{g=1}^{h-1}\left\{\left|\operatorname{cord} a-d\left(s_{g}^{\prime}, s_{i}\right)\right|+\left|\operatorname{cor} d a-d\left(s_{g}^{\prime \prime}, s_{i}\right)\right|\right\}
$$

O segundo pivô do eixo $h$ também considero o primeiro elemento do eixo calculado pela Equação 4.3, então é o elemento de $S$ que minimiza:

$$
\operatorname{Min}_{i=1}^{n} \sum_{g=1}^{h-1}\left\{\left|\operatorname{cord} a-d\left(s_{g}^{\prime}, s_{i}\right)\right|+\left|\operatorname{cord} a-d\left(s_{g}^{\prime \prime}, s_{i}\right)\right|\right\}+\left|\operatorname{cor} d a-d\left(s_{h}^{\prime}, s_{i}\right)\right|
$$

Essas equações são utilizadas no Passo 2 do Algoritmo 4.1.1.

A ideia do algoritmo M-FAMES é determinar alguns eixos em um espaço métrico ou um número de eixos menor do que a dimensionalidade do conjunto de um espaço multidimensional, e buscar o medoide na região em volta das medianas de todos os eixos simultaneamente.

Os principais passos para determinar os múltiplos eixos são apresentados no Algoritmo 4.1.2. Além do conjunto de elementos cujo medoide deve ser encontrado, o M-FAMES requer também o número de eixos definido pelo usuário como entrada. O primeiro eixo é determinado nos passos 2-5 do Algoritmo 4.1.2 exatamente como no Algoritmo 4.1.1. Os demais eixos são contemplados nos passos de 6 a 11, sendo que os passos 7 e 8 utilizam as equações 4.3 e 4.4 para encontrar os pivôs, que são elementos afastados entre si e afastados dos pivôs previamente selecionados. Os passos 9 e 10 correspondem aos passos 3 e 4 do primeiro eixo, que termina a distância da projeção para o elemento mediano desses eixos. 
Finalmente, o Passo 12 seleciona utilizando uma única função de minimização o medoide $r$ como o elemento de $S$ que está simultaneamente mais próximo dos pontos imaginários localizados na projeção do elemento mediano sobre cada uma das cordas, esses pontos distam $m_{g}$ do primeiro pivô do eixo $g$ e $\left(d\left(s_{g}^{\prime}, s_{g}^{\prime \prime}\right)-m_{g}\right)$ do segundo pivô.

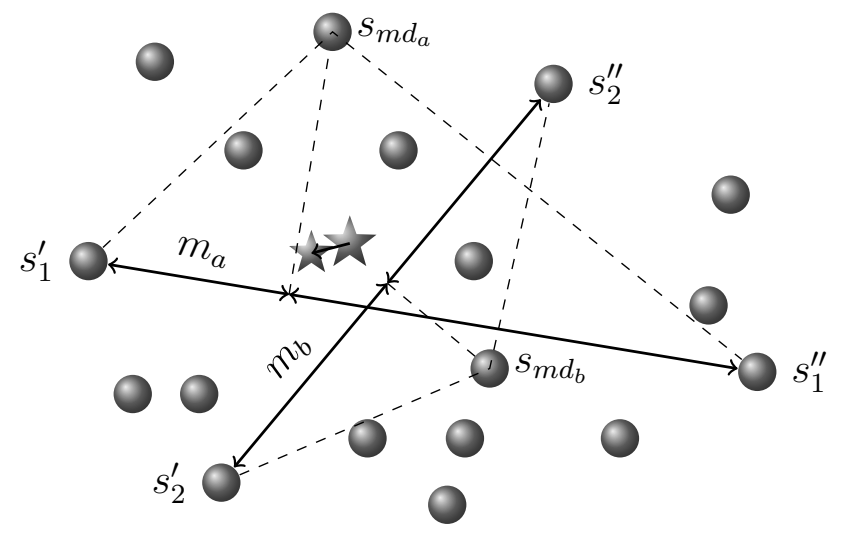

Figura 4.4: Um conjunto de elementos que mostra a intuição do algoritmo M-FAMES representando elementos, distâncias e dois eixos $\overline{s_{1}^{\prime} s_{1}^{\prime \prime}}$ and $\overline{s_{2}^{\prime} s_{2}^{\prime \prime}}$.

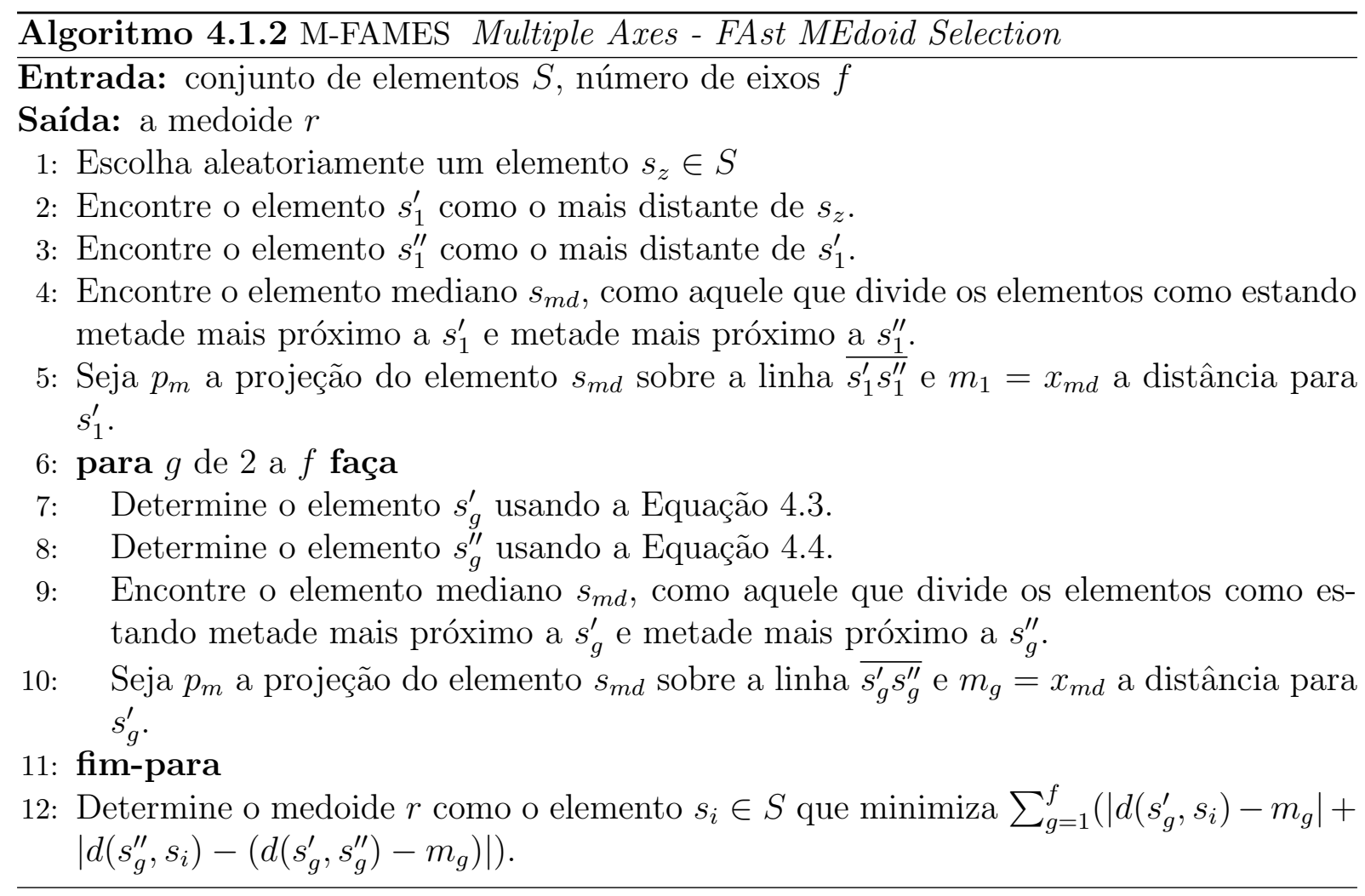

Para analisar a complexidade computacional da variação com múltiplos eixos apresentado pelo Algoritmo 4.1.2, basicamente seguem-se os passos equivalentes aos do Algorimo 4.1.1. A diferença corresponde essencialmente a necessidade de repetir os passos de 
1 a 5 do Algoritmo 4.1.1 para cada eixo. Então, os passos de 1 a 5 do Algoritmo 4.1.2 determinam o primeiro eixo, exatamente como no Algoritmo 4.1.1, enquanto os passos 7 a 10 determinam os elementos dos demais eixos utilizando a mesma intuição. Com isso, a complexidade computacional do Algoritmo 4.1.2 é a complexidade computacional do Algoritmo 4.1.1 multiplicada pelo número de eixos desejado.

O número de cálculos de distância é também o dobro da cardinalidade do conjunto de dados multiplicado pelo número de eixos solicitado.O mesmo espaço de memória é utilizado para armazenar os valores intermediários das distâncias $x_{i}$ e as distâncias de cada $s_{i}$ para os pivôs, por isso o uso de mais eixos não aumenta significativamente o consumo de memória. Nota-se que nos passos 9 e 10 do algoritmo 4.1 .2 as variáveis $x_{m d}$, $s_{m d}$ e $p_{m}$ não possuem índice $g$, pois somente as distâncias $m_{g}$ precisam ser armazenadas para serem utilizadas fora da iteração (Passo 12).

\subsection{Detecção de agrupamentos com faMes}

O algortimo FAMES pode ser incorporado em algoritmos que dependem da seleção de medoides de um subconjunto de elementos. De fato, um novo algoritmo para um KMA, denominado $k$-Medoids FAMES, foi diretamente obtido de um típico algoritmo de KMA, alterando o método utilizado para determinar os medoides em cada iteração. Na Seção 5.2 será mostrado que com essa modificação o algoritmo resultante torna-se mais eficiente e não menos efetivo do que os algoritmos correlatos existentes, apresentados na Seção 3.1.

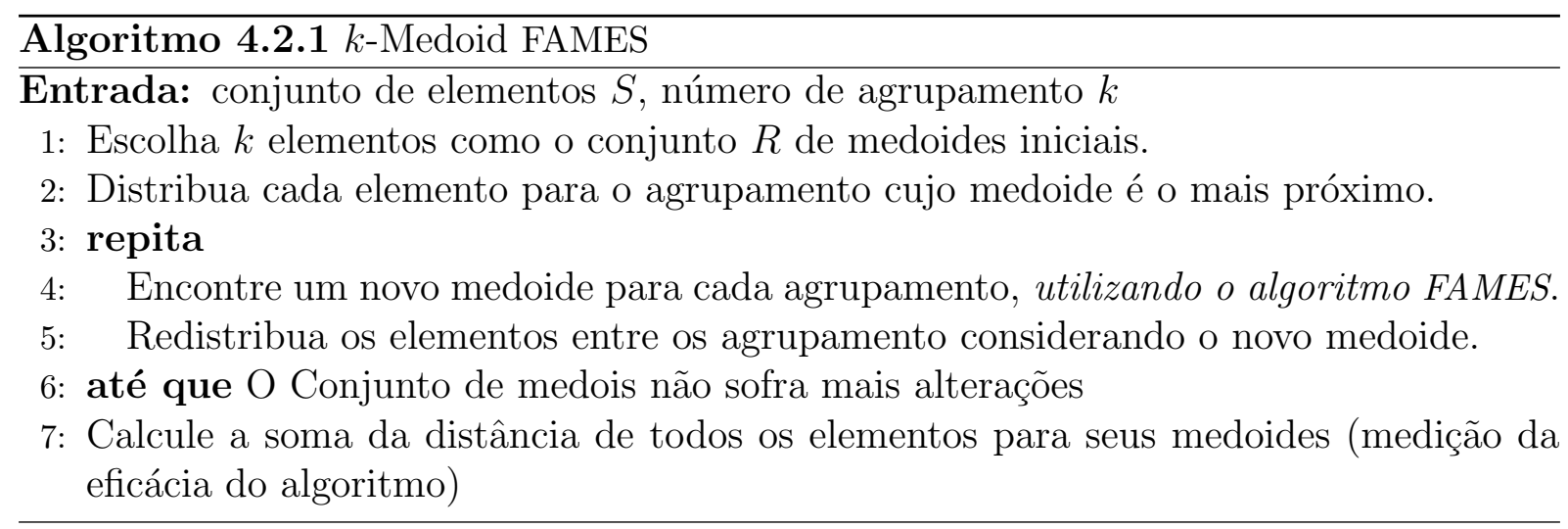


Um algoritmo para detecção de agrupamentos utilizando a seleção de medoides com o algoritmo M-FAMES também foi desenvolvido e os resultados são apresentados na Seção 5.2.3.

\subsection{Consultas por similaridade com o fAMESMAM}

Neste trabalho é proposto um novo método de acesso para dados métricos, chamado FAMESMAM, que realiza a imersão do conjunto de dados em um espaço multidimensional utilizando elementos representativos encontrados nos agrupamentos do conjunto. Os agrupamentos são determinados com eficiência utilizando um algoritmo para detecção de agrupamentos usando o algoritmo FAMES. Nas próximas seções apresentamos a motivação para a proposta do novo método de acesso, detalhando o método de construção da estrutura, e os algoritmos para realizar as consultas por similaridade. Na Seção 5.3 são mostrados os resultados dos experimentos realizados.

\subsubsection{Motivação}

O objetivo dos métodos de indexação é responder a consultas por similaridade de forma eficiente. O método proposto é aplicável a espaços métricos e é similar a métodos que realizam imersões de um espaço em outro utilizando simultaneamente múltiplos representantes globais, ao invés de um único representante por nível hierárquico. Para a concepção do novo método, foi admitida a hipótese que as consultas por similaridade buscam elementos próximos, levando em conta que, em conjuntos com agrupamentos bem definidos, a resposta tende a ficar concentrada no mesmo agrupamento a que pertence o elemento de consulta, mesmo que uma pequena parte da resposta ainda esteja em outros agrupamentos adjacentes.

A Figura 4.5 ilustra um conjunto de dados com 4 agrupamentos no espaço euclidiano bidimensional, tendo em destaque o elemento de uma consulta $s_{q}$ e dois elementos focais $f_{1}$ e $f_{2}$ que são utilizados para realizar podas pela propriedade da desigualdade triangular. A região mais escura contém os elementos que não foram desqualificados pe- 
los focos, mas que não fazem parte do conjunto resposta. Os elementos representantes foram escolhidos na borda do conjunto de dados e portanto afastados entre si, seguindo a sugestão dos métodos baseados na técnica OMNI.

Como se pode ver na Figura 4.5, colocar os focos na borda do conjunto tende a homogenizar a complexidade de resolução de consultas para centros colocados em qualquer região do conjunto. No entanto, nossa hipótese é que se os focos fossem colocados na borda de um agrupamento, isso tenderia a tornar mais eficientes a resolução de concultas com centros colocados nesse agrupamento (embora isso tenda a reduzir a eficiência de consultas com centros em outros agrupamentos).

A Figura 4.6 destaca a parte da Figura 4.5 focando no agrupamento que contém o elemento de consulta. Dois elementos do agrupamento foram agora escolhidos como representantes $s_{1}$ e $s_{2}$. A região em cinza contém os elementos que não foram eliminados com esses novos representantes, e vê-se que ela é menor que a área quadriculada que foi mantida da figura anterior para facilitar a comparação, indicando a tendência de prover maior capacidade de poda de elementos.

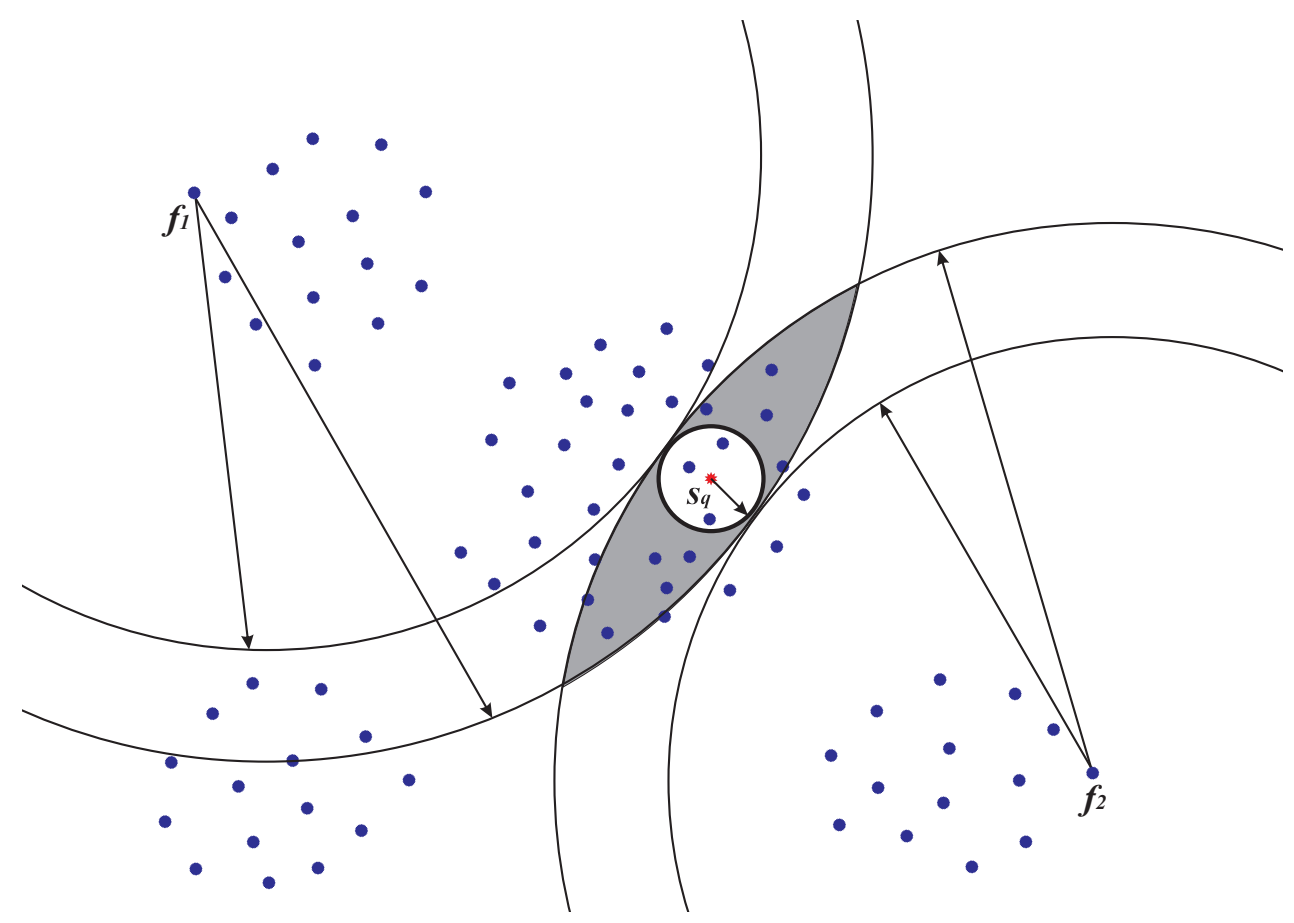

Figura 4.5: Conjunto de dados com 4 agrupamentos, sendo $s_{q}$ um elemento de consulta e os elementos $s_{1}$ e $s_{2}$ posicionados na borda do conjunto e afastados entre si são utilizados para realizar um poda por desigualdade triangular. 
Considerando a existências de agrupamento nos conjuntos e a possibilidade de melhorar a capacidade de poda explorando essa característica, é que foi um proposto o novo método de indexação baseado em imersão de espaços. Para tornar esse método de indexação de dados mais eficiente, utiliza-se um algoritmo de detecção de agrupamentos apresentado na Seção 4.1.O método proposto é baseado em escolher um conjunto de focos para cada agrupamento detectado. No momento da consulta, é determinado o agrupamento mais próximo do centro da consulta e os focos que estão neste agrupamento são utilizados para tornar a consulta mais eficiente.

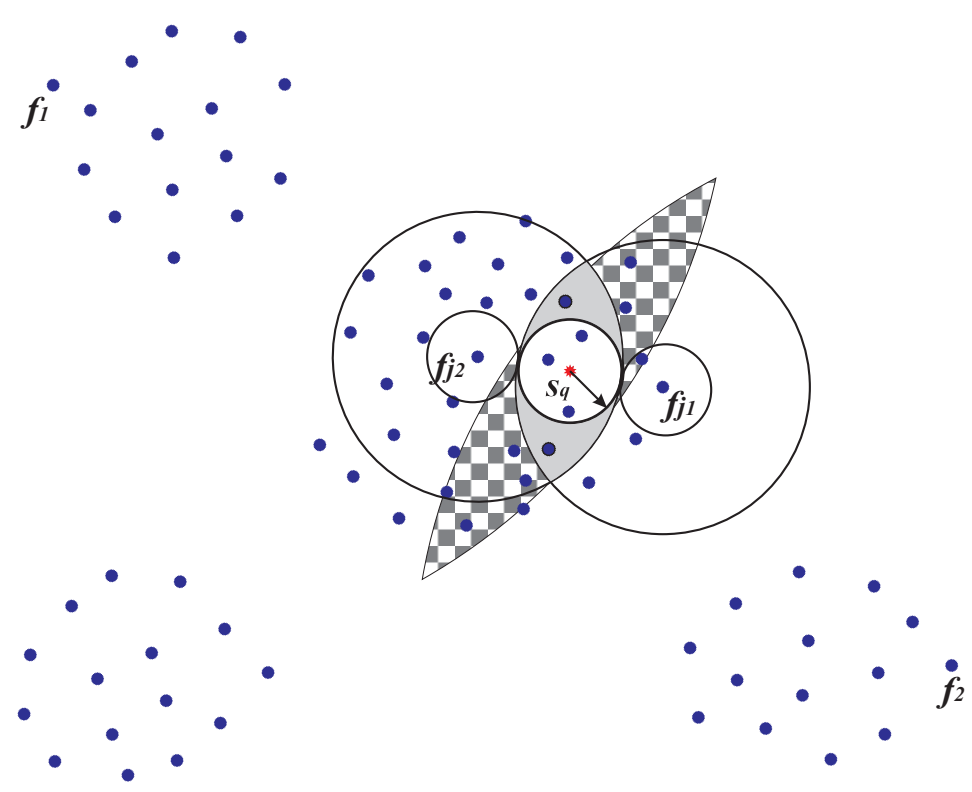

Figura 4.6: Comparativo entre o espaço de busca com dois representantes utilizando o método proposto (região cinza) e o método tradicional (região quadriculada)

\subsubsection{Método de construção}

A construção da estrutura proposta é realizada nas seguintes etapas:

O primeiro passo realiza a leitura dos elementos $s_{i}$ do conjunto de dados $S$, que são escritos em páginas em disco para que possam ser acessados diretamente em ordem aleatória;

Em seguida, o algoritmo busca os medoides $\left(r_{i}\right)$ dos $k$ agrupamentos. O valor de $k$ pode ser escolhido pelo usuário especialista no domínio dos dados, ou utilizando um 
algoritmo apropriado. No caso do conjunto possuir um único agrupamento, o método utiliza o algoritmo FAMES para encontrar o medoide do conjunto completo. Para conjuntos com mais agrupamentos exitem duas alternativas. A primeira recebe como entrada os elementos rotulados de acordo com os os agrupamentos previamente determinados. A segunda abordagem consiste no próprio método encontrar os agrupamentos. Neste trabalho os medoides foram encontrados utilizando o método proposto na Seção 4.2;

O próximo passo é escolher um conjunto de focos para cada agrupamento, visando permitir uma melhor poda dos falsos positivos. Essa tarefa utiliza o Algoritmo 4.3.1, que é uma modificação do HF apresentado na Seção 2.6.2. O primeiro foco selecionado é o medoide do agrupamento de dados, por ser o elemento que minimiza a distância entre os demais elementos do agrupamento. Os demais focos são selecionados próximos à borda do agrupamento e afastados entre si;

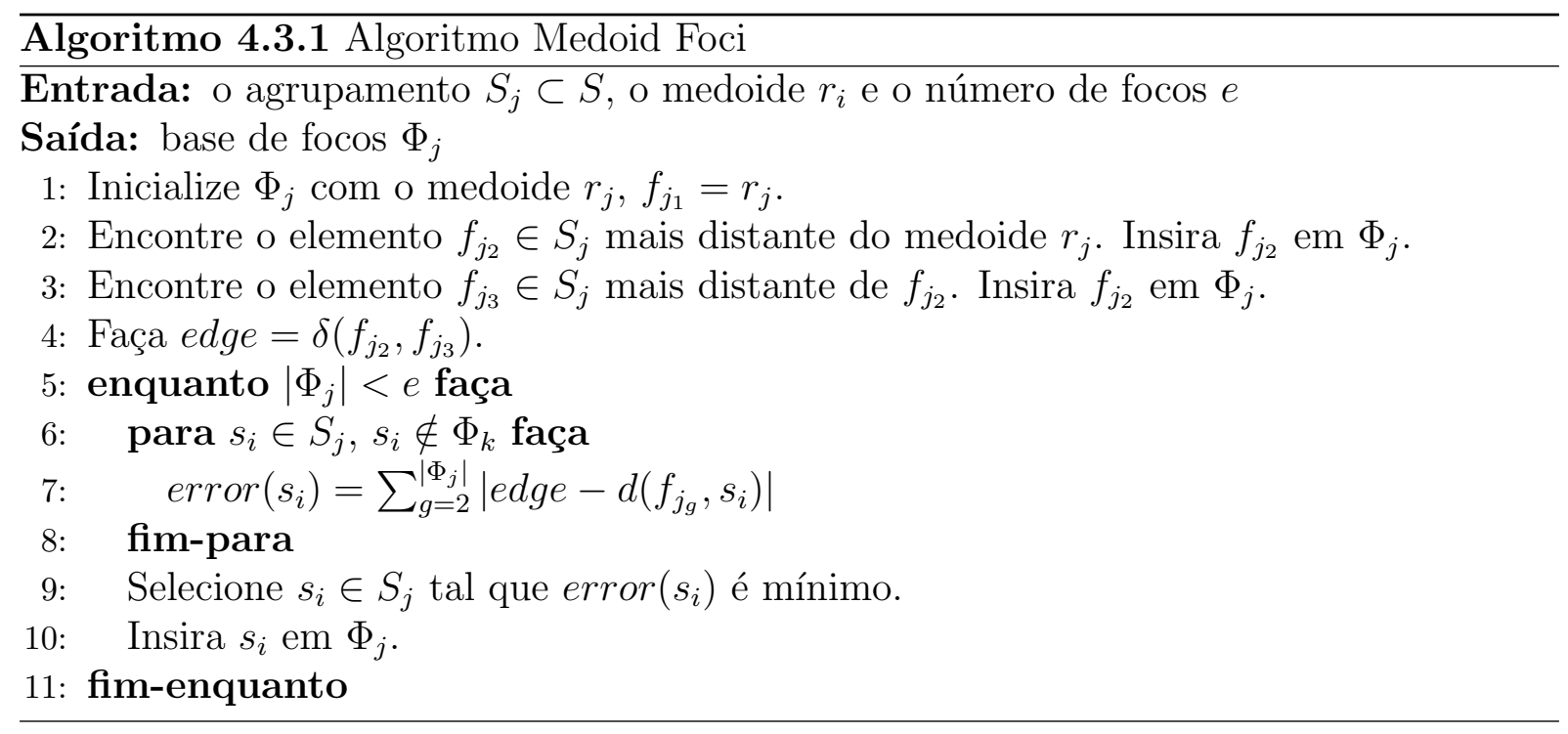

Finalmente, criar $k$ espaços mapeados $S_{j}^{E} \operatorname{com} j=1 \ldots k$ utilizando as distâncias entre cada elemento $s_{i} \in S$ e cada um $\operatorname{dos} e$ focos locais. Note que todos os elementos do conjunto $S$ são imersos em cada um dos espaços mapeados e não apenas o elementos que pertencem ao agrupamento correspondente, pois caso contrÁrio as consultas por similaridade estariam sujeitas a falsos descartes.

O conjunto de todos os $e$ focos locais usados para a imersão de $S$ com os focos de cada agrupamento $j=1 \ldots k$ é chamada Base Focal Local $\Phi_{j}=\left\{f_{j_{1}}, \ldots f_{j_{e}}\right\}$, e o conjunto de distâncias de cada elemento $s_{i} \in S$ a cada elemento da Base Focal Local é chamado 
de elemento do espaço mapeado $\varsigma_{j i}$ em cada um dos espaços de imersão $S_{j}^{E}$, com $j=1 . . k$ e definido como $\varsigma_{j i}=\left(\delta\left(f_{j_{1}}, s_{i}\right), \ldots, \delta\left(f_{j_{e}}, s_{i}\right)\right)$.

Conforme mostrado na seção anterior, as distâncias entres pares de elementos de qualquer dos espaços mapeados atendem a propriedade de contratividade do mapeamento para todos os elementos do conjunto $S$.

Para realizar as consultas por similaridade, é necessário utilizar a abordagem de etapas de filtragem e refinamento. Para isso, deve-se mostrar que: i) se a distância entre dois elementos $s_{i}$ e $s_{q}$ é menor ou igual a $\xi$, então a distância entre $\varsigma_{j i}$ e $\varsigma_{j q}$ também é menor ou igual a $\xi$ para todo $j=1 . . k$; e ii) se a distância entre dois elementos $\varsigma_{j i}$ e $\varsigma_{j q}$ é maior do que $\xi$, então a distância entre $s_{i}$ e $s_{q}$ também é maior do que $\xi$ para todo $j=1 . . k$. A combinação dessas afirmações permitem descartar elementos na etapa de filtragem analisando apenas a distância no espaço mapeado.

Formalmente, a hipótese i) diz que: Se $\delta\left(s_{i}, s_{q}\right) \leq \xi$, então $\delta_{L_{\infty}}\left(\varsigma_{j i}, \varsigma_{j q}\right) \leq \xi$ para todo $1 \leq j \leq k$. Essa hipótese pode ser provada da seguinte maneira:

Sejam $\left\{f_{j_{1}}, \ldots f_{j_{e}}\right\}$ os elementos do conjunto escolhidos como focos do espaço mapeado. Considerando as propriedades de poda pela desigualdade triangular, um elemento $s_{i}$ está na região de filtragem quando:

$$
\begin{aligned}
& \delta\left(f_{j_{h}}, s_{i}\right)>\delta\left(f_{j_{h}}, s_{q}\right)-\xi, \forall h=1 \ldots e \\
& \delta\left(f_{j_{h}}, s_{i}\right)<\delta\left(f_{j_{h}}, s_{q}\right)+\xi, \forall h=1 \ldots e
\end{aligned}
$$

A partir das equações 4.5 e 4.6 e considerando todos os focos simultaneamente, obtém-se a região de filtragem pela intersecção:

$$
\bigcap_{h=1}^{e}\left\{\left|\delta\left(f_{j_{h}}, s_{i}\right)-\delta\left(f_{j_{h}}, s_{q}\right)\right| \leq \xi\right\}
$$

Na Equação 4.7, cada um dos fatores da intersecção devem ser menores do que $\xi$, então é suficiente que o maior desses fatores seja menor do que $\xi$, resultando na equação: 


$$
\max _{h=1}^{e}\left\{\left|\delta\left(f_{j_{h}}, s_{i}\right)-\delta\left(f_{j_{h}}, s_{q}\right)\right|\right\} \leq \xi
$$

Pela definição, os elementos mapeados possuem como coordenadas as distâncias para os elementos da base de focos, portanto temos:

$$
\begin{gathered}
\varsigma_{j i}=\left(\delta\left(f_{j_{1}}, s_{i}\right), \ldots, \delta\left(f_{j_{e}}, s_{i}\right)\right) \\
\varsigma_{j q}=\left(\delta\left(f_{j_{1}}, s_{q}\right), \ldots, \delta\left(f_{j_{e}}, s_{q}\right)\right)
\end{gathered}
$$

Finalmente, combinando-se a equação 4.8 com as equações 4.9 e 4.10, obtém-se:

$$
\delta_{L_{\infty}}\left(\varsigma_{j i}, \varsigma_{j q}\right) \leq \xi
$$

A hipótese ii) pode ser demonstrada de maneira análoga e foi por isso omitida. A próxima seção apresenta os algoritmos para realizar as consultas por similaridade na estrutura proposta nesta seção.

O algoritmo 4.3.2 resume os passos descritos nesta seção para a construção do método de acesso métrico proposto FAMESMAM.

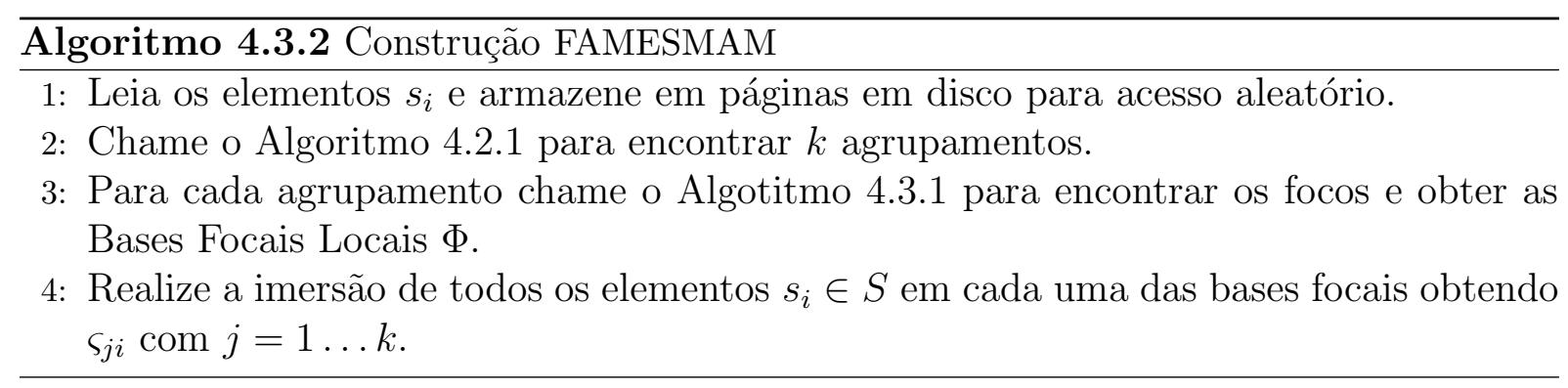

\subsubsection{Consultas por similaridade}

Na estrutura FAMESMAM, as consultas por similaridade são realizadas utilizando o espaço mapeado com algoritmos de filtragem e refinamento, de forma semelhante ao que foi 
apresentado na Seção 2.5.2. A satisfação da propriedade de contratividade torna possível garantir que não ocorram falsos descartes.

Os algoritmos para consultas por similaridade propostos nas próximas seções inicialmente calculam a distância entre o elemento de consulta e os medoides dos agrupamentos e escolhem o conjunto de focos correspondente ao medoide mais próximo. Para dar continuidade à etapa de filtragem, utilizam-se as distâncias entre os elementos mapeados para definir o resultado final, pois o mapeamento realizado é sempre contrativo.

\section{Consultas por Abrangência}

Consultas por abrangência utilizando o método de indexação proposto são realizadas utilizando o Algoritmo 4.3.3. Inicialmente, o algoritmo escolhe o conjunto de focos que será utilizado, calculando a distância do elemento de consulta aos medoides dos agrupamentos (Passo 1). Desta forma apenas $k$ cálculos de distâncias são utilizados para identificar a qual agrupamento o centro da consulta está mais próximo. Em seguida, é realizada a imersão do elemento de consulta com o conjunto de focos do agrupamento escolhido, calculando a distância para todos esses focos (Passo 2). Todos os elementos do espaço mapeado $S_{j}^{E}$ são analisados na etapa de filtragem (Passos 3-4): é importante ressaltar que o conjunto de elementos de $S_{j}^{E}$ não é restrito aos elementos do agrupamento $j$, evitando a ocorrência de falsos descartes. Os elementos que se classificam na etapa de filtragem são recuperados no Passo 5 e avaliados na etapa de refinamento (Passo 6). Finalmente, os elementos que atendem a condição da consulta são inseridos no conjunto resposta no Passo 7.

Os experimentos que mostram a eficiência desse método são apresentados na Seção 5.3.1 e mostram os resultados das consultas realizadas com diversos conjuntos sintéticos com agrupamentos, que ilustram o comportamento do algoritmo ao variar o número de elementos, o número de dimensões e o raio da consultas. Além disso, conjuntos reais são utilizados para validar a eficiência do método. 


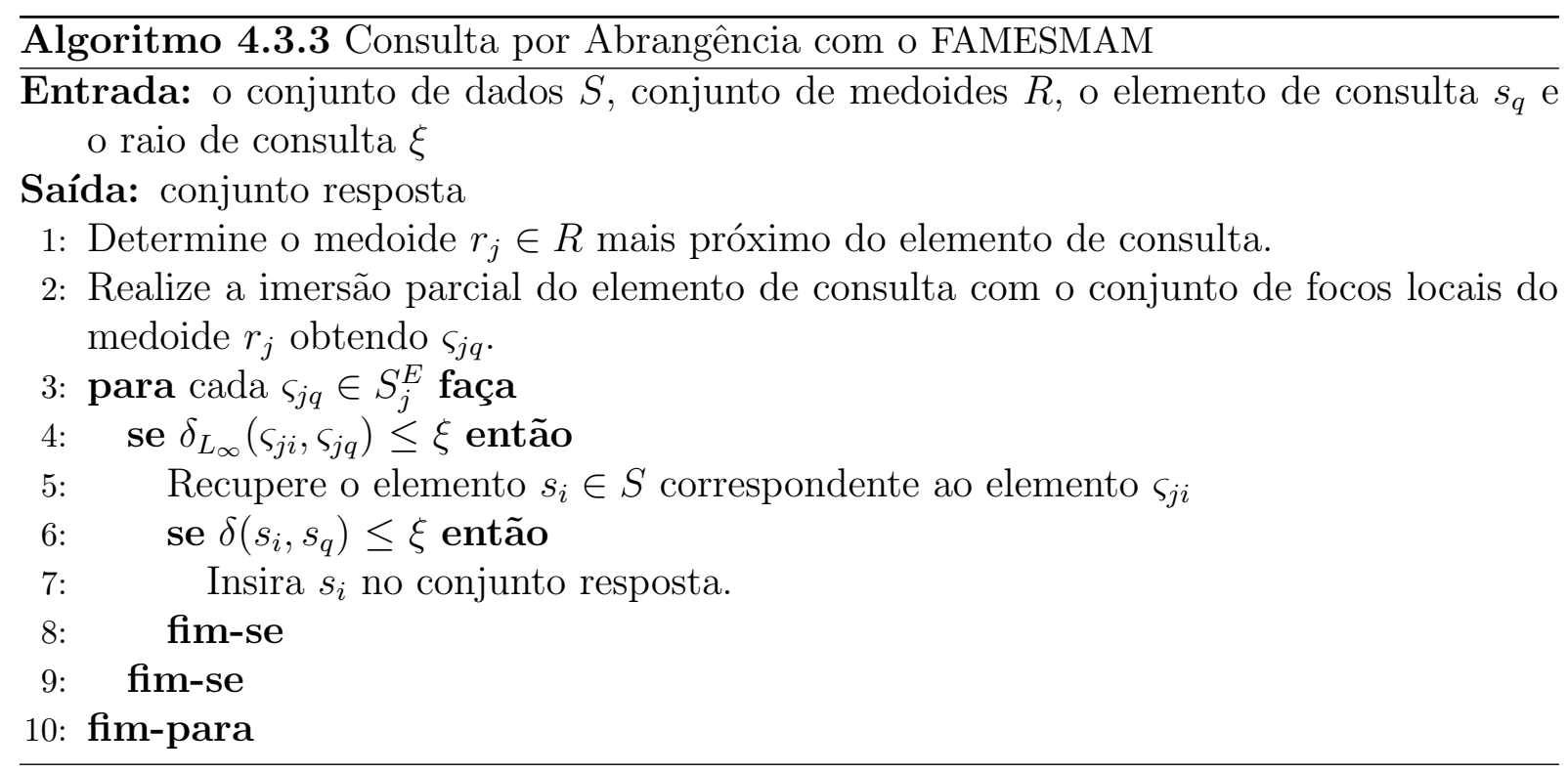

\section{Consultas aos $\kappa$-Vizinhos Mais Próximos}

A maneira de realizar consultas aos $\kappa$-Vizinhos Mais Próximos utilizando o FAMESMAM é mostrada no Algoritmo 4.3.4. De maneira semelhante à consulta por abragência, o algoritmo escolhe o conjunto de focos que será utilizado calculando a distância do elemento de consulta aos medoides dos agrupamentos. Em seguida, é realizada a imersão do elemento de consulta com o conjunto de focos escolhido, calculando a distância para esses focos. Na sequência, o algoritmo inicializa o conjunto resposta com os $\kappa$ primeiros elementos do conjunto. Dessa forma, o espaço de busca é reduzido iterativamente, usando a bola centrada em $s_{q}$ com raio igual à distância máxima entre $s_{q}$ e os elementos do conjunto resposta corrente, denotada como $\xi_{\max }$. Os demais elementos são testados em duas etapas, primeiro no espaço mapeado e depois no espaço original. Os elementos que sejam mais próximos do elemento de consulta entram no conjunto resposta e o raio máximo é atualizado.

\subsection{Considerações finais}

Nessa seção as principais contribuições dessa dissertação de mestrado foram apresentadas. O próximo capítulo mostra os resultados obtidos com os experimentos realizados com os 
Algoritmo 4.3.4 Algoritmo Consulta aos $\kappa$-Vizinhos Mais Próximos

Entrada: o conjunto de dados $S$, medoide dos agrupamentos $R$, o elemento de consulta $s_{q}$ e o número de vizinhos $\kappa$.

Saída: conjunto resposta de elementos

1: Determine o medoide $r_{j} \in R$ mais próximo do elemento de consulta.

2: Realize a imersão parcial do elemento de consulta com o conjunto de focos locais do medoide $r_{j}$ obtendo $\varsigma_{j q}$.

3: Insira os primeiros $\kappa$ elementos no conjunto resposta.

4: Atualize $\xi_{\max }$ (Distância entre o $\kappa$-ésimo elemento atual e o elemento de consulta $s_{q}$ ).

5: para cada $\varsigma_{j i} \in S_{j}^{E}$ faça

6: $\quad$ se $\delta_{L_{\infty}}\left(\varsigma_{j i}, \varsigma_{j q}\right)<\xi_{\max }$ então

7: $\quad$ Recupere o elemento $s_{i}$ correspondente ao elemento $\varsigma_{j i}$

8: $\quad$ se $\delta\left(s_{i}, s_{q}\right)<\xi_{\max }$ então

9: $\quad$ Insira $s_{i}$ no conjunto resposta.

10: $\quad$ Remova o último elemento do conjunto resposta.

11: $\quad$ Atualize $\xi_{\max }$.

12: $\quad$ fim-se

13: fim-se

14: fim-para

algoritmos propostos: FAMES e M-FAMES para detecção de agrupamentos e consultas por similaridade utilizando o método de acesso FAMESMAM. 


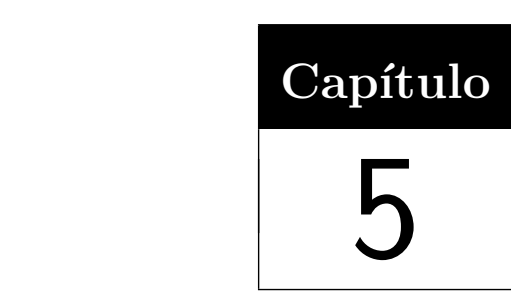

Experimentos

este capítulo são apresentados os experimentos realizados com os métodos
propostos neste programa de mestrado. Os experimentos estão dividos em duas partes: A detecção de agrupamentos com os algoritmo FAMES e M-FAMES na Seção 5.2; e as consultas por similaridade com o método de acesso FAMESMAM na Seção 5.3. Além disso, a Seção 5.1 descreve os conjunto de dados empregados.

\subsection{Conjuntos de dados}

A descrição dos conjuntos de dados é apresentada na Tabela 5.1, contendo para cada um o nome do conjunto, o número total de elementos $(n)$, o número de agrupamentos $(k)$, a dimensionalidade do conjunto $(D)$, e a função de distância $(\delta)$. Todos os conjuntos de agrupamentos sintéticos foram gerados utilizando distribuição gaussiana em um hipercubo unitário de dimensionalidade $D$. Os conjuntos foram gerados utilizando o mesmo processo descrito em [Ciaccia et al., 1997] com variância $\sigma^{2}=0.1$ e os centros do agrupamentos randomicamente distribuídos. Os conjunto sintéticos possuem no nome a quantidade de elementos no conjunto, o número de agrupamento com o qual o conjunto foi gerado e a 
dimensionalidade do conjunto, por exemplo um conjunto com 5 mil elementos, gerado com 10 agrupamentos e dimensionalidade 30 é denominado $\operatorname{SyntCL}(n=5 \mathrm{mil}|k=10| D=30)$.

O conjunto AloiL [Geusebroek et al., 2005] é composto por dados adimensionais reais com os Histogramas Métricos (Seção 2.2.5) extraídos de cada imagem. As imagens foram obtidas da biblioteca Amsterdam Library of Object Images (ALOI) ${ }^{1}$. As imagens compõem uma coleção de fotos coloridas de mil objetos. Para os experimentos foi selecionado o conjunto de imagens fotografado com 12 diferentes iluminações, totalizando 12,000 elementos.

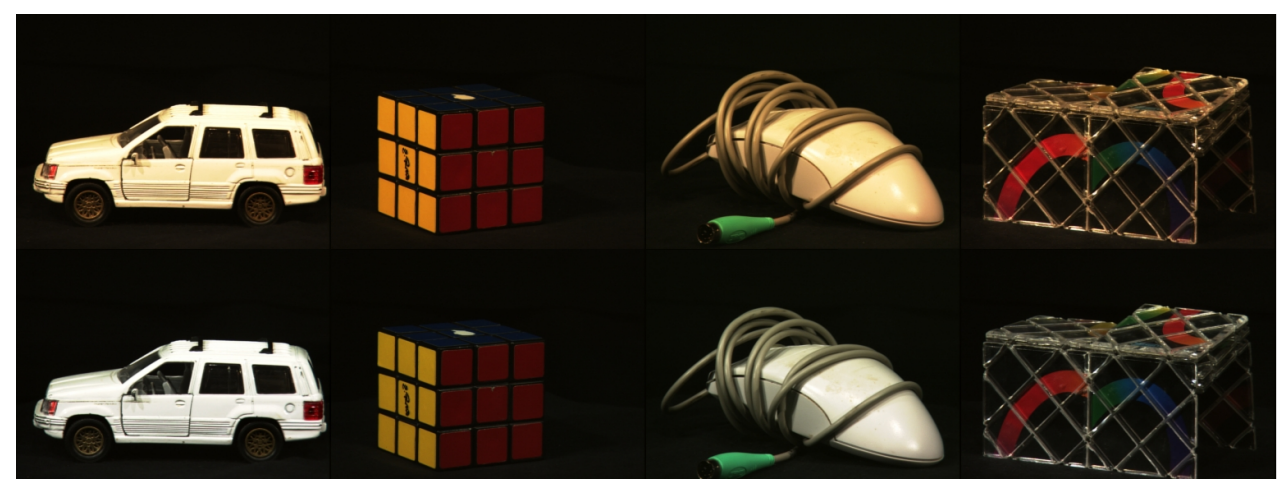

Figura 5.1: Amostra de imagens da base dados Aloi com duas iluminações de quatro imagens distintas.

O conjunto de dados pendigits pode ser obtido do repositório de aprendizado de maquina da UCI ${ }^{2}$. Este conjunto é constituído por avaliações de reconhecimento de escrita de dígitos (os 10 algarismos arábicos).

A base de imagens CT_Lung_ROIs, é um coleção de 3.257 imagens, de tamanho 64 x 64 pixels e 256 níveis de cinza, contendo Regiões de Interesse (ROIs) de imagens de Tomografia Computadorizada (CT) de exames de pulmão. A base de dados é organizada em 6 classes, sendo uma para pulmão normal e as outras cinco para anomalias distintas. Nessa base de dados, o extrator de cores não foi utilizado, pois esse tipo de extrator não é relevante para representar ROIs de imagens de pulmão. As imagens da base de dados CT_Lung_ROIs foram processadas para extrair as características de texturas de Haralick e dos primeiros 256 momentos de Zernike, obtendo respectivamente os conjuntos de dados Haralick e Zernike para essa base de imagens.

\footnotetext{
${ }^{1}$ Avaliable at www.science.uva.nl/ aloi/

${ }^{2}$ http://archive.ics.uci.edu/ml/
} 
Tabela 5.1: Descrição dos conjuntos utilizados nos experimentos. 15 conjuntos sintéticos gerados variando $n, k$ e $D$ como alguns dos valores mostrados

\begin{tabular}{|l|l|l|l|l|}
\hline Name & $n$ & $k$ & $D$ & $\delta$ \\
\hline \hline SyntCL(n | k | D) & 5 mil,10mil,20mil & $5,10,20$ & $5,10,20,30,50,100$ & $\delta_{L_{2}}$ \\
AloiL & 12 mil & - & - & $L_{H M}$ \\
Pendigits & 10993 & 10 & 16 & $L_{2}$ \\
Haralick (CT_Lung_ROIs) & 3257 & 6 & 140 & $\delta_{C}$ \\
Zernike (CT_Lung_ROIs) & 3257 & 6 & 256 & $\delta_{C}$ \\
\hline
\end{tabular}

Os algoritmos foram desenvolvidos para operar com elementos de espaços métricos. Assim, mesmo que os conjuntos de dados sintéticos sejam também multidimensionais, não foram utilizadas as operações disponíveis apenas nesse tipo de espaço. A distância entre dois elementos foi sempre calculada utilizando uma função de distância.

Os experimentos foram executados em um computador com processador Intel(R) Core(TM)2 Quad @ 2.83GHz e 4 GB de mémoria RAM.

\subsection{Detecção de Agrupamentos com o famese com o}

\section{M-FAMES}

Os algoritmos propostos foram comparado quanto à qualidade e eficiência com os algoritmos mais conhecidos de detecção de agrupamentos por medoides: PAM, CLARA e CLARANS. Por simplicidade, nesta seção, os algoritmos para detecção de agrupamentos baseados em $k$-medoides que determinam os medoides utilizando os métodos propostos são chamados apenas de FAMESe M-FAMES. Para medir a qualidade dos agrupamentos foi utilizada a distância média (average distance), a qual mede a média das distâncias de cada elemento do conjuntos para o seu medoide mais próximo (valores menores indicam um agrupamento melhor). A eficiência de cada algoritmo foi medida pelo número de cálculos de distâncias, o qual segue um comportamento bastante similar em relação ao tempo de execução.

Nas próximas seções mostra-se como os algoritmos foram avaliados, seguindo abordagens distintas. Os três primeiros experimentos analisam os algoritmos variando as propriedades dos conjuntos de dados sintéticos, sendo que a variação do número de agru- 
pamentos é avaliada na Seção 5.2.1, o número de dimensões na Seção 5.2.2 e o número de elementos na Seção 5.2.3. A Seção 5.2.3 também analisa os efeitos ao utilizar o algoritmo de múltiplos eixos M-FAMES proposto e finalmente a Seção 5.2.4 analisa como o algoritmo proposto se comporta processando conjuntos de dados reais.

\subsubsection{Analisando o efeito da variação do número de agrupamen- tos $k$}

Para analisar o efeito da variação do número de agrupamentos foram utilizados 6 conjuntos de dados sintéticos, todos com 5 dimensões. Os 3 primeiros conjuntos têm 5 mil elementos e os outros 3 têm 10 mil elementos. O número de agrupamento escolhidos para gerar os conjuntos foram 5, 10 e 20, resultando nos conjuntos $\operatorname{SyntCL}(n=5 \mathrm{mil}|k=5| D=5)$, $\operatorname{SyntCL}(n=5 m i l|k=10| D=5), \operatorname{SyntCL}(n=5 m i l|k=20| D=5), \operatorname{SyntCL}(n=$ $10 m i l|k=5| D=5), \operatorname{SyntCL}(n=10 m i l|k=10| D=5)$ e $\operatorname{SyntCL}(n=10 m i l|k=20| D=$ $5)$.

Na Figura 5.2 é mostrada a comparação de qualidade dos algoritmos para os conjuntos com 5 mil elementos. Nota-se que o algoritmo proposto apresenta o melhor resultado para os 3 conjuntos de dados, obtendo até $36 \%$ de ganho. A eficiência dos algoritmos é comparada na Figura 5.3. Como já esperado o PAM apresenta o pior resultado em eficiência (velocidade para obter a resposta). Nesse teste, o FAMES é superado pelo método CLARA apenas para o caso do conjunto com o menor número de agrupamentos.

A eficácia dos algoritmos de detecção de agrupamentos para os conjuntos de $10 \mathrm{mil}$ elementos é mostrada na Figura 5.4. O algoritmo proposto obteve os resultados mais eficazes atingindo até $32 \%$ de ganho em relação aos demais algoritmos. Considerando a eficiência, mostrada na Figura 5.5, o algoritmo FAMES obteve também o melhor desempenho, exceto para o conjunto $\operatorname{SyntCL}(n=10 \mathrm{mil}|k=5| D=5)$, que tem um número de agrupamentos reduzido, caso em que o algoritmo CLARA foi mais rápido.

O melhor desempenho do algoritmo CLARA nos conjuntos $\operatorname{SyntCL}(n=5 m i l \mid k=$ $5 \mid D=5)$ e $\operatorname{SyntCL}(n=10$ mil $|k=5| D=5)$ não é significativo quando for considerado que o pequeno aumento de desempenho do algoritmo acompanha uma queda bem drástica 


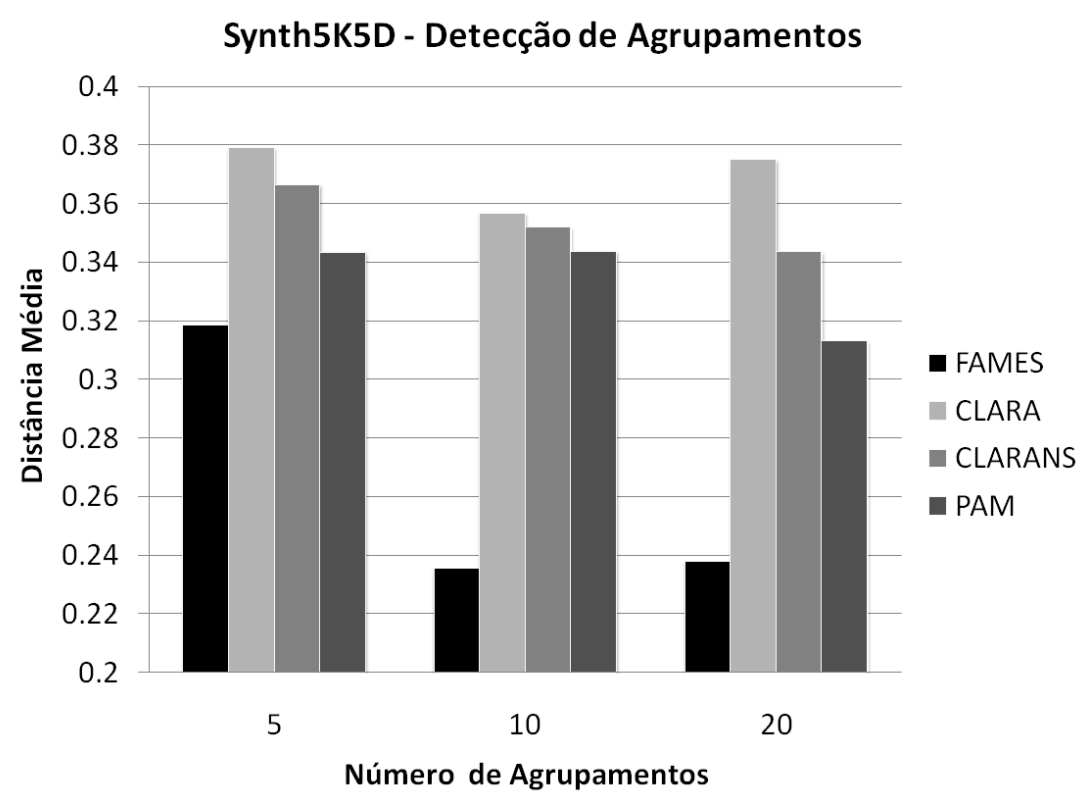

Figura 5.2: Distância média de todos os elementos para o medoide correspondente (mais próximo) para avaliar a qualidade dos agrupamentos encontrados pelos algoritmos FAMES, CLARA, CLARANS e PAM em conjuntos sintéticos de 5 mil elementos, 5 dimensões e com 5, 10 e 20 agrupamentos.

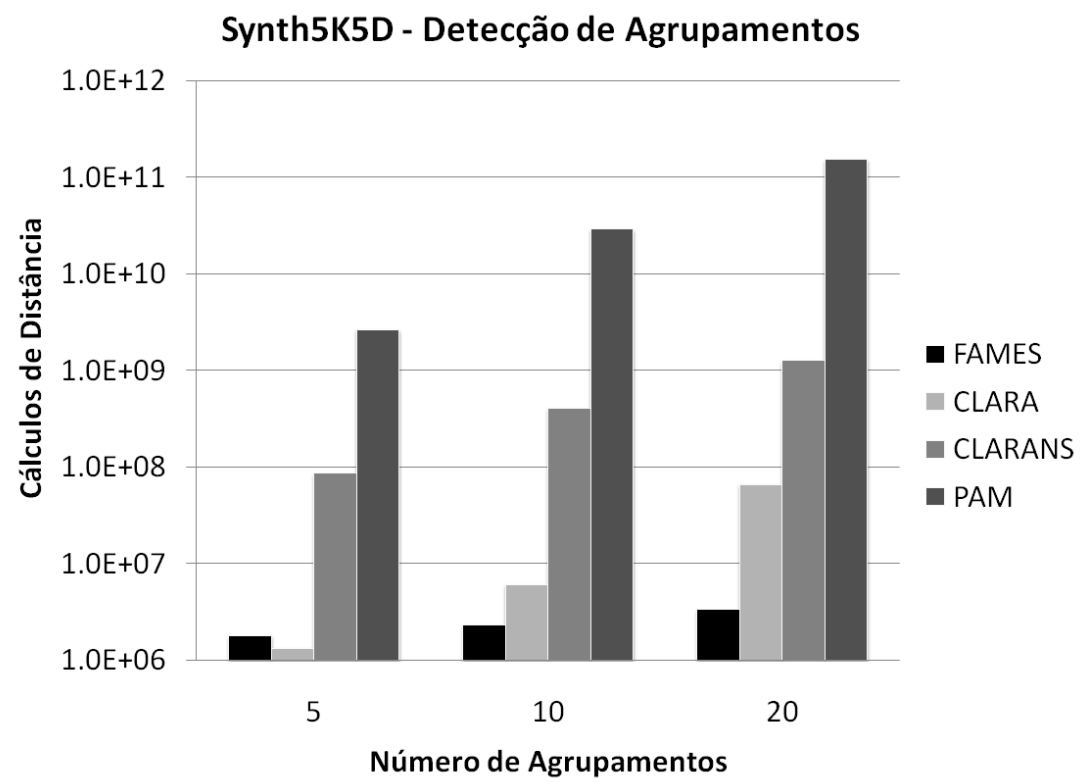

Figura 5.3: Número de cálculos de distâncias para avaliar a eficiência dos algoritmos FAMES, CLARA, CLARANS e PAM para encontrar agrupamentos em conjuntos sintéticos de 5 mil elementos, 5 dimensões e com 5,10 e 20 agrupamentos.

na qualidade dos agrupamentos. Esse fato pode ser entendido lembrando que o CLARA trabalha com amostras de tamanho fixo para determinado número de agrupamentos $(40+$ 
$2 k)$, no caso com 5 amostras de 50 elementos, tendo portanto menos de $1 \%$ de chance do melhor medoide estar no conjunto amostrado.

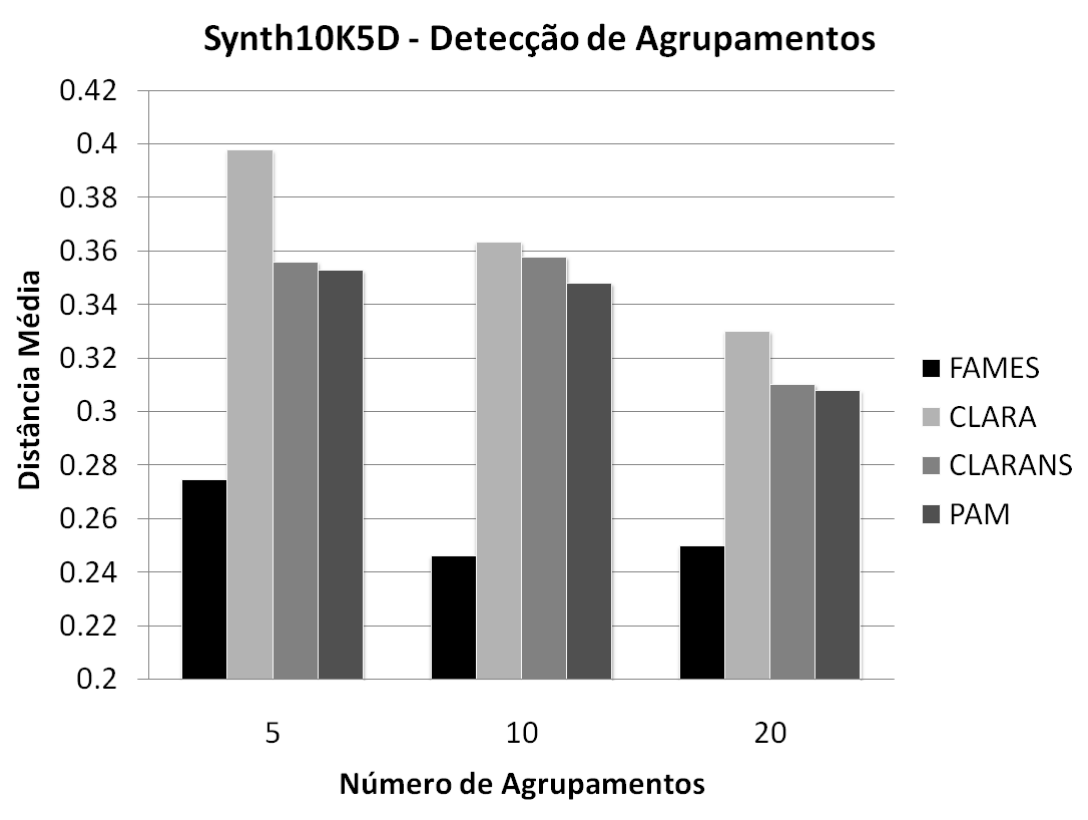

Figura 5.4: Distância média de todos os elementos para o medoide correspondente (mais próximo) para avaliar a qualidade dos agrupamentos encontrados pelos algoritmos FAMES, CLARA, CLARANS e PAM em conjuntos sintéticos de 10 mil elementos, 5 dimensões e com 5, 10 e 20 agrupamentos.

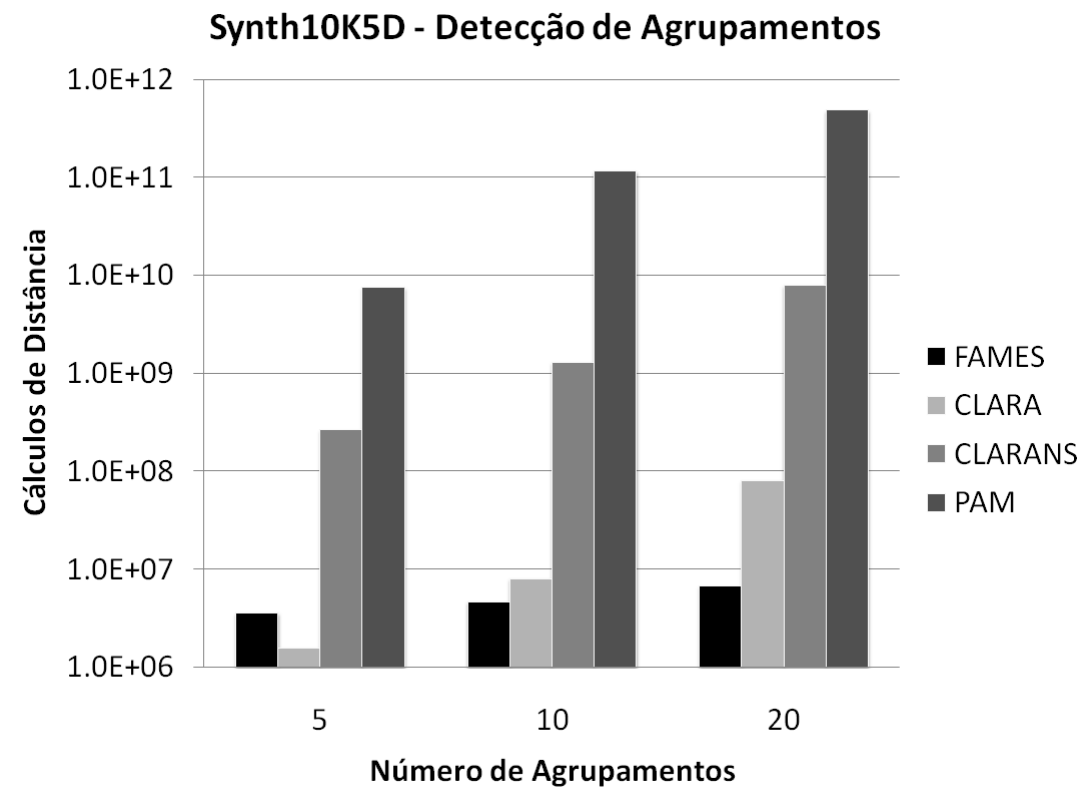

Figura 5.5: Número de cálculos de distâncias para avaliar a eficiência dos algoritmos FAMES, CLARA, CLARANS e PAM para encontrar agrupamentos em conjuntos sintéticos de 10 mil elementos, 5 dimensões e com 5,10 e 20 agrupamentos. 


\subsubsection{Aumento da dimensionalidade e a Variante M-FAMES}

Com o objetivo de analisar a aplicabilidade da variante M-FAMES algoritmo, que encontra os medoides utilizando projeções em múltiplos eixos, três conjuntos de dados foram utilizados $\operatorname{SyntCL}(n=10 \mathrm{mil}|k=10| D=10,20$ e 50). Então, além dos algoritmos CLARA, CLARANS e PAM o algoritmo M-FAMES é mostrado com projeções em 1 a 5 eixos.

Os resultados obtidos quanto a qualidade e desempenho desses algoritmos são apresentados nas Figuras 5.6 e 5.7 respectivamente. Como esperado, o aumento da dimensionalidade não influencia o número de cálculos de distância, que se mantem estável para todos os algoritmos. No entanto, revela-se claramente que o desempenho do algoritmo proposto é claramente superior ao dos demais algoritmos. A qualidade dos agrupamentos decai em todos os algoritmos com o aumento da dimensionalidade, influenciada pelo efeito conhecido como "maldição da dimensionalidade", que ocasiona o aumento da distância entres os pares de elementos. Mesmo assim, a qualidade proporcionada pelo algoritmo FAMES é melhor para todos os casos, atingindo uma melhora de eficácia de mais de $36 \%$ em relação ao algoritmo CLARA no conjunto com 50 dimensões.

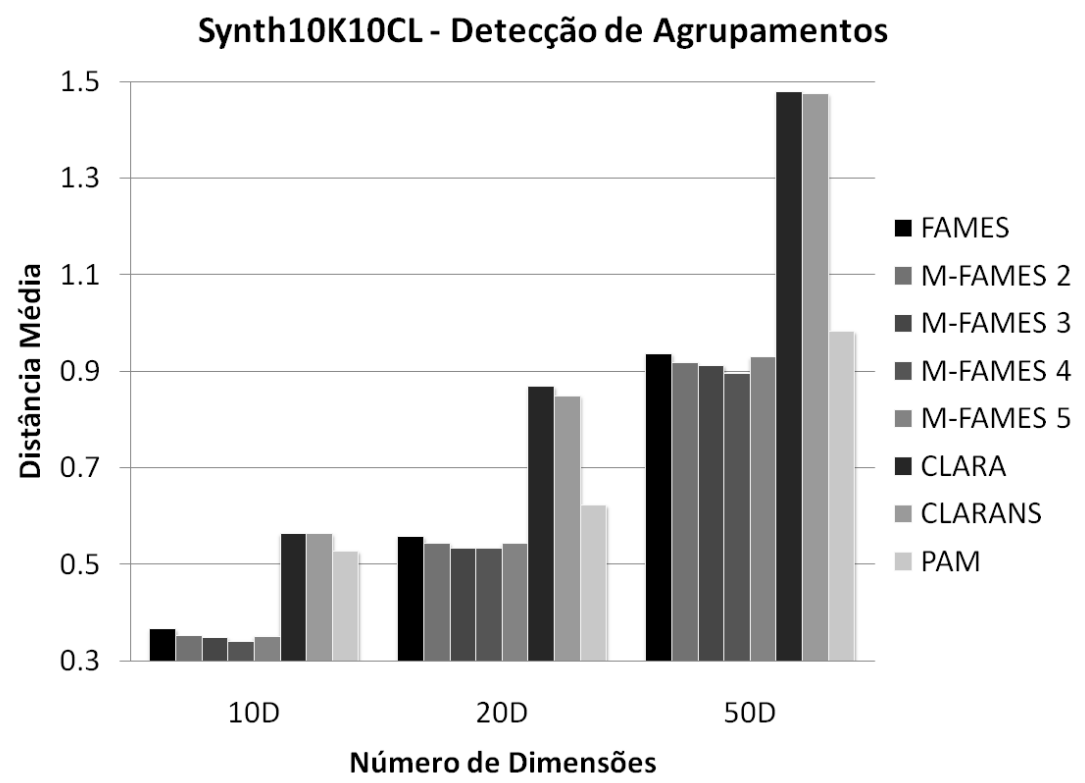

Figura 5.6: Distância média de todos os elementos para o medoide correspondente (mais próximo) para avaliar a qualidade dos agrupamentos encontrados pelos algoritmos MFAMES, CLARA, CLARANS e PAM em conjuntos sintéticos de 10mil elementos, 5, 10 e 20 dimensões e 10 agrupamentos. 


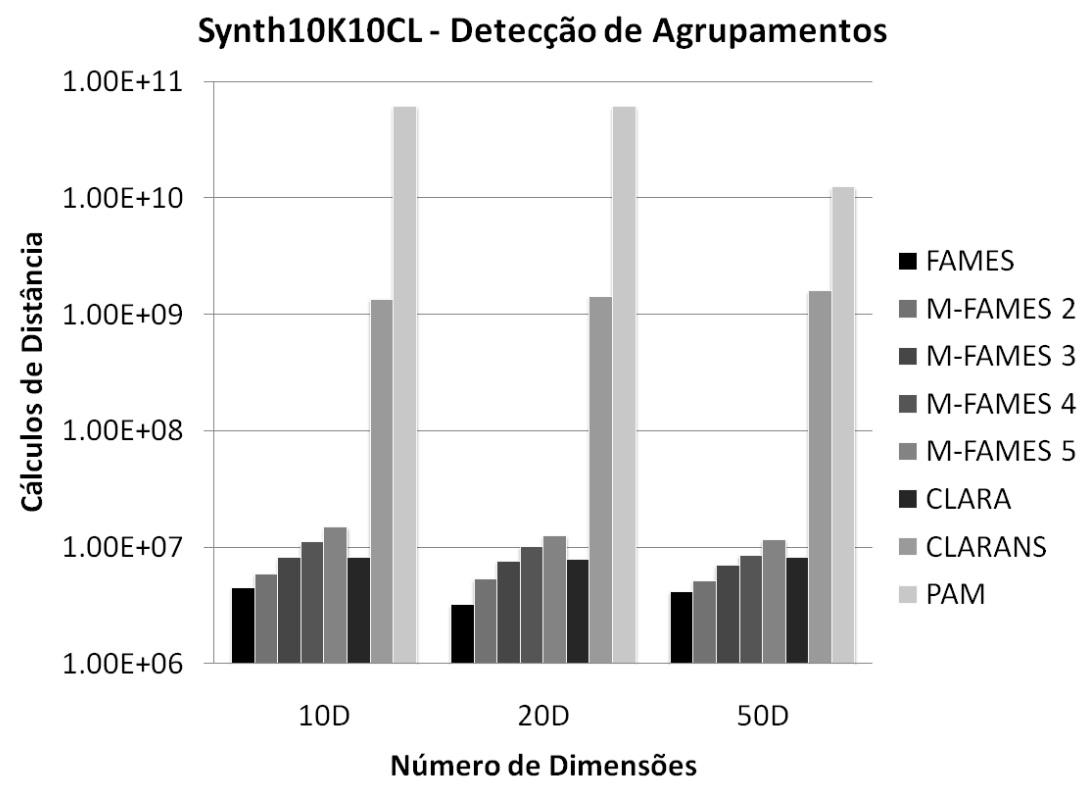

Figura 5.7: Número de cálculos de distâncias para avaliar a eficiência dos algoritmos M-FAMES, CLARA, CLARANS e PAM para encontrar agrupamentos em conjuntos sintéticos de 10 mil elementos, 5, 10 e 20 dimensões e 10 agrupamentos.

Além disso, a Figura 5.6 mostra que o M-FAMES com 4 eixos proporciona o melhor resultado em eficácia nos três conjuntos de dados. Nota-se entretanto, observando a Figura 5.7, que o aumento no número de eixos aumenta o custo do algoritmo M-FAMES. Em particular para todos esses três conjuntos, o uso de mais do que 3 eixos torna o algoritmo M-FAMES mais custoso do que o algoritmo CLARA. Observa-se que a qualidade do algoritmo M-FAMES sempre foi melhor, para qualquer número de eixos, do que qualquer de seus concorrentes.

É interessante notar que a qualidade dos resultados foi sempre a melhor quando se usou 4 eixos de projeção para o M-FAMES, independentemente da dimensionalidade do conjunto. Embora essa análise não seja suficiente para garantir que isso ocorra para qualquer conjunto de dados, esses resultados apoiam estabelecer que o uso de 4 eixos seja recomendado como padrão para o caso geral. Considerando-se a qualidade do resultados (Na Figura 5.7, verifica-se que a qualidade dos resultados tende a ser independente da dimensionalidade uma vez que não se detecta um padrão de comportamento. 


\subsubsection{Escalabilidade}

Com o objetivo de analisar a escalabilidade dos algoritmos propostos, foram utilizados três conjuntos de dados $\operatorname{SyntCL}(n=5$ mil, 10 mil e 20 mil $|k=10| D=10)$. Nesta seção mostram-se os resultados de escalabilidade com tempo em segundos. Os resultados são apresentados nas Figuras 5.8, 5.9 e 5.10.

A análise de desempenho dos algoritmos com esses conjuntos de dados mostra que o aumento do número de elementos dos conjuntos causa um aumento exatamente em relação ao número de cálculos de distâncias efetuados pelo algoritmo FAMES. Comparando as Figuras 5.9 e 5.10 nota-se que o tempo de execução dos algoritmos possui de fato um comportamento diretamente relacionado ao número de cálculos de distância efetuados.

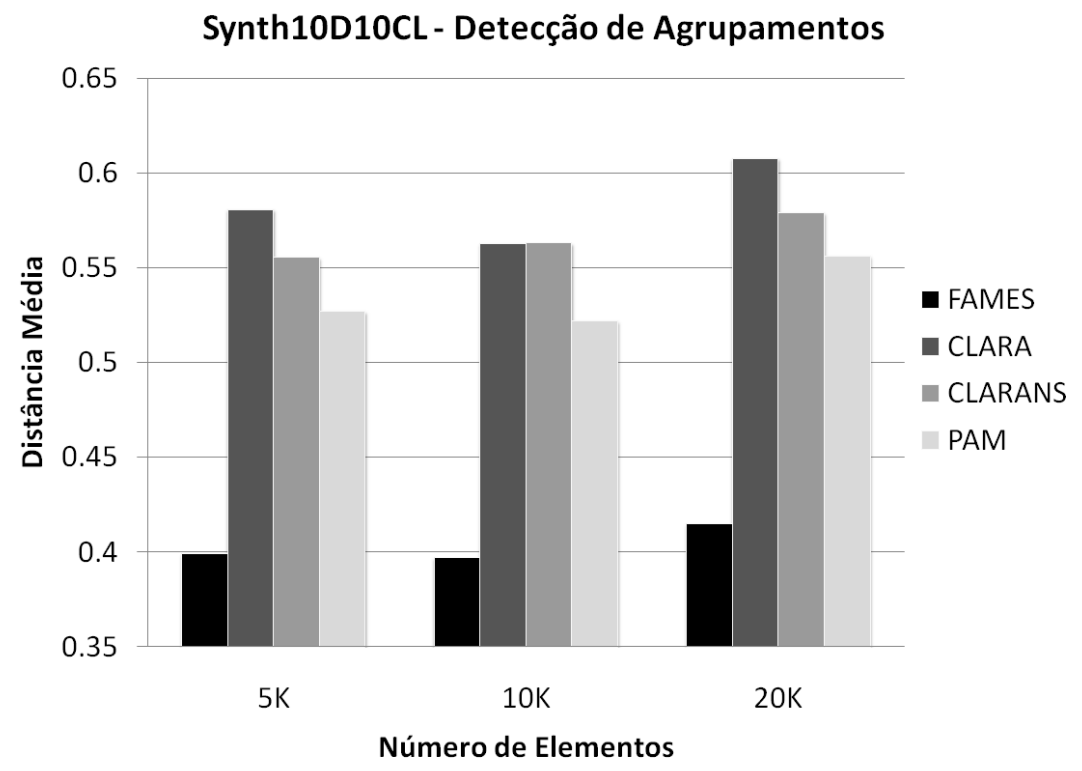

Figura 5.8: Distância média de todos os elementos para o medoide correspondente (mais próximo) para avaliar a qualidade dos agrupamentos encontrados pelos algoritmos FAMES, CLARA, CLARANS e PAM em conjuntos sintéticos de 5 mil, 10 mil e 20 mil elementos, 10 dimensões e 10 agrupamentos.

\subsubsection{Explorando conjuntos de dados reais}

Com o objetivo de validar os resultado obtidos, foram selecionados dois conjuntos de dados representativos. Como o conjunto AloiL não possui um número conhecido de agrupamentos, os algoritmos de detecção de agrupamentos foram executados para detectar 10 e 20 


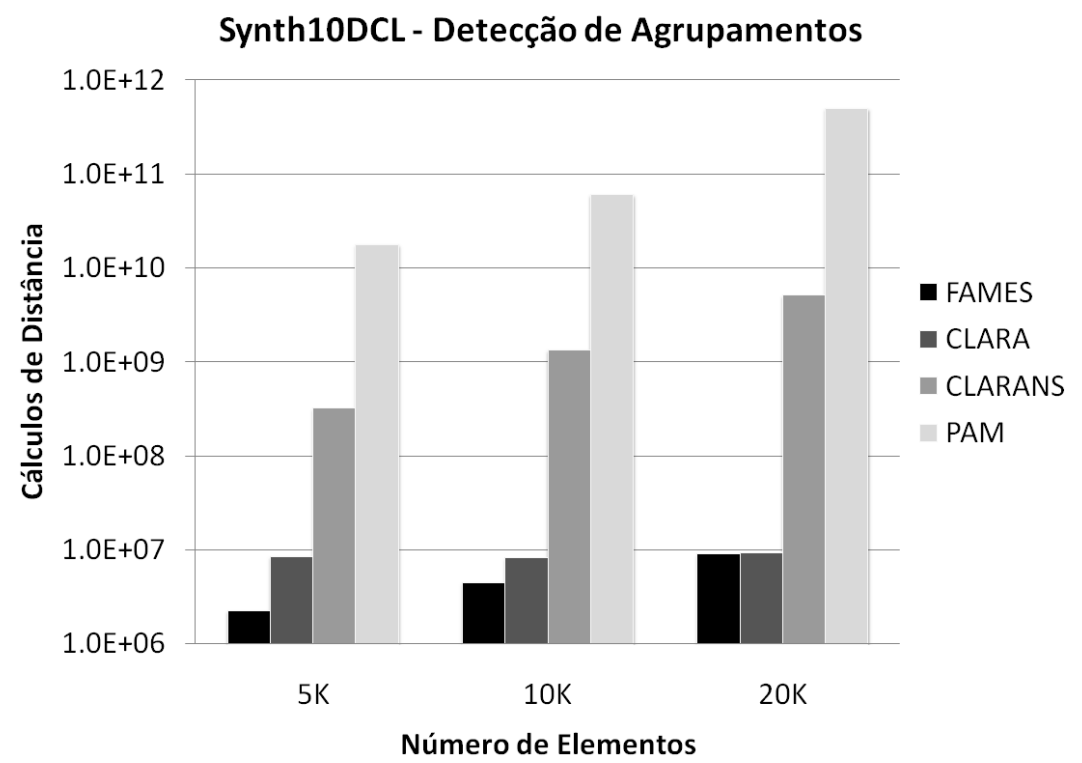

Figura 5.9: Número de cálculos de distâncias para avaliar a eficiência dos algoritmos FAMES, CLARA, CLARANS e PAM para encontrar agrupamentos em conjuntos sintéticos de 5 mil, 10 mil e 20 mil elementos, 10 dimensões e 10 agrupamentos.

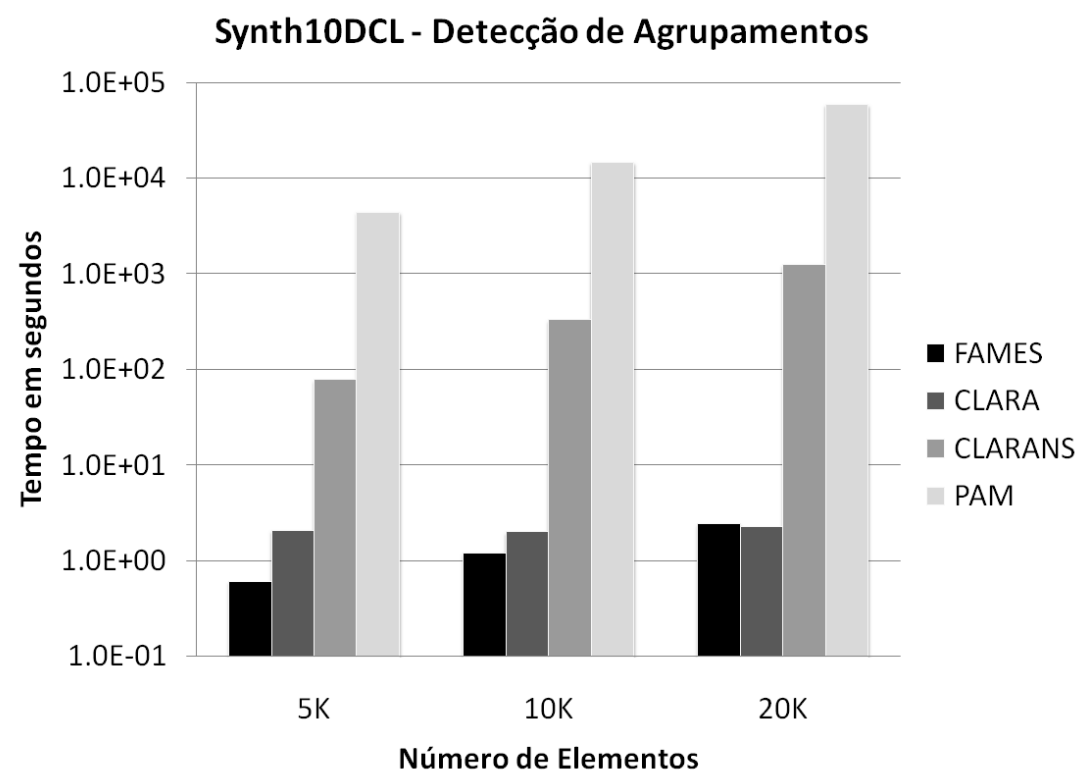

Figura 5.10: Tempo em segundos para avaliar a eficiência dos algoritmos FAMES, CLARA, CLARANS e PAM para encontrar agrupamentos em conjuntos sintéticos de 5 mil, 10 mil e 20 mil elementos, 10 dimensões e 10 agrupamentos.

agrupamentos, enquanto para o conjunto Pendigits buscou-se 10 agrupamentos. O algoritmo PAM foi interrompido após 48 horas executando o conjunto AloiL sem encontrar uma resposta e por isso foi desconsiderado nesta seção. 
Os experimentos mostram que o algoritmo FAMES obteve melhora na qualidade dos agrupamentos nos conjuntos reais testados comparando a aplicabilidade do algoritmo nesses conjuntos, como pode ser observado na Figura 5.11. Além disso, a Figura 5.12 mostra que o algoritmo sempre foi também mais eficiente, retornando uma resposta mais rápida.

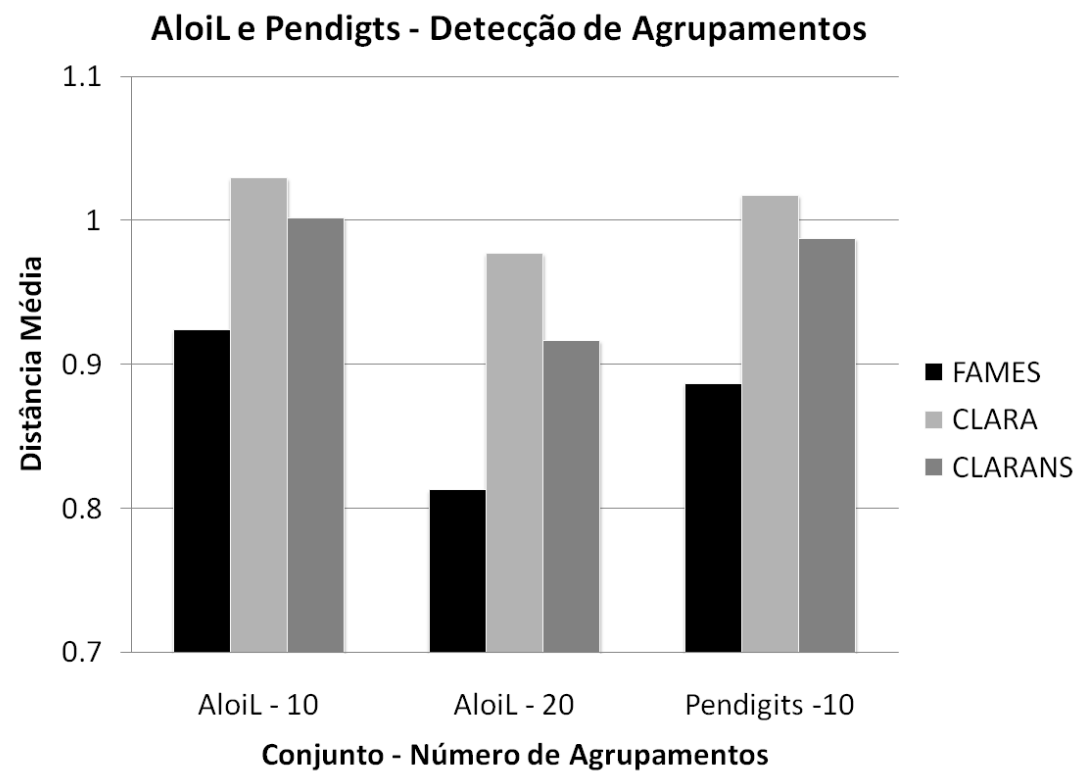

Figura 5.11: Distância média de todos os elementos para o medoide correspondente (mais próximo) para avaliar a qualidade dos agrupamentos encontrados pelos algoritmos FAMES, CLARA, CLARANS e PAM no conjunto Aloi Ilumination com 12mil Histogramas métricos e no conjunto Pendigits

\subsection{Consultas por similaridade usando o algoritmo}

\section{FAMESMAM}

Os algoritmos propostos para consulta por similaridade utilizando o FAMESMAM foram comparados com os algoritmos da técnica Omni-Sequencial quanto à eficiência na realização das consultas por similaridade. Para garantir que não ocorram falsos descartes o resultado da consulta deve ser sempre o mesmo, qualquer que seja o algoritmo utilizado. A eficiência efetiva é uma combinação de acessos a disco e cálculos de distância que pode ser sumarizada pelo tempo médio das consultas realizadas e nos experimentos mostrados é sempre medida em milissegundos. Portanto, nesta seção mostra-se apenas as medidas 


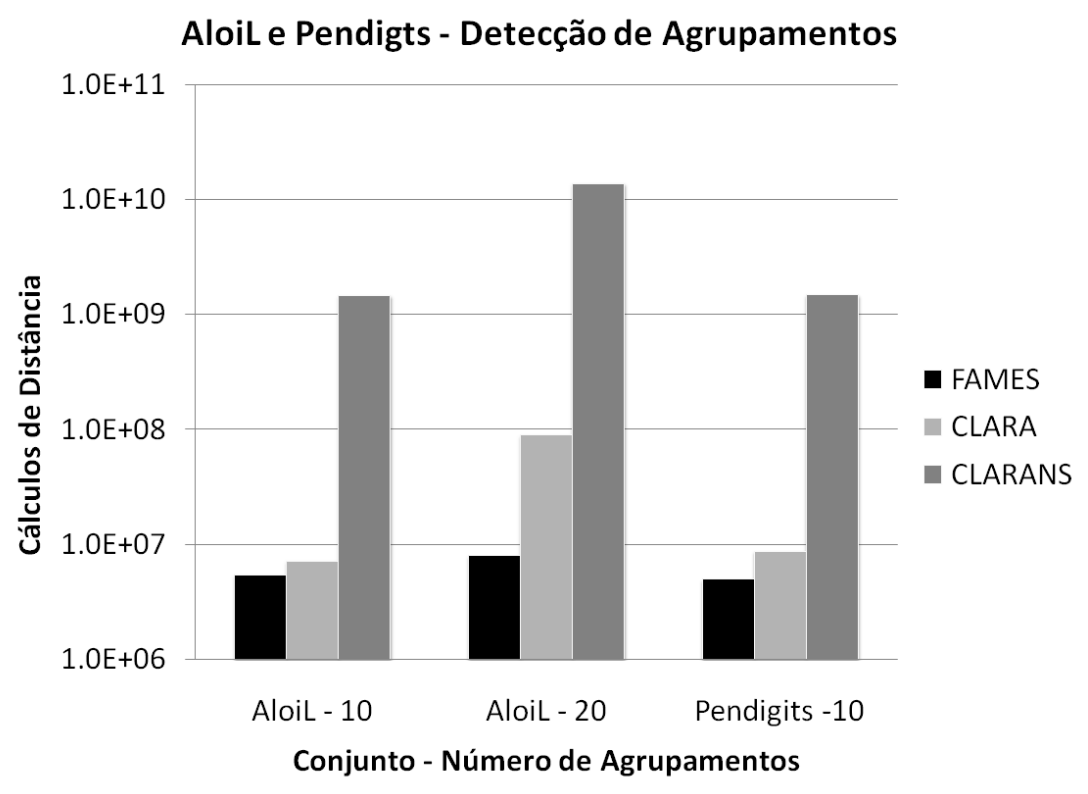

Figura 5.12: Número de cálculos de distâncias para avaliar a eficiência dos algoritmos FAMES, CLARA, CLARANS e PAM para encontrar agrupamentos no conjunto Aloi Ilumination com 12 mil Histogramas métricos e no conjunto Pendigits

de eficiência do novo método proposto. Neste trabalho, em cada experimento $N$ consultas são realizadas utilizando como centro de consulta cada um dos elementos do conjunto, onde $N$ é a cardinalidade do conjunto correspondente.

As consultas por abrangência são analisadas na seção 5.3.1, e em seguida as consultas aos $\kappa$-vizinhos mais próximos são analisadas na seção 5.3.2. Na seção 5.2.4 são utilizados conjuntos de dados reais para validar o método de indexação.

\subsubsection{Consulta por abrangência}

As consultas por abrangência foram realizadas com o Algoritmo 4.3.3 que utiliza o FAMESMAM. Foram realizados experimentos com diversos conjuntos de dados e os resultados mais relevantes são apresentados nesta seção. Para cada conjunto, três estruturas de dados foram construídas: a primeira refere-se à técnica Omni-Sequencial e as outras duas utilizam o método proposto FAMESMAM, com 3 focos por agrupamento e com 5 focos por agrupamento.

A primeira análise utilizou três conjuntos de dados sintéticos com as seguintes características $\operatorname{SyntCL}(n=5 \mathrm{mil}|k=5| D=10,30$ e 100). Nota-se na Figura 5.13 que 
o algoritmo Omni-Sequencial é bastante influenciado pelo aumento da dimensionalidade do conjunto, principalmente no caso em que a dimensão intrínsica é alta. O algoritmo Omni é comparado com duas versões do algoritmo proposto FAMESMAM: a primeira com 3 focos por agrupamento e a segunda com 5 focos por agrupamento. Nota-se que com 3 focos o resultado mais eficiente já é obtido, por isso resultados com mais de 5 focos foram omitidos. Nota-se que para 10 dimensões, o algoritmo FAMESMAM chega a levar apenas 59\% do tempo para processar o conjunto de dados em relação ao método OMNI.

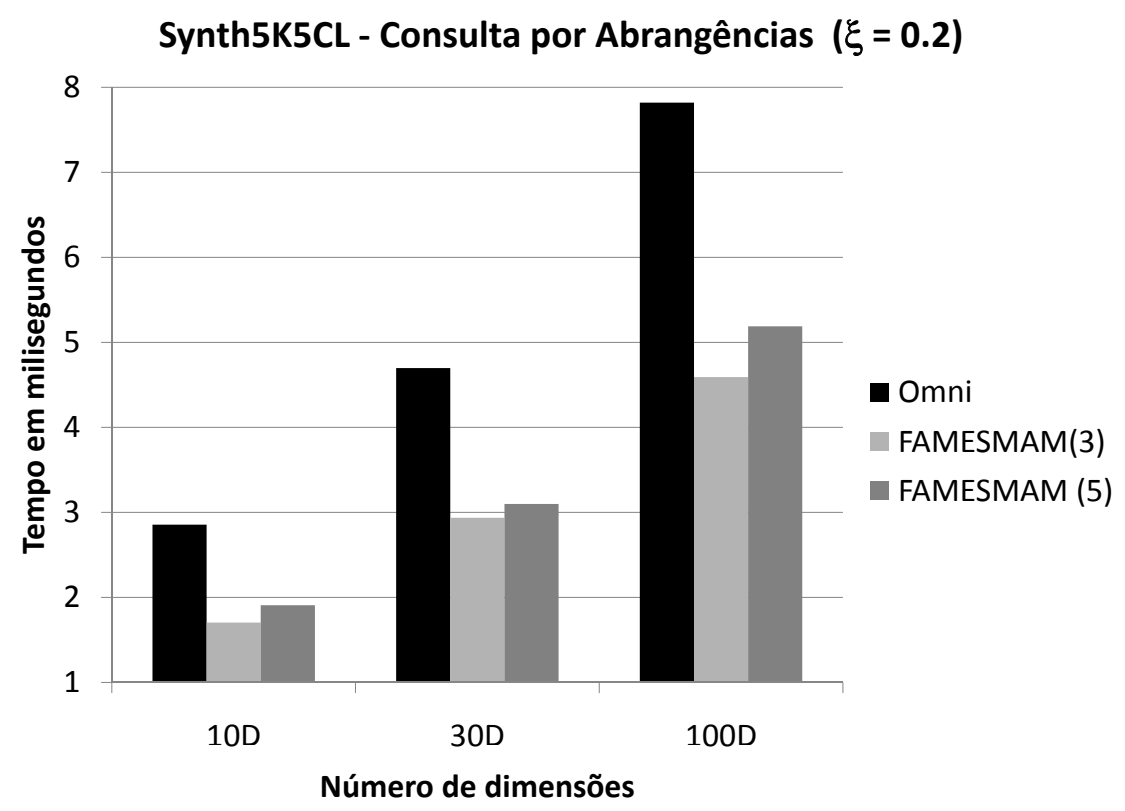

Figura 5.13: Consultas por abrangência com raio $\xi=0.2$ em 3 conjuntos de dados com 5 mil elementos, 5 agrupamentos e com 5, 30 e 100 dimensões.

Em seguida, na Figura 5.14 analisamos o aumento do número de elementos nos conjuntos de dados $\operatorname{SyntCL}(n=5 \mathrm{mil}, 10 \mathrm{mil}$ e $20 \mathrm{mil}|k=10| D=10)$. O melhor resultado é obtido pelo método FAMESMAM com 3 focos por agrupamento, atingindo uma redução de $40 \%$ do tempo de processamento. Além disso, observa-se que o aumento no tempo de processamento das consultas novamente segue linearmente o aumento do número de elementos nos conjuntos de dados.

O efeito do aumento do raio de abrangência é mostrado na Figura 5.15. Com o conjunto de dados $\operatorname{SyntCL}(n=5 \mathrm{mil}|k=10| D=30)$ a consulta por abrangência recupera em média aproximadamente $0.1 \%$ do conjunto para $\xi=0.1,1 \%$ do conjunto para $\xi=0.2$ e $10 \%$ do conjunto para $\xi=0.3$. Nota-se que o acréscimo do tempo de processamento 


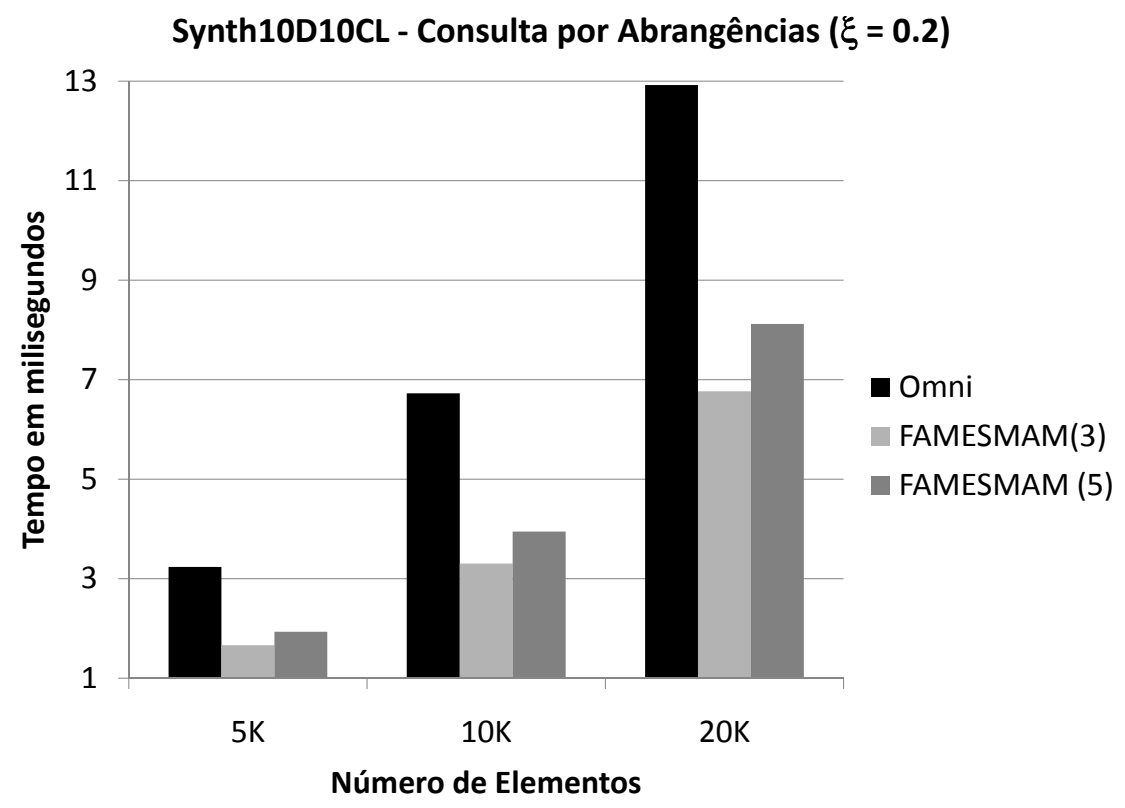

Figura 5.14: Consultas por abrangência com $\xi=0.2$ em 3 conjuntos de dados com 10 agrupamentos, 10 dimensões e com 5 mil, 10 mil e 20 mil elementos.

causado pelo aumento do raio de cobertura de 0.1 para 0.2 é de apenas $59 \%$ para o algoritmo M-FAMES enquanto para o algoritmo OMNI o aumento é de $72 \%$.

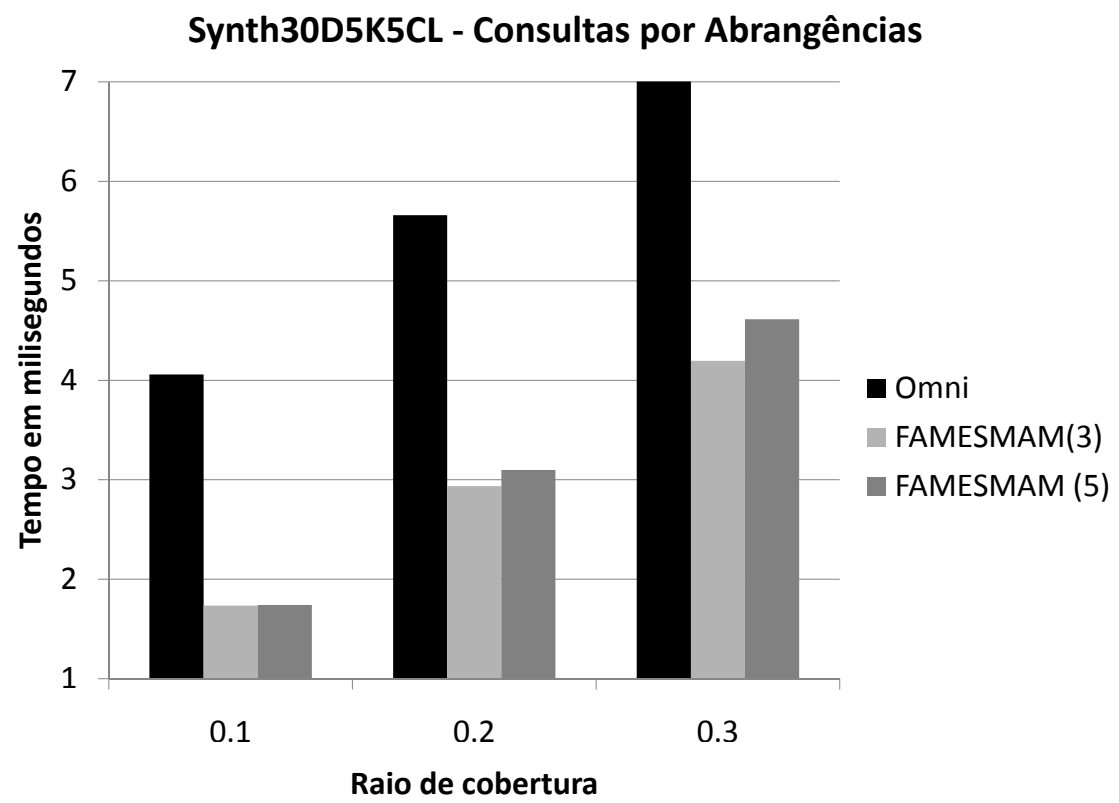

Figura 5.15: Consultas por abrangência com o conjuntos de dados sintético que possui 5 mil elementos, 5 agrupamentos e 30 dimensões, com raio de cobertura da consulta $0.1,0.2$ e 0.3 . 


\subsubsection{Consulta aos $\kappa$-Vizinhos Mais Próximos}

As consultas aos $\kappa$-Vizinhos Mais Próximos foram realizadas utilizando o Algoritmo 4.3.4. Foram realizados experimentos com os diversos conjuntos de dados, e os resultados mais relevantes são apresentados nesta seção. Novamente, para cada conjunto, três estruturas de dados foram construídas: a primeira refere-se à técnica Omni-Sequencial e as outras duas utilizando o algoritmo FAMESMAM, com 3 e 5 focos por agrupamento.

Da mesma forma que nas consultas por abrangência, inicialmente três conjuntos de dados foram utilizados para analisar o aumento da dimensionalidade do conjunto. $\mathrm{O}$ tempo médio de processamento é mostrado na Figura 5.16. Nota-se que o algoritmo FAMESMAM com 3 focos por agrupamento supera o algoritmo OMNI em $25 \%$ para 10 dimensões e $34 \%$ para 30 dimensões.

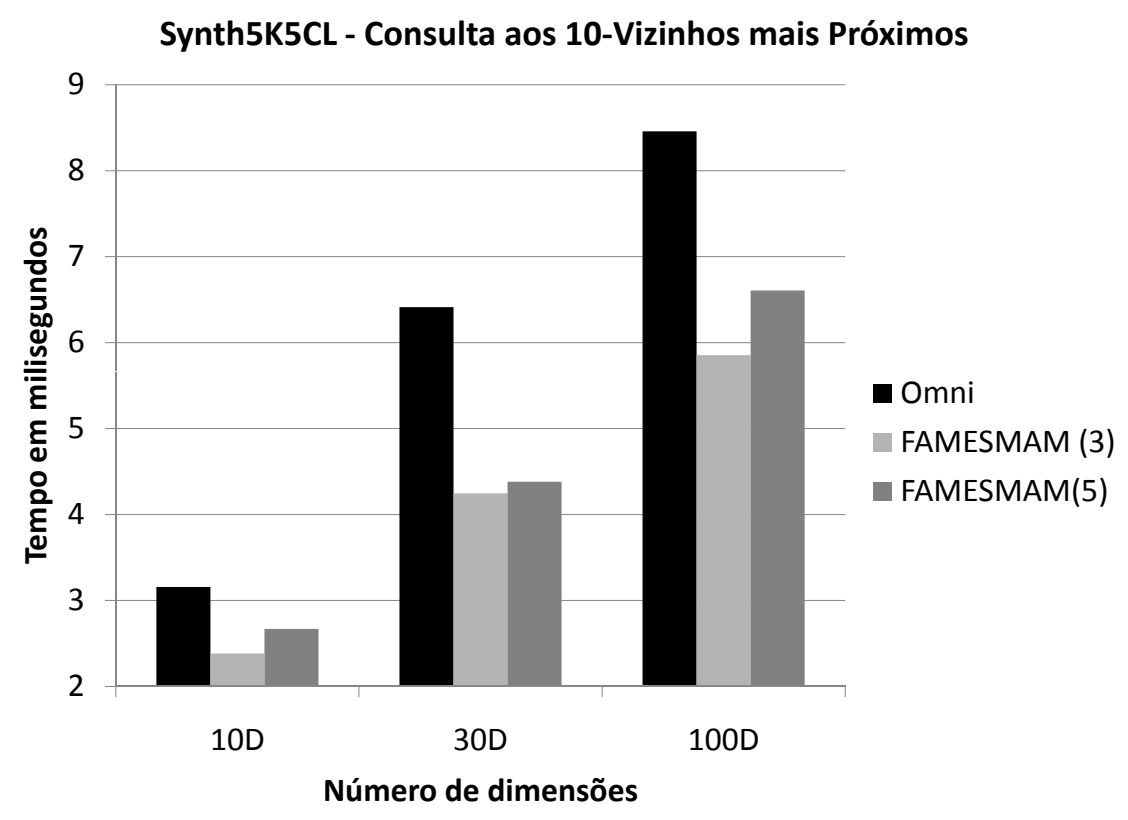

Figura 5.16: Consulta aos 10-Vizinhos Mais Próximos com 3 conjuntos de dados com 5mil elementos e 5 agrupamentos, variando a dimensão do conjunto entre 5, 30 e 100 dimensões.

Em seguida, a Figura 5.17 mostra o tempo médio de processamento para realizar uma consulta pelos 10-Vizinhos Mais Próximos com os conjuntos de dados $\operatorname{SyntCL}(n=$ 5 mil, 10 mil e 20 mil $|k=10| D=10)$. O algoritmo proposto com 3 focos por agrupamento supera o algoritmo OMNI em $21 \%$ para 20 mil elementos e $25 \%$ para 5 mil dimensões. Além disso, observa-se também que o aumento no tempo de processamento das consultas 
por vizinhos mais próximos segue linearmente o aumento do número de elementos nos conjuntos de dados.

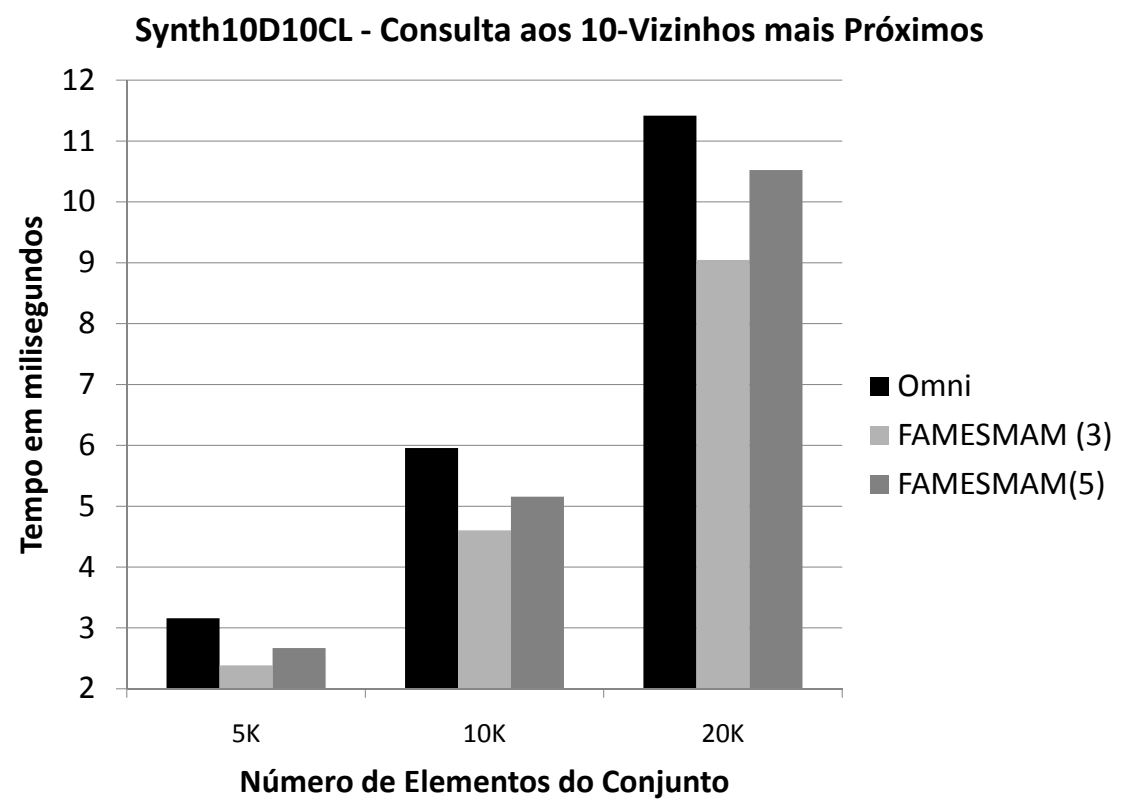

Figura 5.17: Consulta aos 10-Vizinhos Mais Próximos com 3 conjuntos de dados com 10 agrupamentos e 10 dimensões, variando o número de elementos do conjunto entre 5 mil, 10 mil e 20 mil.

Finalmente, os resultados com o conjunto de dados $\operatorname{SyntCL}(n=5 m i l|k=10| D=$ 30) é apresentado na Figura 5.18, que mostra os efeitos do aumento do $\kappa$ comparando o MAM proposto com o método OMNI. Com 3 focos por agrupamento, o algoritmo atinge de $34 \%$ de redução no tempo de processamento com 250 vizinhos a $37 \%$ de redução com 10 vizinhos.

\subsubsection{Explorando conjuntos de dados reais}

Com o objetivo de validar os resultado obtidos, em conjuntos de dados reais, foram selecionados dois conjuntos de dados: Haralick e Zernike obtidos da base de imagens CT_Lung_ROIs. Os conjuntos foram agrupados em 6 grupos utilizando o algoritmo para detecção de agrupamentos FAMES. Para cada conjunto quatro estruturas de dados foram construídas: a primeira refere-se à técnica Omni-Sequencial e as outras três utilizando o algoritmo proposto, com 3,5 e 8 focos por agrupamento. 


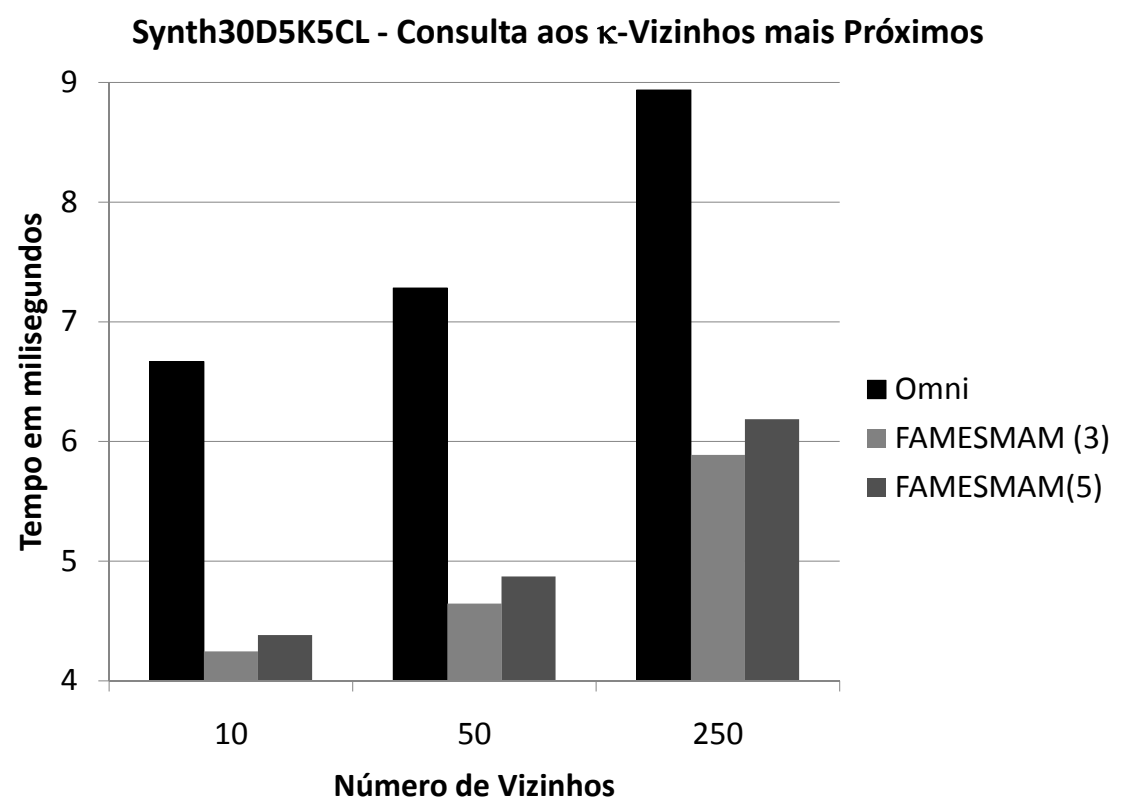

Figura 5.18: Consulta aos $\kappa$-Vizinhos Mais Próximos com o conjuntos de dados sintético que possui 5 mil elementos, 5 agrupamentos e dimensionalide 30 , com $\kappa=10,50$ e 250 .

Foram realizadas consultas aos $\kappa$-Vizinhos Mais Próximos com $\kappa=10,50$ e 250 . Os resultados são apresentados na Figura 5.19 para o conjunto Haralick e na Figura 5.20 para o conjunto Zernike. Observa-se que os melhores resultados são obtidos com o método de acesso proposto FAMESMAM com 5 focos por agrupamento, atingindo uma melhoria de $15 \%$ no conjunto Haralick e $4 \%$ no conjunto Zernike.

\subsection{Considerações Finais}

Neste capítulo foram apresentados os experimentos realizados com os métodos propostos por este trabalho de mestrado. Os experimentos mostraram que a detecção de agrupamentos com os algoritmo FAMES e M-FAMES superam em eficiência e eficâcia os demais algoritmos baseados em k-medoides: PAM, CLARA e CLARANS. Além disso, as consultas por similaridade com o método de acesso FAMESMAM mostraram melhoria na eficiência em relação a Omni-Sequencial principalmente em conjuntos com agrupamentos bem definidos, atingindo ganhos de até $40 \%$ de velocidade de reposta nas consultas por similaridade. 


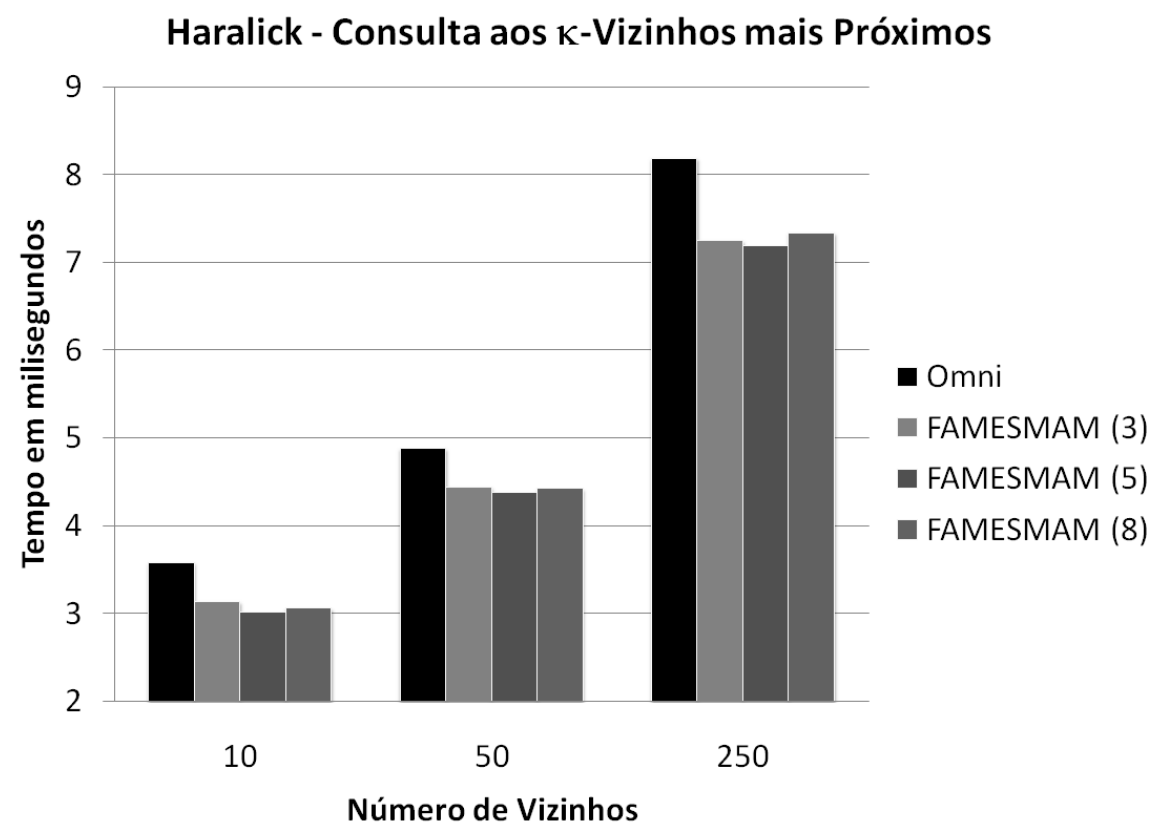

Figura 5.19: Consulta aos $\kappa$-Vizinhos Mais Próximos com o conjunto de dados Haralick

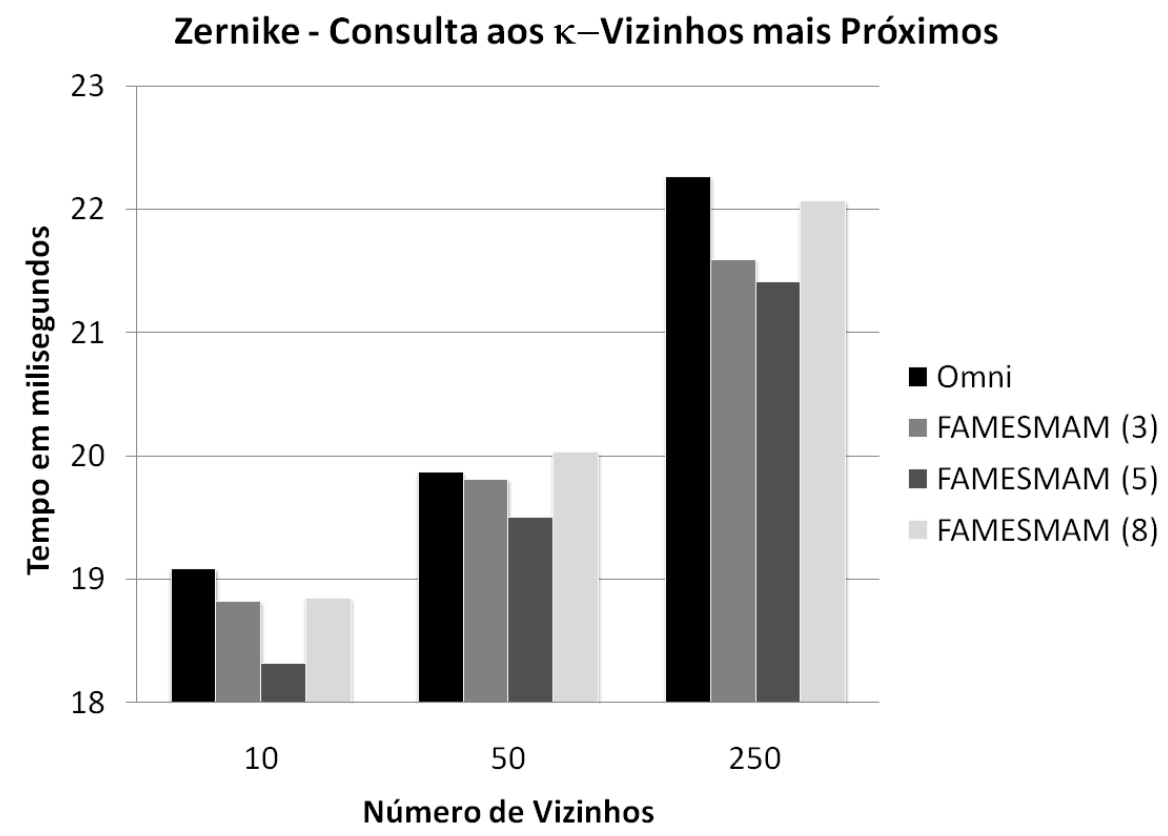

Figura 5.20: Consulta aos $\kappa$-Vizinhos Mais Próximos com o conjunto de dados Zernike 


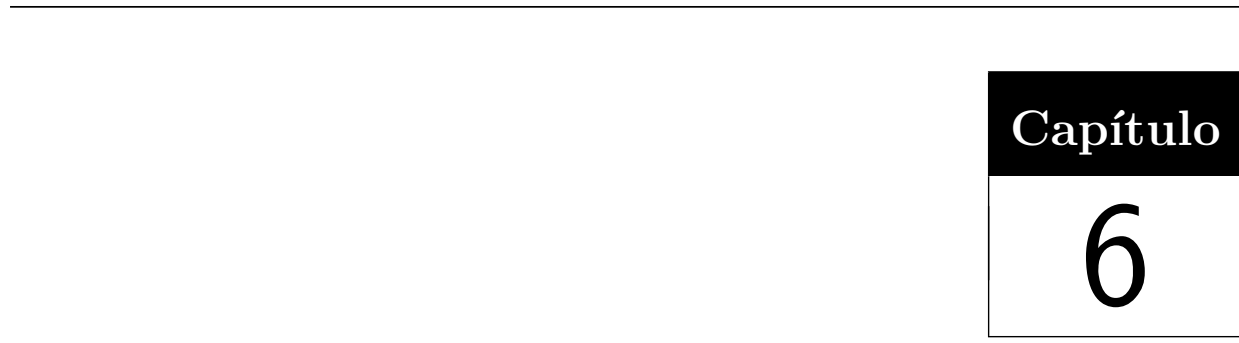

\section{Conclusão}

$\mathcal{E}$ ste trabalho mostra que o sucesso dos Sistemas de Gerenciamento de Banco de Dados (SGBDs) em aplicações envolvendo dados tradicionais (números e textos curtos) pode ser aplicado em novos tipos de aplicações, que exigem a manipulação de dados complexos. Esses dados complexos podem ser provenientes das mais diversas aplicações e eles normalmente não seguem uma distribuição uniforme.

Técnicas de descoberta de conhecimentos podem também ser utilizadas para analisar dados complexos. O KDD (Knowledge Discovery in Database) é um processo interativo e iterativo com diversas fases, sendo a mais conhecida delas a mineração de dados. Em especial alguns algoritmos de detecção de agrupamentos podem ser aplicados a dados complexos. Entretanto, estes algoritmos possuem custo computacional elevado, o que dificulta a sua utilização em grandes conjuntos de dados.

Além disso, as técnicas anteriormente desenvolvidas na Área de Bases de Dados para indexação de espaços métricos tratam o conjunto de maneira uniforme, sem considerar a existência de agrupamentos nos dados. Por isso as estruturas buscam maximizar a eficiência das consultas para todo o conjunto simultaneamente. No entanto, muitas vezes o conjunto tem distribuição não uniforme, e as consultas por similaridade estão limitadas a uma região específica do conjunto de dados. 


\subsection{Principais Contribuições}

Um dos objetivos desta dissertação foi propor um novo método de acesso para dados métricos principalmente para conjuntos que contenham agrupamentos. Para atingir esse objetivo, este trabalho também propõe um novo algoritmo para detecção de agrupamentos em dados métricos que torna mais eficiente a escolha do medoide de determinado conjunto de elementos.

Os resultados dos experimentos mostram que os algoritmo propostos FAMES e M-FAMES usados para determinar de forma mais eficiente os medoides de determinado conjunto de elementos podem ser utilizados para a detecção de agrupamentos em dados complexos e superam os algoritmos PAM, CLARA e CLARANS em eficácia e eficiência. os As consultas por similaridade realizadas com o método de acesso métrico proposto FAMESMAM mostraram ser mais eficiente do que com o método de acesso OMNI-Sequencial, um dos mais rápidos existentes especialmente em conjuntos de dados com agrupamentos.

\subsection{Trabalhos Futuros}

Os principais direcionamentos para trabalho futuro para este trabalho de pesquisa são listados a seguir:

- O algoritmo FAMES proposto para determinar medoides em um conjunto de dados possui características que permitem a detecção de agrupamentos on-line, ou seja, novos elementos inseridos no conjunto de dados podem ser automaticamente agrupados, mas isso pode levar a distorções com o passar do tempo, a medida que mais e mais elementos são inseridos e removidos da base. Para tal, poderia ser criado um algoritmo similar ao proposto pela estrutura OMNI para determinar quando se faz necessário trocar os medoides.

- O passo mais custoso do algoritmo FAMES envolve a ordenação de distâncias das projeções de todos os elementos do conjunto, esse passo pode ser otimizado utilizando 
uma heurística para limitar o número de elementos, de tal forma que o elemento mediano seja determinado sem que todas as distâncias precisem ser ordenadas.

- Neste trabalho optou-se pelo uso do acesso sequencial para percorrer os elementos dos $k$ espaços mapeados utilizados para compor a estrutura de indexação proposta. Essa escolha levou em conta os resultados já obtidos em experimentos da família OMNI. De fato a OMNI-Sequential apresenta bons resultados, no entanto nada impede que outros tipos de acessos sejam escolhidos constituindo uma boa abordagem para trabalho futuro.

- A escolha dos focos nos agrupamentos pode ser melhor explorada para determinar se de fato o melhor local é utilizar um foco como o medoide do agrupamento e os demais na borda do agrupamento.

- Outra maneira de agrupar os elementos do conjunto é utilizando métricas distintas, de fato uma métrica produto poderia ser utilizada para realizar consultas por similaridade entre elementos que pertencem a mais de um espaço métrico simultaneamente. Por exemplo, para cada extrator aplicado a uma imagem obtém-se um espaço métrico distinto.

\subsection{Publicações}

As publicações relacionadas a essa dissertação:

- PATERlini, Adriano A. ; NASCimento, Mario A. ; TRAinA, Caetano Jr. . "Using Pivots to Speed-Up k-Medoid Clustering". (em submissão).

Outras publicações durante o período do mestrado:

- BUeno, R. ; KASter, D. S. ; PATERLini, Adriano A. ; TRAinA, Agma Juci Machado ; TRAINA, Caetano Jr. . "Unsupervised Scaling of Multi-Descriptor Similarity Functions for Medical Image Datasets". In: 22nd IEEE Intl Symposium on 
Computer-Based Medical Systems (CBMS), 2009, Albuquerque, NM, USA. Proceedings of the CBMS. Los Alamitos : IEEE Computer Society, 2009. p. 24-31.

- APPEL, A. P. ; PATERLINI, Adriano A. ; TRAINA, Caetano Jr. . "RDBMS as an Efficient Tool to Mine Cliques on Complex Networks. Journal of Information and Data Management", JIDM 2010, Vol 1, No 3, SBBD 2010, Belo Horizonte, Brasil, 407-422p;

\subsection{Considerações Finais}

Concluindo, esta dissertação fez um amplo e valioso estudo de grandes conjuntos de dados sob uma abordagem de dados métricos, englobando o desenvolvimento de métodos para consultas por similaridade e para mineração de dados obtendo bons resultados. 


\section{Referências Bibliográficas}

[Achtert et al., 2009] Achtert, E., Kriegel, H.-P., Kröger, P., Renz, M., and Züfle, A. (2009). Reverse k-nearest neighbor search in dynamic and general metric databases. In Proceedings of the 12th International Conference on Extending Database Technology: Advances in Database Technology, EDBT '09, pages 886-897, New York, NY, USA. ACM.

[Appel et al., 2010] Appel, A. P., Paterlini, A. A., and Jr., C. T. (2010). Rdbms as an efficient tool to mine cliques on complex networks. JIDM, 1(3):407-422.

[Baeza-Yates et al., 1994] Baeza-Yates, R. A., Cunto, W., Manber, U., and Wu, S. (1994). Proximity matching using fixed-queries trees. In Combinatorial Pattern Matching (CPM), volume 807 of Lecture Notes in Computer Science, pages 198-212, Asilomar, CA. Springer Verlag.

[Beckmann et al., 1990] Beckmann, N., Kriegel, H.-P., Schneider, R., and Seeger, B. (1990). The $\mathrm{r}^{*}$-tree: An efficient and robust access method for points and rectangles. In ACM SIGMOD International Conference on Management of Data, pages 322-331.

[Bentley, 1975] Bentley, J. L. (1975). Multidimensional binary search trees used for associative searching. Communications of the ACM (CACM), 18(9):509-517.

[Bentley and Friedman, 1979] Bentley, J. L. and Friedman, J. H. (1979). Data structures for range searching. ACM Computing Surveys (CSUR), 11(4):397-409. 
[Berkhin, 2002] Berkhin, P. (2002). Survey of clustering data mining techniques. Technical report, Accrue Software, Inc, San Jose, CA, USA.

[Böhm et al., 2001] Böhm, C., Berchtold, S., and Keim, D. A. (2001). Searching in highdimensional spaces - index structures for improving the performance of multimedia databases. ACM Computing Surveys, 33(3):322 - 373.

[Bourgain, 1985] Bourgain, J. (1985). On lipschitz embedding of finite metric spaces in hilbert space. Israel J. Mathematics, 52:46-52.

[Bozkaya and Özsoyoglu, 1997] Bozkaya, T. and Özsoyoglu, Z. M. (1997). Distance-based indexing for high-dimensional metric spaces. In ACM SIGMOD International Conference on Management of Data, pages 357-368, Tucson, AZ. ACM Press.

[Brent Seales et al., 1997] Brent Seales, W., Yuan, C., and Brown, M. (1997). Efficient content extraction in compressed images. Content-Based Access of Image and Video Libraries, 1997. Proceedings. IEEE Workshop on, pages 52-58.

[Bueno, 2002] Bueno, J. M. (2002). Suporte à Recuperação de Imagens Médicas baseada em Conteúdo através de Histogramas Métricos. Tese de doutorado, Universidade de São Paulo.

[Bueno et al., 2009] Bueno, R., Kaster, D. S., Paterlini, A. A., Traina, A. J. M., and Jr., C. T. (2009). Unsupervised scaling of multi-descriptor similarity functions for medical image datasets. In $C B M S$, pages 1-8. IEEE.

[Burkhard and Keller, 1973] Burkhard, W. A. and Keller, R. M. (1973). Some approaches to best-match file searching. Communications of the ACM (CACM), 16(4):230-236.

[Carpineto et al., 2009] Carpineto, C., Osiński, S., Romano, G., and Weiss, D. (2009). A survey of web clustering engines. ACM Comput. Surv., 41(3):1-38.

[Chu et al., 2002] Chu, S.-C., Roddick, J. F., and Pan, J. S. (2002). An efficient kmedoids-based algorithm using previous medoid index, triangular inequality elimination 
criteria, and partial distance search. In Data Warehousing and Knowledge Discovery, pages $301-311$.

[Chávez et al., 2001] Chávez, E., Navarro, G., Baeza-Yates, R. A., and Marroquín, J. L. (2001). Searching in metric spaces. ACM Computing Surveys, 33(3):273-321.

[Ciaccia et al., 1997] Ciaccia, P., Patella, M., and Zezula, P. (1997). M-tree: An efficient access method for similarity search in metric spaces. In Proceedings of 23rd International Conference on Very Large Data Bases (VLDB), pages 426-435, Athens, Greece. Morgan Kaufmann.

[Cox and Cox, 2001] Cox, T. F. and Cox, M. A. (2001). Multidimensional scaling. Chapman and Hall/CRC, 2nd edition.

[Deza and Deza, 2006] Deza, E. and Deza, M.-M. (2006). Dictionary of Distances. Elsevier B.V.

[Digout et al., 2004] Digout, C., Nascimento, M. A., and Coman, A. (2004). Similarity search and dimensionality reduction: Not all dimensions are equally useful. In Lee, Y.-J., Li, J., Whang, K.-Y., and Lee, D., editors, DASFAA, volume 2973 of Lecture Notes in Computer Science, pages 831-842. Springer.

[Emran and Ye, 2002] Emran, S. M. and Ye, N. (2002). Robustness of chi-square and canberra distance metrics for computer intrusion detection. Quality and Reliability Engineering International, 18:19-28.

[Ester et al., 1996] Ester, M., Kriegel, H.-P., Sander, J., and Xu, X. (1996). A densitybased algorithm for discovering clusters in large spatial databases with noise. In Simoudis, E., Han, J., and Fayyad, U. M., editors, Proceedings of the Second International Conference on KDD-96, pages 226-231. AAAI Press.

[Ester et al., 1995] Ester, M., Kriegel, H.-P., and Xu, X. (1995). Knowledge discovery in large spatial databases: Focusing techniques for efficient class identification. In 4th Int. Symp. on Large Spatial Databases (SSD '95), volume 951 of Lecture Notes in Computer Science, pages 67-82. 
[Finkel and Bentley, 1974] Finkel, R. A. and Bentley, J. L. (1974). Quad trees: A data structure for retrieval on composite keys. Acta Informatica, 4:1-9.

[Gaede and Günther, 1998] Gaede, V. and Günther, O. (1998). Multidimensional access methods. ACM Computing Surveys, 30(2):170-231.

[Geusebroek et al., 2005] Geusebroek, J.-M., Burghouts, G. J., and Smeulders, A. W. M. (2005). The amsterdam library of object images. Int. J. Comput. Vision, 61(1):103-112.

[Guha et al., 1998] Guha, S., Rastogi, R., and Shim, K. (1998). Cure: an efficient clustering algorithm for large databases. In SIGMOD '98: Proceedings of the 1998 ACM SIGMOD international conference on Management of data, pages 73-84, New York, NY, USA. ACM Press.

[Guttman, 1984] Guttman, A. (1984). R-tree : A dynamic index structure for spatial searching. In ACM SIGMOD International Conference on Management of Data, pages 47-57, Boston, MA. ACM PRess.

[Halmos, 1978] Halmos, P. R. (1978). Espaços vetoriais de dimensão finita. Editora Campus Ltda.

[Han and Kamber, 2000a] Han, J. and Kamber, M. (2000a). Data Mining - Concepts and Techniques. Morgan Kaufmann Publishers, New York, 1st edition edition.

[Han and Kamber, 2000b] Han, J. and Kamber, M. (2000b). Data Mining - Concepts and Techniques. Morgan Kaufmann Publishers, New York, 1st edition edition.

[Hartigan and Wong, 1979] Hartigan, J. A. and Wong, M. A. (1979). A k-means clustering algorithm. Applied Statistics, 28(1):100-108.

[Hjaltason and Samet, 2003a] Hjaltason, G. and Samet, H. (2003a). Properties of embedding methods for similarity searching in metric spaces. Pattern Analysis and Machine Intelligence, IEEE Transactions on, 25(5):530-549. 
[Hjaltason and Samet, 2003b] Hjaltason, G. R. and Samet, H. (2003b). Index-driven similarity search in metric spaces. ACM Transactions on Database Systems (TODS), $21(4): 517-580$.

[Kaufman and Rousseeuw, 2005] Kaufman, L. and Rousseeuw, P. J. (2005). Finding Groups in Data: An Introduction to Cluster Analysis (Wiley Series in Probability and Statistics). Wiley-Interscience.

[Korn and Muthukrishnan, 2000] Korn, F. and Muthukrishnan, S. (2000). Influence sets based on reverse nearest neighbor queries. In Eich, M. H., editor, 2000 ACM SIGMOD international conference on Management of data, pages 201-212, Dallas, TX. ACM Press.

[Korn et al., 1996] Korn, F., Sidiropoulos, N., Faloutsos, C., Siegel, E. L., and Protopapas, Z. (1996). Fast nearest neighbor search in medical image databases. In Vijayaraman, T. M., Buchmann, A. P., Mohan, C., and Sarda, N. L., editors, International Conference on Very Large Databases (VLDB), pages 215-226, Bombay, India. Morgan Kaufmann.

[Kriegel et al., 2009] Kriegel, H.-P., Kröger, P., and Zimek, A. (2009). Clustering highdimensional data: A survey on subspace clustering, pattern-based clustering, and correlation clustering. ACM Trans. Knowl. Discov. Data, 3(1):1-58.

[Lance and Williams, 1967] Lance, G. N. and Williams, W. T. (1967). Mixed-data classificatory programs i - agglomerative systems. Australian Computer Journal, 1(1):15-20.

[Lee et al., 2008a] Lee, C.-H., Zaïane, O. R., Park, H.-H., Huang, J., and Greiner, R. (2008a). Clustering high dimensional data: A graph-based relaxed optimization approach. Inf. Sci., 178(23):4501-4511.

[Lee et al., 2008b] Lee, K. C. K., Zheng, B., and Lee, W.-C. (2008b). Ranked reverse nearest neighbor search. IEEE Trans. on Knowl. and Data Eng., 20:894-910.

[Levenshtein, 1966] Levenshtein, V. (1966). Binary codes capable of correcting deletions, insertions, and reversals. Cybernetics and Control Theory, 10(8):707-710. 
[Linial et al., 1995] Linial, N., London, E., and Rabinovich, Y. (1995). The geometry of graphs and some of its algorithmic applications. Combinatorica, 15(2):215-245.

[MacQueen, 1967] MacQueen, J. B. (1967). Some methods for classification and analysis of multivariate observations. In Cam, L. M. L. and Neyman, J., editors, Proc. of the fifth Berkeley Symposium on Mathematical Statistics and Probability, volume 1, pages 281-297. University of California Press.

[Mouratidis et al., 2005] Mouratidis, K., Papadias, D., and Papadimitriou, S. (2005). Medoid queries in large spatial databases. In SSTD, volume 3633 of Lecture Notes in Computer Science, pages 55-72.

[Ng and Han, 1994] Ng, R. T. and Han, J. (1994). Efficient and effective clustering methods for spatial data mining. In Bocca, J. B., Jarke, M., and Zaniolo, C., editors, International Conference on Very Large Databases (VLDB), pages 144-155, Santiago de Chile, Chile. Morgan Kaufmann.

[Samet, 1984] Samet, H. (1984). The quadtree and related hierarchical data structures. ACM Computing Surveys (CSUR), 16(2):187-260.

[Samet, 2006] Samet, H. (2006). Foundations of Multidimensional and Metric Data Structure. Morgan Kaufmann.

[Santos Filho, 2003] Santos Filho, R. F. (2003). Métodos de Acesso Métricos para suporte a Consultas por Similaridade: Apresentação da Técnica Omni. Phd, University of São Paulo.

[Santos Filho et al., 2001] Santos Filho, R. F., Traina, A. J. M., Traina Jr., C., and Faloutsos, C. (2001). Similarity search without tears: The omni family of all-purpose access methods. In IEEE International Conference on Data Engineering (ICDE), pages 623-630, Heidelberg, Germany. IEEE Computer Society.

[Sellis et al., 1987] Sellis, T. K., Roussopoulos, N., and Faloutsos, C. (1987). The r+tree: A dynamic index for multi-dimensional objects. In Stocker, P. M., Kent, W., and 
Hammersley, P., editors, International Conference on Very Large Databases (VLDB), pages 507-518, Brighton, England. Morgan Kaufmann.

[Sibson, 1973] Sibson, R. (1973). SLINK: An optimally efficient algorithm for the singlelink cluster method. The Computer Journal, 16(1):30-34.

[Stehling et al., 2002] Stehling, R. O., Nascimento, M. A., and Falcão, A. X. (2002). Microm: A metric distance to compare segmented images. In Chang, S.-K., Chen, Z., and Lee, S.-Y., editors, 5th International Conference in Recent Advances in Visual Information Systems, VISUAL 2002, volume 2314 / 2002 of Lecture Notes in Computer Science, pages 12-23, Hsin Chu, Taiwan. Springer Verlag.

[Tamminen, 1984] Tamminen, M. (1984). Comment on quad- and octtrees. Communications of the ACM, 27(3):248-249.

[Traina et al., 2002] Traina, A. J. M., Traina Jr., C., Bueno, J. M., and Marques, P. M. d. A. (2002). The metric histogram: A new and efficient approach for content-based image retrieval. In Zhou, X. and Pu, P., editors, Sixth IFIP Working Conference on Visual Database Systems, volume 216 of IFIP Conference Proceedings, pages 297-311, Brisbane, Australia. Kluwer Academic Publishers.

[Traina et al., 2007] Traina, Caetano, J., Santos Filho, R. F., Traina, A. J. M., Vieira, M. R., and Faloutsos, C. (2007). The omni-family of all-purpose access methods: A simple and effective way to make similarity search more efficient. The International Journal on Very Large Databases, page 35 p.

[Traina Jr. et al., 2000] Traina Jr., C., Traina, A. J. M., Seeger, B., and Faloutsos, C. (2000). Slim-trees: High performance metric trees minimizing overlap between nodes. In Zaniolo, C., Lockemann, P. C., Scholl, M. H., and Grust, T., editors, International Conference on Extending Database Technology (EDBT), volume 1777 of Lecture Notes in Computer Science, pages 51-65, Konstanz, Germany. Springer Verlag. 
[Tran et al., 2009] Tran, Q. T., Taniar, D., and Safar, M. (2009). Reverse $k$ Nearest Neighbor and Reverse Farthest Neighbor Search on Spatial Networks, pages 353-372. Springer-Verlag, Berlin, Heidelberg.

[Wilson and Martinez, 1997] Wilson, D. R. and Martinez, T. R. (1997). Improved heterogeneous distance functions. Journal of Artificial Intelligence Research, 6:1-34.

[Yianilos, 1993] Yianilos, P. N. (1993). Data structures and algorithms for nearest neighbor search in general metric spaces. In Fourth Annual ACM/SIGACT-SIAM Symposium on Discrete Algorithms (SODA), pages 311-321, Austin, TX.

[Zezula et al., 2006] Zezula, P., Amato, G., Dohnal, V., and Batko, M. (2006). Similarity Search The Metric Space Approach. Birkhäuser.

[Zhang et al., 2005] Zhang, C., Yang, Q., and Liu, B. (2005). Guest editors' introduction: Special section on intelligent data preparation. IEEE Transactions on Knowledge and Data Engineering (TKDE), 17(9):1163-1165.

[Zhang et al., 1996] Zhang, T., Ramakrishnan, R., and Livny, M. (1996). Birch: An efficient data clustering method for very large databases. In Jagadish, H. V. and Mumick, I. S., editors, ACM SIGMOD International Conference on Management of Data, volume 1 of SIGMOD Record 25(2), pages 103-114, Montreal, Quebec, Canada. ACM Press. 